\title{
Studien zur Expression und Lokalisation von P-Typ ATPasen aus Dunaliella bioculata
}

\author{
Dissertation zur Erlangung des Doktorgrades \\ der Mathematisch-Naturwissenschaftlichen Fakultäten \\ der Georg-August-Universität zu Göttingen
}

vorgelegt von

Sandra Schönberg

aus Witzenhausen

Göttingen 2001 
D 7

Referent: Prof. Dr. Gerhard Thiel

Korreferent: PD Giselbert Hinz

Tag der mündlichen Prüfung: 3.5.2001 
Zur Erinnerung an meinen Vater 


\section{Abkürzungen}

Grundsätzlich werden die international üblichen Abkürzungen der SI-Einheiten verwendet. Aminosäuren und Nukleotide werden im Einbuchstabencode dargestellt.

\begin{tabular}{|c|c|}
\hline Abb. & Abbildung \\
\hline AS & Aminosäure \\
\hline ATP & Adenosin-5'-triphosphat \\
\hline ATPase & Adenosintriphosphatase \\
\hline bp & Basenpaare \\
\hline cDNA & copy DNA \\
\hline DNA & Desoxyribonukleinsäure \\
\hline dNTD & Desoxyribonukleosid 5'-triphosphat \\
\hline E. coli & Escherichia coli \\
\hline EDTA & Ethylendiamin-tetra-Essigsäure \\
\hline EGFP & Enhanced Green Fluorescent Protein \\
\hline ER & Endoplasmatisches Retikulum \\
\hline g & Erdbeschleunigung \\
\hline GFP & Green Fluorescent Protein (Grün Fluoreszierendes Protein) \\
\hline h & Stunde \\
\hline HBSS & Hank's balanced salt solution \\
\hline HEPES & N-2-hydroxyethylpiperazin-N-2-Ethansulfonsäure \\
\hline kbp & Kilobasenpaare \\
\hline $\mathrm{kDa}$ & Kilodalton \\
\hline l & Liter \\
\hline M & Molarität \\
\hline $\mathrm{m}$ & milli- \\
\hline$\mu$ & mikro- \\
\hline $\min$ & Minute \\
\hline $\mathrm{mol}$ & Mol \\
\hline mRNA & messenger RNA \\
\hline$n$ & nano- \\
\hline $\mathrm{N}$-Terminus & Aminoterminus \\
\hline OD & Optische Dichte \\
\hline PBS & phosphate buffered saline \\
\hline PCI & Phenol-Chloroform-Isoamylalkohol \\
\hline PCR & Polymerasekettenreaktion \\
\hline PEG & Polyethylenglykol \\
\hline PM & Plasmamembran \\
\hline RNA & Ribonukleinsäure \\
\hline RT & Raumtemperatur \\
\hline SER & Sarkoendoplasmatisches Retikulum \\
\hline
\end{tabular}




$\begin{array}{ll}\text { SDS } & \text { Natriumdodecylsulfat } \\ \text { TBE } & \text { Tris-Borat/EDTA } \\ \text { TE } & \text { Tris-HCl/EDTA } \\ \text { Tris } & \text { Tris(hydroxymethyl)-aminomethan } \\ \text { U } & \text { unit, Enzymeinheit } \\ \text { Upm } & \text { Umdrehung pro Minute } \\ \text { UTR } & \text { untranslatierte Region } \\ \text { UV } & \text { ultraviolett } \\ \text { Vol } & \text { Volumen } \\ \text { v/v } & \text { Volumen pro Volumen } \\ \text { w/v } & \text { Gewicht pro Volumen } \\ \text { x g } & \text { x-fache Erdbeschleunigung }\end{array}$




\section{Inhaltsverzeichnis}

$1 \quad$ Einleitung 8

1.1 Transportsysteme in biologischen Membranen 8

1.2 P-Typ ATPasen 8

1.3 Protonen-ATPasen 9

$\begin{array}{lll}1.4 & \text { Calcium-ATPasen } & 10\end{array}$

$\begin{array}{ll}\text { 1.4.1 Lokalisation pflanzlicher } \mathrm{Ca}^{2+} \text {-ATPasen } & 11\end{array}$

$1.5 \quad$ Signalsequenzen und topogene Signale 13

$1.6 \quad$ Translationsinitiationsstelle 16

1.7 Das Grün Fluoreszierende Protein (GFP) als Reportergen 16

$1.8 \quad$ Zwei P-Typ ATPasen aus Dunaliella bioculata 18

$\begin{array}{ll}1.9 \text { Zielsetzung } & 19\end{array}$

$2 \quad$ Material und Methoden 20

$2.1 \quad$ Material 20

$\begin{array}{lll}\text { 2.1.1 Organismen und Plasmide } & 20\end{array}$

2.1.1.1 Escherichia coli 20

2.1.1.2 COS-7-Zellen 20

2.1.1.3 HeLa-Zellen 20

$\begin{array}{lll}2.1 .1 .4 & \text { Tabak } & 20\end{array}$

2.1.1.5 cDNA der Calcium- und Protonen-ATPase 21

2.1.1.6 Grün Fluoreszierendes Protein (GFP) 21

2.1.1.6.1 pEGFP-N1 21

2.1.1.6.2 HBT-L 22

2.1.2 Oligonukleotide 23

2.1.3 Chemikalien, Enzyme und Reaktionssysteme 24

2.1.4 Mikroskopie 24

2.1.4.1 Fluoreszenzmikroskopie 24

2.1.4.2 Konfokale Fluoreszenzmikroskopie 24

2.1.5 Software 25

$2.2 \quad$ Methoden 25

2.2.1 Kultivierung von Escherichia coli 25

2.2.2 Transformation von E. coli mit Calciumchlorid 26

2.2.3 Plasmidisolierung 26

2.2.4 Reinigung und Konzentrierung von Nukleinsäuren 28

2.2.4.1 Phenol-Chloroform-Extraktion 28

2.2.4.2 Schleudersäulen-Chromatographie 28

2.2.4.3 Alkoholische Fällung von DNA 28

2.2.5 Konzentrationsbestimmung 29

$\begin{array}{ll}\text { 2.2.6 Enzymatische Fragmentierung von DNA } 29 & 29\end{array}$ 
$\begin{array}{lll}\text { 2.2.7 Gelelektrophorese } & 29\end{array}$

$\begin{array}{ll}2.2 .8 & \text { Ligation von DNA-Fragmenten }\end{array}$

$\begin{array}{lll}\text { 2.2.9 Polymerasekettenreaktion (PCR) } & 31\end{array}$

2.2.9.1 Amplifikation von Fragmenten aus CDNA 31

$\begin{array}{lll}2.2 .9 .2 & \text { Sequenzierung } & 31\end{array}$

2.2.10 Kultivierung von HeLa-Zellen 33

2.2.11 Bestimmung der Zellzahl 33

$\begin{array}{ll}\text { 2.2.12 Anzucht auf Objektträgern } & 34\end{array}$

2.2.13 Liposomentransfektion von HeLa-Zellen 34

2.2.14 Morphologische Präparate 35

2.2.15 Kernfärbung mit H33342 36

2.2.16 Kultivierung von COS-7-Zellen 36

2.2.17 Liposomentransfektion von COS-7-Zellen 36

$\begin{array}{ll}\text { 2.2.18 Fixierung von COS-7-Zellen } & 37\end{array}$

2.2.19 Axenische Kulturen von Tabakpflanzen 37

$\begin{array}{ll}\text { 2.2.20 Präparation von Tabak-Protoplasten } & 37\end{array}$

2.2.21 Elektroporation von Tabak-Protoplasten 40

$3 \quad$ Ergebnisse $\quad 41$

3.1 Klonierungsstrategie für die Expression von

3.1.1 Analyse der Translationsstartsignale der $\mathrm{H}^{+}$- und $\mathrm{Ca}^{2+}$-ATPase aus Dunaliella bioculata $\quad 42$

3.1.2 Konstruktion von ATPase-sGFP-S65T-Fusionsvektoren für die
Transfektion von Tabak-Protoplasten

Expression von ATPase-GFP-Fusionsproteinen
in Tabak-Protoplasten

3.2.1 Cytoplasmatische und nukleare Lokalisation von sGFP-S65T
in Tabak-Protoplasten

3.2.2 Negativkontrollen 51

3.2.3 Fehlende Expression der ATPase-sGFP-S65T-Fusionsproteine in
Tabak-Protoplasten

Konstruktion der ATPase-EGFP-Fusionsvektoren für die
Expression in HeLa- und COS-7-Zellen

3.4 Expression der ATPase-EGFP-Fusionsgene in HeLa-Zellen 56

3.4.1 Positiv- und Negativkontrolle: Expression von EGFP in HeLa-Zellen 56

3.4.2 Expression von M2-Ca ${ }^{2+}$-EGFP und M3-Ca ${ }^{2+}$-EGFP in HeLa-Zellen 57

3.4.3 Expression von M1-H+-TAG-EGFP in HeLa-Zellen 59

3.5 Expression der ATPase-EGFP-Fusionsproteine in COS-7-Zellen 59

3.5.1 Cytoplasmatische und nukleare Lokalisation von EGFP in COS-7-Zellen 60

3.5.2 Ca ${ }^{2+}$-ATPase-EGFP-Fusionsproteine in COS-7-Zellen 61 
3.5.3 Lokalisation der Fusionsproteine M1- $\mathrm{H}^{+}$-EGFP und M2- $\mathrm{H}^{+}$-EGFP im ER von COS-7-Zellen

3.5.4 Quantitative Bestimmung der Fluoreszenzverteilung und Expressionsrate von EGFP und der Fusionsproteine in COS-7-Zellen 65

3.5.5 Kozak-Mutante in COS-7-Zellen

$4 \quad$ Diskussion $\quad 70$

4.1 Expression der ATPase-GFP-Chimären in Tabak-Protoplasten 70

$\begin{array}{ll}\text { 4.1.1 Konstruktion der Fusionsvektoren } & 71\end{array}$

$\begin{array}{lll}\text { 4.1.2 Unterbindung der Translation } & 71\end{array}$

$\begin{array}{lll}\text { 4.1.3 Aggregation der ATPase-GFP-Fusionsproteine } & 72\end{array}$

$\begin{array}{lll}\text { 4.1.4 Proteinabbau } & 73\end{array}$

4.2 Expression der ATPase-GFP-Fusionsproteine in tierischen Expressionssystemen $\quad 74$

4.2.1 Natives GFP in heterologen Expressionssystemen 74

4.2.2 ER-Lokalisation der $\mathrm{H}^{+}$- und $\mathrm{Ca}^{2+}$-ATPase-GFP-Fusionsproteine in COS-7-Zellen $\quad 75$

4.2.3 Signalsequenzen/Signalsequenzbereiche für ER-Insertion 75

4.2.4 Lokalisation oder Retention im ER tierischer Zellen 77

4.2.4.1 Topogene Signale für ER-Retention der $\begin{array}{ll}\mathrm{Ca}^{2+} \text {-ATPase-GFP-Fusionsproteine } & 78\end{array}$

4.2.4.2 Retention der $\mathrm{H}^{+}$-ATPase-GFP-Fusionsproteine im ER 80

4.2.4.3 Qualitätskontrolle im ER 80

4.2.4.4 Zusätzliche Signale 81

4.3 Translationsstartcodons der Fusionsproteine 83

4.3.1 Steigerung der Proteinsynthese mit Verkürzung der N-Termini der $\mathrm{H}^{+}$- und $\mathrm{Ca}^{2+}$-ATPase $\quad 84$

4.3.2 Übertragbarkeit der Ergebnisse auf Dunaliella bioculata 85

4.3.3 Steigerung der Proteinsynthese in COS-7-Zellen durch Mutation in der Kozak Consensus-Sequenz 86

$\begin{array}{lll}\text { 4.3.4 Reinitiation am Startcodon des EGFP } & 87\end{array}$

$\begin{array}{lll}4.4 & \text { Weiterführende Experimente } & 89\end{array}$

$\begin{array}{lll}5 & \text { Zusammenfassung } & 90\end{array}$

$\begin{array}{lll}6 & \text { Literaturverzeichnis }\end{array}$ 


\section{$1 \quad$ Einleitung}

\subsection{Transportsysteme in biologischen Membranen}

Bei Transportvorgängen über Zellmembranen lassen sich aktive und passive Prozesse unterscheiden. Passiver Transport erfolgt immer entlang eines Gradienten, der vom Konzentrationsverhältnis des Stoffes zwischen beiden Membranseiten und bei geladenen Teilchen (z. B. Ionen) zusätzlich von der elektrischen Potentialdifferenz abhängt. Er erfolgt durch Ionenkanäle, die kleinere polare Moleküle im geöffneten Zustand hindurch diffundieren lassen oder durch Carrier, die die Diffusion von Teilchen begünstigen.

Aktive Prozesse können auch entgegen einen solchen Gradienten transportieren. Die dazu benötigte Energie kann durch die Spaltung energiereicher Verbindungen wie z. B. ATP gewonnen werden.

Die kontrollierte Verteilung von Ionen im Intra- und Extrazellularraum ist essentiell für viele physiologische Prozesse in Organismen, wie $\mathrm{pH}$-Homöostase, $\mathrm{Ca}^{2+}$-vermittelte Signaltransduktion, Wachstum, Zellvolumen-Regulation, Aufbau und Aufrechterhaltung des Membranpotentials sowie der Ausbildung von Aktionspotentialen.

\section{$1.2 \quad$ P-Typ ATPasen}

Adenosintriphospatasen (ATPasen) stellen die größte Gruppe aktiver Transportsysteme in Zellen dar. Die Hydrolyse von ATP setzt Energie frei, die dafür verwendet wird, Ionen gegen einen Konzentrationsgradienten über Membranen zu transportieren (PEDERSEN \& CARAFOLI 1987).

Eine klassische Einteilung von PEDERSEN \& CARAFOLI (1987) unterscheidet F-Typ, V-Typ und P-Typ ATPasen. Während F-Typ und V-Typ ATPasen fast ausschließlich Protonen transportieren, befördern die verschiedenen Vertreter der P-Typ ATPasen eine Vielzahl von Kationen.

Die Klasse der P-Typ ATPasen unterscheidet sich von anderen ATPasen fundamental in Struktur und Reaktionsmechanismus. Durch Übertragung der $\gamma$-Phosphatgruppe des hydrolysierten ATP auf einen spezifischen Aspartylrest im aktiven Zentrum der Enzyme entsteht ein Acylphosphatintermediat, dem die P-Typ ATPasen ihren Namen verdanken. Die durch diese Phoshorylierung bedingte Konformationsänderung ermöglicht es dem Enzym, das Kation auf der anderen Seite der Membran freizusetzen. Diese funktionalen Fähigkeiten sind in der Aminosäureabfolge einer jeden P-Typ ATPase festgelegt und spiegeln sich in konservierten Aminosäuremotiven wider (AXELSEN \& PALMGREN 1997, GREEN \& MAC LENNAN 1989). Übereinstimmende Vorhersagen zur Protein-Sekundärstruktur eukaryontischer P-Typ ATPasen (SERRAN0 et al. 1990, WACH et al. 1992) und die Übereinstimmung mit elektronenkristallographi- 
schen Daten einer $\mathrm{H}^{+}$-ATPase und $\mathrm{Ca}^{2+}$-ATPase aus Neurospora crassa zeigen, daß das Protein aus zwei hydrophoben Domänen und zehn Transmembransegmenten aufgebaut ist (AUER et al. 1998, ZHANG et al. 1998).

P-Typ ATPasen werden nach ihrer Substratspezifität und phylogenetischen Verwandtschaft in fünf Gruppen eingeteilt: Typ I ATPasen umfassen die Schwermetallpumpen, Typ II ATPasen die $\mathrm{Ca}^{2+}-, \mathrm{Na}^{+} / \mathrm{K}^{+}$- und $\mathrm{H}^{+} / \mathrm{K}^{+}$-ATPasen, Typ III ATPasen $\mathrm{H}^{+}$- und $\mathrm{Mg}^{2+}$-ATPasen, Typ IV ATPasen die Phospholipidpumpen und die Typ V ATPasen setzen sich aus ATPasen ohne definierte Substratspezifität zusammen (AXELSEN \& PALMGREN 1997).

Während die P-Typ $\mathrm{Na}^{+} / \mathrm{K}^{+}$- und $\mathrm{H}^{+} / \mathrm{K}^{+}$-ATPase sich aus einer $\alpha$-Untereinheit und glycosylierten $\beta$-Untereinheiten zusammensetzt, bestehen die Typ IIA und IIB $\mathrm{Ca}^{2+}$-ATPasen sowie die Typ III $\mathrm{H}^{+}$-ATPasen aus nur einem einzigen Polypeptid.

\subsection{Protonen-ATPasen}

Die P-Typ $\mathrm{H}^{+}$-ATPase ist die primäre Ionenpumpe der Plasmamembran von Pilzen und Pflanzen (PORTILLO 2000). Die Schlüsselfunktion der $\mathrm{H}^{+}$-ATPase ist die Erzeugung eines elektrochemischen Protonen-Gradienten über der Membran (SZE 1985, KASEI \& MUTO 1990). Dieser wird, analog zum Natriumgradienten in tierischen Zellen, durch energetische Kopplung zur Aufnahme (Cotransport) von Zuckern und Aminosäuren oder zur Abgabe (Antiport) von $\mathrm{Ca}^{2+}$ und $\mathrm{Na}^{+}$genutzt. $\mathrm{H}^{+}$-ATPase ist für die intrazelluläre pH-Regulation und die Aktivierung der meisten Ionen- und Metabolit-Transporte durch die Plasmamembran verantwortlich.

Das Enzym besteht aus einem einzelnen Polypeptid von 100 - 105 kDa und transportiert Protonen mit einer 1:1 Stöchiometrie zu hydrolysiertem ATP (PALMGREN \& AXELSEN 1998).

Die $\mathrm{H}^{+}$-ATPase höherer Pflanzen wird von einer Multigenfamilie kodiert. $11 \mathrm{H}^{+}$-ATPase Gene wurden im Genom von Arabidopsis identifiziert, 7 in Tomate und 9 in Tabak (MORSOMME \& BOUTRY 2000, OUFATTOLE et al. 2000). Auf Grund ihrer SequenzIdentität werden die Gene der $\mathrm{H}^{+}$-ATPase in zwei Subfamilien klassifiziert. Die zwei Subfamilien repräsentieren die am stärksten exprimierten Gene der $\mathrm{H}^{+}$-ATPase in Pflanzen.

Unterschiede in gewebespezifischer Expression (DE WITT et al. 1996, HARPER et al. 1994), asymmetrischer Verteilung innerhalb der Zelle (DE WITT \& SUSSMAN 1995, JAHN et al. 1998) und den katalytischen Eigenschaften (MORIAU et al. 1999) der einzelnen Isoformen sind gefunden worden. Bis zu drei Isoformen der $\mathrm{H}^{+}$-ATPase mit verschiedener Kinetik können in einer Zelle nebeneinander vorkommen (MORIAU et al. 1999, LU0 et al. 1999). Die physiologische Relevanz dieses Phänomens ist bis jetzt ungeklärt (PORTILLO 2000). 
Zusätzlich zur gewebe- bzw. entwicklungsspezifischen Expression erfolgt die transkriptionale Kontrolle der pflanzlichen $\mathrm{H}^{+}$-ATPase vermutlich durch eine Vielzahl von Umweltfaktoren.

So führen der Anstieg von Glucose in der Zelle (RA0 et al. 1993, VANEMA et al. 1995, GHISLAIN et al. 1992), osmotischer Stress (CURTI et al. 1993, BARBAKOV et al. 2000), niedrige pH-Werte (SUROWY \& BOYER 1991), Dunkelheit (HARMS et al. 1994) und verschiedene Hormone (FRIAS et al. 1996) zu erhöhter Expression und verstärkter katalytischer Aktivität des Enzyms.

Neben der transkriptionalen Kontrolle des Enzyms wird von LUKASZEWICZ (1998) eine translationale Regulation der ATPase vermutet. So besitzen die meisten pflanzlichen $\mathrm{H}^{+}$-ATPasen einen ungewöhnlich langen 5'-untranslatierten Bereich (LeaderSequenz), der einen kurzen offenen Leserahmen (5 - 13 Codons) enthält. Die Analyse der Leader-Sequenz mit dem $\beta$-Galactosidase-Gen als Reporter zeigte, daß sie die Aktivierung der Translation durch den Mechanismus translationaler Reinitiation beeinflußt.

Die funktionale Diversität der $\mathrm{H}^{+}$-ATPase wirft die Frage auf, ob die verschiedenen Isoformen neben gewebespezifischen Expressionsmustern auch unterschiedliche subzelluläre Lokalisationen in der Zelle besitzen könnten. Die Lokalisation der Vielzahl verschiedener Isoformen der $\mathrm{H}^{+}$-ATPasen aus Arabidopsis, Tabak und Tomate wird zwar auf Grund von Sequenzhomologien zu bereits molekularbiologisch charakterisierten $\mathrm{H}^{+}$-ATPasen in der Plasmamembran vermutet, wurde aber immunocytologisch oder mit Reportergenen in nur wenigen Fällen belegt (DE WITT et al. 1996, MORIAU et al. 1999). Dagegen wurden zwei $\mathrm{H}^{+}$-ATPasen aus der marinen Goldalge Heterosigma akashiwo, die größte Ähnlichkeiten zu P-Typ H+-ATPasen höherer Pflanzen und Protozoen zeigen, immunocytologisch in intrazellulären Membranen nachgewiesen (WADE et al. 1994). Es kann daher nicht grundsätzlich ausgeschlossen werden, daß P-Typ $\mathrm{H}^{+}$-ATPasen auch in anderen Membranen vorkommen.

\subsection{Calcium-ATPasen}

$\mathrm{Ca}^{2+}$-Ionen sind in allen Eukaryonten wichtige sekundäre Botenstoffe (second messenger) (BERRIDGE 1995, CLAPHAM 1995, SANDERS et al. 1999). Sie spielen eine elementare Rolle bei Signaltransduktions-Vorgängen, der Kontrolle und Genexpression vieler Proteine und scheinen auch einen Einfluß auf die Protein-Prozessierung im sekretorischen Stoffwechsel zu haben (GILL et al. 1996, SANDERS et al. 1999). Voraussetzung für diese Funktionen ist eine niedrige Konzentration an freien $\mathrm{Ca}^{2+}$-Ionen im Cytosol der Zelle. In Pflanzen wird der Influx der $\mathrm{Ca}^{2+}$-Ionen ins Cytoplasma über Kanäle aus intrazellulären Speichern geleitet, wie dem Endomembransystem und der Vakuole. Die Wiederherstellung einer niedrigen Calciumkonzentration im Cytosol geschieht durch biochemische Pufferung und intrazelluläre Sequestrie- 
rung in ER, Golgi, Mitochondrien, Chloroplasten und Vakuole, sowie durch den Export von $\mathrm{Ca}^{2+}$-Ionen gegen die elektrochemische Potentialdifferenz über die Plasmamembran (SANDERS et al. 1999).

Da die Konzentration an freien Ionen in den Organellen wesentlich höher ist als im Cytoplasma, sind für den Efflux der $\mathrm{Ca}^{2+}$-Ionen aus dem Cytosol energieabhängige Transportsysteme die Voraussetzung (SANDERS et al. 1999). Neben den $\mathrm{Ca}^{2+} / \mathrm{H}^{+}-\mathrm{Anti}$ portern im Tonoplasten, die geringe Affinität zu Ca ${ }^{2+}$-Ionen besitzen (HIRSCHI et al. 1996), spielen die hochaffinen P-Typ Ca ${ }^{2+}$-ATPasen der Plasmamembran und des Endomembransystems eine wichtige Rolle bei der Aufrechterhaltung der Calciumhomöostase (KREIMER et al. 1985, J0HNSON et al. 1995, SANTELLA \& CARAFOLI 1997).

\subsubsection{Lokalisation pflanzlicher $\mathrm{Ca}^{2+}$-ATPasen}

Die pflanzlichen $\mathrm{Ca}^{2+}$-ATPasen werden aufgrund ihrer Proteinsequenz-Identitäten in zwei Untergruppen gegliedert (AXELSEN \& PALMGREN 1998; EVANS \& WILLIAMS 1998, SANDERS et al. 1999, GEISLER et al. 2000):

\section{Typ IIA $\mathrm{Ca}^{2+}-\mathrm{ATPasen}$}

Sie sind den tierischen $\mathrm{Ca}^{2+}$-ATPasen des Sarkoplasmatischen und Endoplasmatischen Retikulums ähnlich und lassen sich durch Calmodulin nicht stimulieren (ER-Typ-Homologe).

\section{Typ IIB $\mathrm{Ca}^{2+}$-ATPasen}

Ähneln den tierischen durch Calmodulin stimulierbaren plasmamembranständigen $\mathrm{Ca}^{2+}$-ATPasen (PM-Typ-Homologe).

Allerdings entsprechen nicht alle pflanzlichen $\mathrm{Ca}^{2+}$-ATPase-Homologe diesen Kriterien (BUSH et al. 1995, BONZA et al. 1998, EWANS \& WILLIAMS 1998). So kommen pflanzliche Typ IIA $\mathrm{Ca}^{2+}$-ATPasen nicht ausschließlich im Endoplasmatischen Retikulum vor. Ein Beispiel ist LCA aus Lycopersicon esculentum (WIMMERS et al. 1992). Die Ca ${ }^{2+}-$ ATPase wurde durch Immunodedektion in Membranfraktionen sowohl in der Plasmamembran als auch im Tonoplasten lokalisiert und besitzt in den verschiedenen Membranen unterschiedliche Molekularmassen, die vermutlich durch alternatives Spleißen bedingt sind (FERROL \& BENNETT 1996). Auch ECA/ACA3 aus Arabidopsis ist trotz sequenztypischer Merkmale für ER-ständige $\mathrm{Ca}^{2+}$-ATPasen, nicht im ER nachweisbar (HONG et al. 1999, LIANG et al. 1997).

Den pflanzlichen Typ IIB Ca ${ }^{2+}$-ATPasen wurden aufgrund von biochemischen Merkmalen eine Lokalisation in der Plasmamembran zugesprochen (CARAFOLI 1991). So wurde die Stimulierbarkeit der $\mathrm{Ca}^{2+}$-ATPase durch Calmodulin als Indiz einer Plasmamembranlokalisation gewertet. Obwohl pflanzliche Calmodulin-stimulierbare 
$\mathrm{Ca}^{2+}$-ATPasen in ihrer Proteinsequenz große Ähnlichkeiten zu tierischen Plasmamembran-ATPasen besitzen, sind, mit zwei Ausnahmen, alle klonierten pflanzlichen Typ IIB ATPasen in Endomembranen lokalisiert worden (ASKERLUND 1996, MALMSTROM et al. 1997, HWANG et al. 1997, HONG et al. 1999). Die Isoform ACA1p der Ca ${ }^{2+-A T P a s e n ~ A C A 1 ~ a u s ~ A r a b i d o p s i s ~(H U A N G ~ e t ~ a l . ~ 1993, ~}$ HARPER et al. 1998) wurde mit Hilfe von Membranfraktionierung und Immunodetektion mit dem polyklonalen Antikörper anti-AC1 in der inneren Hüllmembran von Plastiden gefunden (HUANG et al. 1993). Die Lokalisation der Isoformen BCA1p aus Brassica oleracea wird aufgrund von Sequenzvergleichen mit einer vakuolären ATPase in der Vakuolen-Membran vermutet (MALMSTROM et al. 1997). ACA2p, der Isoform von ACA2, wurde zuerst mittels Immunodetektion in Membranfraktionen eine Lokalisation im ER zugeschrieben, die durch C-terminale Fusion des Proteins mit GFP optisch bestätigt werden konnte (HARPER et al. 1998, HONG et al. 1999). Die ersten klonierten plasmamembranständigen $\mathrm{Ca}^{2+}$-ATPasen sind die Isoformen At-ACA8 aus Arabidopsis (B0NZA et al. 2000) und SCA1 aus der Sojabohne (CHUNG et al. 2000). Auch sie besitzen wie alle bisher klonierten pflanzlichen Typ IIB

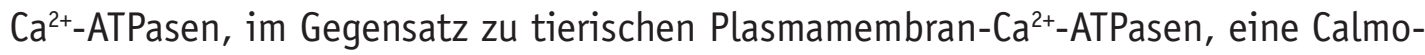
dulin-Bindungsstelle am N- und nicht am C-Terminus (MALMSTROM et al. 1997, HARPER et al. 1998, BONZA et al. 2000).

Calmodulin-stimulierbare pflanzliche $\mathrm{Ca}^{2+}$-ATPasen der Endomembranen und der Plasmamembran haben ähnliche biochemische Merkmale und lassen sich nur schwer voneinander unterscheiden (ASKERLUND \& SOMMARIN 1996, ASKERLUND 1996, HWANG et al. 1998). Als biochemische Unterscheidungsmerkmale werden mittlerweile auch das Molekulargewicht der ATPasen und die Hemmbarkeit durch Fluoreczin-Derivate herangezogen (BONZA et al. 1998). Plasmamembranständige $\mathrm{Ca}^{2+}$-ATPasen haben ein höheres Molekulargewicht als die der Endomembranen (THOMSON et al. 1993, ASKERLUND \& SOMMARIN 1996, ASKERLUND 1996, HWANG et al. 1998) und lassen sich durch Fluoreczin-Derivate schneller hemmen (THOMSON et al. 1993, BUSH \& WANG 1995, ASKERLUND \& SOMMARIN 1996).

Pflanzliche Typ IIA und Typ IIB $\mathrm{Ca}^{2+}$-ATPasen können gleichzeitig nebeneinander im selben Membransystem auftreten (EVANS \& WILLIAMS 1998, GEISLER et al. 2000, HONG et al. 1999, SANDERS et al. 1999). Diese Verteilung steht im Gegensatz zu tierischen Zellen, in denen Typ IIA und Typ IIB $\mathrm{Ca}^{2+}$-ATPasen entweder im Endomembransystem oder der Plasmamembran gefunden wurden (BRANDT \& VANAMAN 1998). Es ist zur Zeit noch unklar, welche Rolle unterschiedlich regulierbare $\mathrm{Ca}^{2+}$-ATPasen in derselben Membran haben. Für das ER werden funktional getrennte Domänen mit räumlich und funktional verschiedenen $\mathrm{Ca}^{2+}$-Speichern vermutet (GOLOVINA \& BLAUSTEIN 1997). 


\subsection{Signalsequenzen und topogene Signale}

In eukaryontischen Zellen hat sich ein komplexes Proteintransport- und Sekretionssystem entwickelt. Der größte Teil des Intermediärstoffwechsels sowie die für Wachstum und Fortbestand der Zelle erforderliche Proteinsynthese findet im Cytosol statt. Die Proteinsynthese der meisten Exportproteine und ebenso die der meisten Membranproteine erfolgt dagegen am Endoplasmatischen Retikulum. Alle Proteine der eukaryontischen Zelle, die über den sekretorischen Transportweg an ihren Bestimmungsort gebracht werden, müssen zunächst durch die Membran des ER transportiert oder, im Falle von integralen Membranproteinen, in diese inseriert werden. Anschließend können sie durch Transportvesikel in die verschiedenen Kompartimente des exocytotischen Transportweges, der Plasmamembran oder in den extrazellulären Raum gelangen.

Signalsequenzen nehmen eine Schlüsselrolle in der Zielsteuerung (Targeting) und der Membraninsertion von sekretorischen- und Membranproteinen in das ER ein (MARTOGLIO \& DOBBERSTEIN 1998).

Signalsequenzen befinden sich im allgemeinen am N-Terminus der zu transportierenden Proteine (Präproteine) und haben eine Länge von 15 - 50 Aminosäuren (VON HEIJNE 1986). Sie werden meistens noch während der Membranpassage auf der trans-Seite der ER-Membran durch eine membrangebundene Signalpeptidase abgespalten (MARTOGLIO \& DOBBERSTEIN 1998). Jedoch sind mittlerweile auch C-terminale Signalsequenzen bekannt (KATAY et al. 1995).

Obwohl die Primärstruktur der Signalsequenzen nicht konserviert ist, können drei charakteristische Bereiche unterschieden werden: ein positiv geladener $\mathrm{N}$-Terminus (N-Region), ein 7 - 16 Aminosäuren langer zentraler hydrophober Bereich (H-Bereich) und eine polare C-terminale Region (C-Bereich), die die Signalpeptidaseschnittstelle definiert. Die Gesamthydrophobizität ist für die Funktion einer Signalsequenz von entscheidender Bedeutung (CHOU \& KENDALL 1990, VON HEIJNE 1985).

Bei Membranproteinen, die meist keine Signalsequenzen besitzen, übernimmt gewöhnlich der Bereich der ersten Transmembrandomäne die Funktion einer Signalsequenz (KLEINIG \& SITTE 1999). Diese sogenannten Signalbereiche sind Oberflächenstrukturen, die sich durch Faltung eines Proteins ausbilden und für das entsprechende Protein charakteristisch sind. Sie unterscheiden sich von Signalsequenzen vor allem durch einen längeren hydrophoben Bereich (20 - 30 Aminosäuren) und das Fehlen einer Signalpeptidaseschnittstelle. Offensichtlich sind die Komponenten der Transportmaschinerie in der Lage, hydrophobe Signalsequenzen variabler Länge und Aminosäurezusammensetzung zu erkennen. Wie dieses Prinzip in der Zelle realisiert wird, ist bisher nur ansatzweise bekannt (ZHENG \& GIERASCH 1996). 
Signalsequenzen besitzen multiple Funktionen und enthalten spezifische Informationen, um die unterschiedlichen Funktionen des Targeting und der Membraninsertion sowie ihre Aufgaben nach Entfernen vom eigentlichen Protein auszuführen. Sie können zwischen den verschiedenen Transportwegen in das ER auswählen, vermitteln die Translokation des $\mathrm{N}$ - oder C-Terminus eines Proteins durch die Membran und sind für die Lokalisation eines Proteins in der Membran, im Lumen oder im Cytoplasma verantwortlich.

Der durch die Signalsequenz initiierte Transportprozeß ins ER kann cotranslational oder posttranslational erfolgen. Signalsequenzen bringen Proteine entweder zu dem co- oder zu dem posttranslationalen Translokationsapparat in der Membran. Beim cotranslationalen Mechanismus gelangen die Proteine während des Syntheseprozesses an den membrangebundenen Ribosomen durch die Membran. Dagegen werden Proteine beim posttranslationalen Prozeß erst nach ihrer Fertigstellung im Cytosol zur Membran gebracht. Studien, in denen die Signalsequenzen von Proteinen ausgetauscht wurden, zeigten, daß allein die Signalsequenzen darüber entscheiden, welcher Weg gewählt wird (FELDHEIM \& SCHEKMAN 1994, NG et al. 1996). Cotranslational transportierte Proteine besitzen offensichtlich hydrophobere Signalsequenzen als posttranslationale Transportsubstanzen.

Unklarheit besteht zudem darüber, wie die Proteine aus dem ER zu den verschiedenen Endomembranen dirigiert werden und ob diesbezügliche Erkenntnisse aus Hefen und Säugetierzellen auf Pflanzen übertragbar sind (GEISLER et al. 2000). Die zu transportierenden Proteine enthalten per se keine Transportsignale. Bekannt sind von ER-residenten Membranproteinen topogene Sequenzen, die für die Zurückhaltung dieser Proteine im ER verantwortlich sind. Diese topogenen Signale sind bestimmte Sequenzenmotive oder Strukturen, die den Bestimmungsort in der Zelle festlegen. Solche Signale ermöglichen das richtige Adressieren der Proteine an ihrem Entstehungsort an freien oder membrangebundenen Ribosomen in Richtung Bestimmungsort, häufig auch das Zurückhalten am Bestimmungsort. Einige dieser topogenen Signale sind bekannt. So ist die H/KDEL-Sequenz in tierischen und pflanzlichen Zellen die Rückhaltesequenz für lösliche Proteine im ER. 


\section{Signal Bedeutung}

Signalsequenz

15 - 30 AS lang, mit positiver $\mathrm{N}-$, hydrophober $\mathrm{H}$ - und unspezifischer C-Region; zum Transfer in das ER

K/H/RDEL, K/H/RDEL, Zurückhaltung löslicher Proteine im ER-Lumen tierischer, H/DDEL-Sequenz pflanzlicher und Hefe-Zellen

NLS Ein oder mehrere Cluster basischer AS. Transport in den Zellkern

R/KILL

Vermutlich Rückhaltesignale für Membranproteine im ER

KXKXX-, XXRR-Sequenz Rückhaltesignale für Membranproteine im ER

\section{Tab. 1: Beispiele topogener Signale für Transport und Kompatimentierung von Proteinen}

Bei tierischen Typ IIA Ca ${ }^{2+}$-ATPasen wurden zwei verschiedene ER-Targeting- bzw. Retentionssignale entdeckt, die für die ER-Assoziation dieser Proteine verantwortlich sein könnten (JACKSON et al. 1990, MAGYAR 1990). Das tierische C-terminale ER-Retentionssignal der Typ I Proteine mit der Consensus-Sequenz (K/X)(K/X)KXXStop findet sich auch in den pflanzlichen Typ IIA Isoformen ECA1 und ECA2 von Arabidopsis und in LCA aus Tomate wieder, ist aber nicht bei der 0sCA-ATPase aus Reis und ECA3 aus Arabidopsis vorhanden (GEISLER et al. 2000). Das Motiv KXKXX scheint trotzdem ein konserviertes ER-Retentionssignal phylogenetisch unterschiedlicher Organismen zu sein, da es sowohl in Hefe (TOWNSLEY \& PELHAM 1994) als auch in Pflanzen und Tieren vorkommt und als solches erkannt wird (HONG et al. 1999).

Das im ersten Transmembransegment tierischer $\mathrm{Ca}^{2+}$-ATPasen lokalisierte Motiv R/KILL wird als weitere Signalsequenz für die Zurückhaltung der Proteine im ER/SER diskutiert (MAGYAR 1990, EVANS \& WILLIAMS 1998). Es kommt in tierischen Typ IIA aber nicht IIB $\mathrm{Ca}^{2+}$-ATPasen vor und ist auch in den meisten pflanzlichen Homologen im ersten Transmembransegment konserviert, wie ein multiples Alignment von GEISLER et al. (2000) zeigte.

Immunofluoreszenzuntersuchungen mit rekombinanten tierischen Chimären aus Typ IIA $\mathrm{Ca}^{2+}$-ATPasen und einer plasmamembranständigen Typ IIB $\mathrm{Ca}^{2+}$-ATPase zeigten, daß innerhalb des ersten Transmembransegmentes der SER-ATPase Signalsequenzen für eine ER-Retention vorhanden sind und auch die ersten beiden Transmembransegmente der plasmamembranständigen ATPase ein Targeting zur Plasmamembran vermittelten (FOLETTI et al. 1995). 


\subsection{Translationsinitiationsstelle}

Vergleiche der Basensequenzen in nächster Umgebung tatsächlicher Startcodons lassen bei Eukaryonten in der Regel Rückschlüsse auf das als Translationsstartcodon genutzte ATG zu (KOZAK 1987, LÜTCKE et al. 1987).

In eukaryontischen Systemen gibt es im Gegensatz zu prokaryontischen keine purinreichen Sequenzen auf der 5'-Seite der mRNA, um zwischen Start- und internen AUG-Codons zu unterscheiden. Eukaryonten benutzen meistens das am nächsten zum 5'-Ende der mRNA liegende AUG als Startstelle. Die 40S-Untereinheit der Ribosomen lagert sich vermutlich an die CAP-Struktur am $5^{\prime}$-Ende eukaryotischer mRNAs an und sucht nach einem AUG-Codon, indem es sich schrittweise in 3'-Richtung bewegt. Mehrere Initiationsfaktoren sind notwendig, damit sich die 60S-Untereinheit mit dem Komplex aus Initiator-tRNA, mRNA und 40S-Untereinheit zu einem 80SInitiationskomplex verbindet. Dabei ist weitgehend unbekannt, welchen genauen Einfluß die um das Startcodon befindlichen Basen haben, da nicht immer das erste AUG-Codon auf der mRNA als Startsignal fungiert. Dennoch wurden durch Vergleiche zahlreicher, hauptsächlich tierischer Transkripte statistisch signifikante Ungleichverteilungen bestimmter Basen in nächster Umgebung tatsächlicher Startcodons gefunden (KOZAK 1987, KOZAK 1996). Diese Gewichtung wurde in ähnlicher Form von LÜTCKE et al. (1987) für pflanzliche Transkripte ermittelt. Während bei tierischen Transkripten die vier Basen CACC vor dem Methionin und die Base $\mathrm{G}$ an Position +4 relativ zum A des AUG nach dem Startcodon für eine effektive Initiation der Translation entscheidend sind, wird für pflanzliche Transkripte den Basen $G$ und $C$ an Position +4 und +5 regulatorische Funktionen in der Translationsinitiationseffizienz zugeschrieben (LÜTCKE et al. 1987).

\subsection{Das Grün Fluoreszierende Protein (GFP) als Reportergen}

Die Probleme der subzellulären Lokalisationsbestimmung können durch den Einsatz von Immunofluoreszenztechniken oder rekombinanten Reportergenen gelöst werden, die sich durch einfache biochemische oder histochemische Methoden nachweisen lassen. Reportergene, wie $\beta$-Galactosidase (LacZ) (HELMER et al. 1984, TERRI et al. 1989), $\beta$-Glucuronidase (GUS) (JEFFERSON 1987, JEFFERSON et al. 1987), Chloramphenicol-Acetyltransferase (CAT) (SEED \& SHEEN 1988) und Luziferase (LUC) (GALLIE et al. 1989, MILLER et al. 1992, OW et al. 1986) benötigen jedoch exogene Substrate, Co-Faktoren oder Antikörper, um nachgewiesen werden zu können. Eine Alternative zu diesen Reportergenen ist das Grün Fluoreszierende Protein - GFP. Es stammt aus der Tiefseequalle Aequorea victoria, deren Fähigkeit zur Biolumineszenz erstmals 1962 beschrieben wurde (SHIMOMURA et al. 1964). Für die Bio- 
lumineszenz ist unter anderem das 26,9 kDa schwere Grün Fluoreszierende Protein verantwortlich (PRASHER et al. 1992). Das eigentliche Fluorophor des GFP bildet sich autokatalytisch aus der Tripeptidsequenz Ser ${ }^{65}-$ Tyr $^{66}$-Gly ${ }^{67}$ innerhalb der 238 Aminosäuren umfassenden Polypeptidkette und benötigt keine exogenen Substrate oder Co-Faktoren (CHALFIE et al. 1994, HEIM \& TSIEN 1996, PRASHER et al. 1992). Der Wildtyp des GFP besitzt zwei ausgeprägte Anregungsmaxima bei $396 \mathrm{~nm}$ und 475 nm, welche zur Emission derselben Wellenlänge von 508 nm führen. Die Entwicklung von GFP-Varianten mit veränderten Anregungs- und Emissionsspektren durch Mutagenese im Bereich der chromophoren Gruppe und Codonoptimierung für unterschiedliche Expressionssysteme führte zu signifikanten Steigerungen der Translationshäufigkeit und Fluoreszenzintensität des Proteins (DELAGRAVE et al. 1995; EHRIG et al. 1995; HEIM et al. 1994; HEIM et al. 1995; SIEMERING et al. 1996). GFP-Varianten, deren Anregungsmaxima in den längerwelligen Bereich verschoben sind (red shifted GFP), sind ideal für standardisierte Argon Laser Anregung (DELAGRAVE et al. 1995).

Die Verwendungsmöglichkeiten des GFP als Reportergen sind vielseitig. Da die Fähigkeit zur Fluoreszenz nach $\mathrm{N}$ - oder C-terminaler Fusion mit anderen Proteinen nicht beeinflußt wird und die Eigenschaften des fusionierten Fremdproteins auch in heterologen Systemen erhalten bleiben, (CHALFIE et al. 1994, GU et al. 1997, HEINLEIN et al. 1995, WANG \& HAZELRIGG 1994) kann es für in vivo Studien über Genexpression, Protein-Transport, Protein-Protein-Interaktionen und die Lokalisation einzelner Proteine in lebenden Zellen eingesetzt werden (KAETHER \& GERDES 1995). Der Gebrauch von GFP-Reportergenen mit unterschiedlichen Emissionswellenlängen macht eine simultane Lokalisation verschiedener Proteine in einer Zelle möglich.

In Pflanzen wurde Wildtyp-GFP mit Hilfe des Kartoffel-Virus-X-Expressionssystemes (BAULCOMBE et al. 1995 ) oder des Tabak-Mosaik-Virus (HEINLEIN et al. 1995) zur Expression gebracht. Der Einsatz von rekombinanten GFP-Proteinen in Chloroplasten (KÖHLER et al. 1997a), Mitochondrien (KÖHLER et al. 1997b), Strukturen des Cytoskeletts (HEINLEIN et al. 1995) und des Zellkerns (GREBENOK et al. 1997) haben dabei neue Einblicke in verschiedene zelluläre Prozesse von Pflanzen ermöglicht. In diesen Experimenten wurde GFP als virale mRNA in großen Mengen exprimiert und konnte im Mikroskop lokalisiert werden. Jedoch konnte wenig oder gar keine grüne Fluoreszenz nach Transfektion in isolierten Zellen und ganzen Pflanzen von Arabidopsis, Tabak- und Gersteprotoplasten eruiert werden (HASELOFF et al. 1995, HU \& CHENG 1995, REICHEL et al. 1996, SHEEN et al. 1995). Erst durch Auffinden und Beseitigen eines kryptischen Introns innerhalb der GFP-Sequenz, das große Ähnlichkeit zu pflanzlichen Introns zeigte (HASELOFF et al. 1997) und einer Optimierung der Codon-Gewichtung (CHIU et al. 1996, PANG et al. 1996, REICHEL et al. 1996), konnten erhöhte Expressionsraten, eine verbesserte Proteinfaltung während des post-translationalen Reifungsprozesses (CORMACK et al. 1996, CRAMERI et al. 
1996) und eine verstärkte subzelluläre Fluoreszenz in transfizierten Pflanzen erreicht werden (HASELOFF \& SIEMERING 1998).

\subsection{Zwei P-Typ ATPasen aus Dunaliella bioculata}

Aus der einzelligen, zellwandlosen und extrem salztoleranten Grünalge Dunaliella bioculata wurden molekularbiologisch bisher zwei putative P-Typ ATPasen charakterisiert, eine $\mathrm{Ca}^{2+}$-ATPase und eine $\mathrm{H}^{+}$-ATPase.

DBCA1 (Dunaliella bioculata Calcium ATPase 1) ist eine putative $\mathrm{Ca}^{2+}$-ATPase (RASCHKE 1996, RASCHKE \& WOLF 1996), DBPMA1 (Dunaliella bioculata Plasmamembran ATPase 1) eine putative $\mathrm{H}^{+}$-ATPase (WOLF 1993, WOLF et al. 1995). Die Gesamtlänge der cDNA-Sequenz von DBCA1 umfaßt 3692 bp. Das längste offene Leseraster kodiert für ein Protein aus 1111 Aminosäuren mit einer kalkulierten Molekülmasse von $114 \mathrm{kDa}$. Das erste Startcodon im richtigen Leseraster befindet sich an Position 48 - 50. Weitere ATG-Tripletts sind an Position 96 - 98 und 117 - 119 zu finden. Die Primärstruktur von DBCA1 weist alle Aminosäurereste auf, die für den Calcium-Transport (S)ER-ständiger Enzyme essentiell sind. So wurde DBCA1 wegen ihrer Ähnlichkeit zu Calcium-translozierenden ATPasen aus dem (S)ER tierischer Organismen (70 \% Ähnlichkeit, 54 \% Identität) (RASCHKE 1996) in der Klasse der P-Typ ATPasen eingeordnet. Auch AXELSEN \& PALMGREN (1997) ordneten DBCA1 den P-Typ IIA ATPasen zu. Aufgrund von Southernblot-Analysen wird vermutet, daß im Genom von Dunaliella bioculata weitere Isoformen der $\mathrm{Ca}^{2+}$-ATPase vorkommen (RASCHKE 1996).

Die Peptidsequenz der $\mathrm{H}^{+}$-ATPase DBPMA1 weist 17 definierte Regionen auf, die charakteristisch für Protonen-translozierende ATPasen sind (SERRANO 1988, GREEN 1989, SERRANO 1989, WACH et al. 1992) und anderen P-Typ ATPasen dagegen fehlen (WACH et al. 1992). Die Gesamtlänge der cDNA umfaßt 4678 bp. Das längste offene Leseraster der Nukleinsäuresequenz kodiert für ein Polypeptid aus 1131 Aminosäuren mit einer kalkulierten Molekülmasse von 123 kDa. Zwei ATG-Tripletts befinden sich im längsten offenen Leserahmen der Nukleinsäuresequenz, die als Translationsstart interpretiert werden könnten. Sequenzvergleiche zeigten, daß das Protein Ähnlichkeit zu H+-ATPasen aus höheren Pflanzen hat (58 - 61 \% Ähnlichkeit, 47 \% Identität) (WOLF 1994) und zur Primärstruktur der plasmamembranständigen $\mathrm{H}^{+}$-ATPase aus Dunaliella acidophila (WEISS \& PICK 1996) $78 \%$ Identität und $87 \%$ Ähnlichkeit aufweist. Von AXELSEN \& PALMGREN (1997) wurde DBPMA1 den Typ IIIA ATPasen zugeordnet. Southernblot-Analysen mit genomischer DNA aus Dunaliella bioculata zeigten, daß das Gen von DBPMA1 (pma1) in einfacher Kopie vorliegt und keine weiteren Isoformen besitzt (WOLF 1993, WOLF et al. 1995). 


\subsection{Zielsetzung}

Immunocytologische Nachweise der subzellulären Lokalisation der beiden ATPasen DBCA1 und DBPMA1 aus Dunaliella bioculata wurden bisher nicht durchgeführt. Die Ergebnisse von GEISLER et al. (2000), HONG et al. (1999), SANDERS et al. (1999) und WADA et al. (1994) zeigen jedoch, daß Rückschlüsse auf die Lokalisation von P-Typ $\mathrm{Ca}^{2+}$-und $\mathrm{H}^{+}$-ATPasen in Pflanzen aufgrund ihrer biochemischen Merkmale und Sequenzhomologien nicht uneingeschränkt gezogen werden können. GFP stellt ein geeignetes Markerprotein zur subzellulären Lokalisationsbestimmung von ATPasen dar. Die Expression rekombinanter Proteine hat den Vorteil, daß GFP direkt sichtbare Fluoreszenz zeigt, in vivo Beobachtungen ermöglicht und dazu keine exogenen Substrate oder Co-Faktoren benötigt. Gegenüber immunocytologischen und Membranfraktions-Analysen, bei denen Kreuzreaktionen zwischen Antikörpern und anderen Isoformen nicht ausgeschlossen werden können, liefern ATPase-GFPChimäre Isoformen-spezifische Informationen. Überdies lassen sich bei der GFP-Markierung Fehlinterpretationen vermeiden, die auf unsaubere Trennung der pflanzlichen Membransysteme bei der Fraktionierung im Gradienten beruhen.

Ziel der Arbeit war, die subzelluläre Lokalisation der Ca ${ }^{2+}$-ATPase DBCA1 und $\mathrm{H}^{+}$-ATPase DBPMA1 aus Dunaliella bioculata fluoreszenzoptisch zu bestimmen. In der Vergangenheit war beobachtet worden, daß heterologe Expression aktiver $\mathrm{H}^{+}$-ATPasen in pflanzlichen Systemen zum Tod der Zelle oder zu stark retardiertem Wachstum führten (MORSOMME \& BOUTRY 2000). Um dieses Problem zu umgehen, sollte für die Lokalisationsstudien keine aktiven ATPasen, sondern nur Teilbereiche von ihnen verwendet werden. Bisher ist wenig über die Sequenz-Informationen bekannt, die für die subzelluläre Verteilung (Sortierung) von ATPasen und den dazugehörigen zellulären Sortierapparat entscheidend sind. Dennoch haben Immunofluoreszenzuntersuchungen rekombinanter Chimären aus tierischen Typ IIA und IIB $\mathrm{Ca}^{2+}$-ATPasen gezeigt, daß Signalsequenzen innerhalb der ersten Transmembransegmente der ATPasen, für eine ER-Retention vorhanden sind und auch das Targeting zur Plasmamembran durch N-terminale Sequenzbereiche der plasmamembranständigen $\mathrm{Ca}^{2+}$-ATPase bestimmt werden kann (FOLETTI et al. 1995).

Dementsprechend sollte in der vorliegenden Arbeit versucht werden, die Lokalisation der ATPasen über GFP markierte N-terminale Transmembransegmente in heterologen Expressionssystemen zu bestimmen. Da beide ATPasen über mehrere potentielle Startcodons verfügen, sollte das Fluoreszenzsignal ferner genutzt werden, die Translationseffizienz von Konstrukten mit verkürztem $\mathrm{N}$-Terminus zu verfolgen, um so die eigentliche Translationsinitiationsstelle zu identifizieren. 


\section{Material und Methoden}

\subsection{Material}

\subsubsection{Organismen und Plasmide}

\subsubsection{Escherichia coli (E. coli)}

Zur Transformation und Vermehrung von Plasmiden wurden die Derivate des E. coli K12 Stammes DH5 $\alpha F^{\prime}$ (HANAHAN 1985) und XL1-Blue (Stratagene, Amsterdam, Niederlande) mit folgenden Eigenschaften eingesetzt:

DH5 $\alpha \mathrm{F}^{\prime}: \quad \sup 644, F^{\prime} \Phi 80 d$ lacZ $\Delta$ M15, $\Delta$ (lacZYA-argF) U169, recA1, end $A 1, h s d R 17\left(r_{K_{-}} m_{K_{+}}\right)$

XL1-Blue: recA1, endA1, gyrA96, thi-1, hsdR17, supE44, relA1, lac, [F'proAB, $\operatorname{lacI}^{q} Z \Delta M 15, \operatorname{Tn} 10$ (tet $\left.\left.^{r}\right)\right]$

\subsubsection{COS-7-Zellen}

Als heterologes Versuchssystem zur fluoreszenzmikroskopischen Untersuchung der ATPase Expression und Lokalisation dienten konfluent gewachsene COS-7-Zellen. Bei COS-7-Zellen handelt es sich um eine von der Affennieren-Zellinie CV1 abgeleitete Linie, die durch Behandlung der Zellen mit einer Mutante des Affenvirus SV40 entstanden ist. Die Zellen wurden freundlicherweise von der Abteilung Molekulare Zellbiologie (Prof. Gruss) des Max-Planck-Institutes für Biophysikalische Chemie in Göttingen zur Verfügung gestellt.

\subsubsection{HeLa-Zellen}

Als weiteres heterologes Versuchssystem wurden adhärent wachsende HeLa-Zellen verwendet. Es handelt sich dabei um Zellen der von GEY et al. (1952) etablierten Kultur eines menschlichen Zervix-Karzinoms epitheler Herkunft.

Die Zellen wurden von der Deutschen Sammlung von Mikroorganismen und Zellkulturen (Braunschweig) (Nr. DSM ACC 57) bezogen.

Optimale Wachstumsbedingungen waren gegeben, wenn die HeLa-Zellmenge zu Beginn ihrer Kultivierung $0,5-1,0 \times 10^{5}$ Zellen pro $\mathrm{ml}$ Kulturmedium bei $37^{\circ} \mathrm{C}$ in einem $5 \%-\mathrm{CO}_{2}$-Milieu betrug.

\subsubsection{Tabak}

Sterile Takakpflanzen wurden aus Samen von Nicotiana tabacum L. cv Samsun NN gezogen. Zur Gewinnung von Tabak-Protoplasten wurden 10 - 12 Wochen alte Pflanzen verwendet (2.2.19). 


\subsubsection{5 cDNA der Calcium- und Protonen-ATPase}

Die cDNA der Calcium-ATPase DBCA1 aus Dunaliella bioculata (RASCHKE \& WOLF 1996, RASCHKE 1996) wurde von Dr. B.C. Raschke zur Verfügung gestellt. Die vollständige Sequenz ist in der Sequenz-Datenbank des National Center of Biotechnology (NCBI; www.ncbi/ulm.nih.gov) unter der Zugangsnummer X93592 aufgeführt.

Die cDNA der Protonen-ATPase DBPMA1 aus Dunaliella bioculata (WOLF et al. 1995, WOLF 1993) stellte Dr. A.H. Wolf zur Verfügung. Die vollständige Sequenz ist in der NCBI Sequenz-Datenbank unter der Zugangsnummer X73901 gespeichert.

\subsubsection{Grün Fluoreszierendes Protein (GFP)}

\subsubsection{1 pEGFP-N1}

Als visueller Marker der Genexpression und Proteinlokalisation in HeLa- und COS-7Zellen diente der pEGFP-N1 N-terminale Protein-Fusions-Vektor (Clontech, Palo Alto, USA; GenBank Zugangsnummer U55762). pEGFP-N1 ist eine "red shifted" Variante des Wildtyp-GFP, mit stärkerer Fluoreszenzintensität und verbesserter Expression in Säugetierzellen. Der Vektor kodiert für die GFPmut1-Variante (CORMACK et al. 1996), die den doppelten Aminosäureaustausch $\mathrm{Phe}^{64}$ zu Leu und Ser ${ }^{65}$ zu Thr enthält. Das Anregungsmaximum liegt bei $488 \mathrm{~nm}$, das Emissionsmaximum bei $507 \mathrm{~nm}$. Die kodierende Sequenz des EGFP-Gens enthält mehr als 190 stille Basensubstitutionen zur Angleichung an die menschliche Codon-Präferenz (HAAS et al. 1996). Zur Verbesserung der Translationseffizienz in eukaryontischen Zellen befindet sich vor der kodierenden EGFP-Sequenz eine Kozak Consensus-Sequenz. Eine multiple Klonierungsstelle (MCS) befindet sich zwischen dem CMV-Promotor $\left(\mathrm{P}_{\text {CMVIE }}\right)$, der die konstitutive Expression in Säugetierzellen kontrolliert, und den EGFP-codierenden Sequenzen. Ein SV40-Polyadenylierungsignal nach der EGFP-Sequenz sorgt für eine Prozessierung des 3'-Endes der EGFP-mRNA.

pEGFP-N1 enthält außerdem das Kanamycinresistenzgen aus Tn5, das das Wachstum transformierter Wirtszellen auf Selektivagar zuläßt.

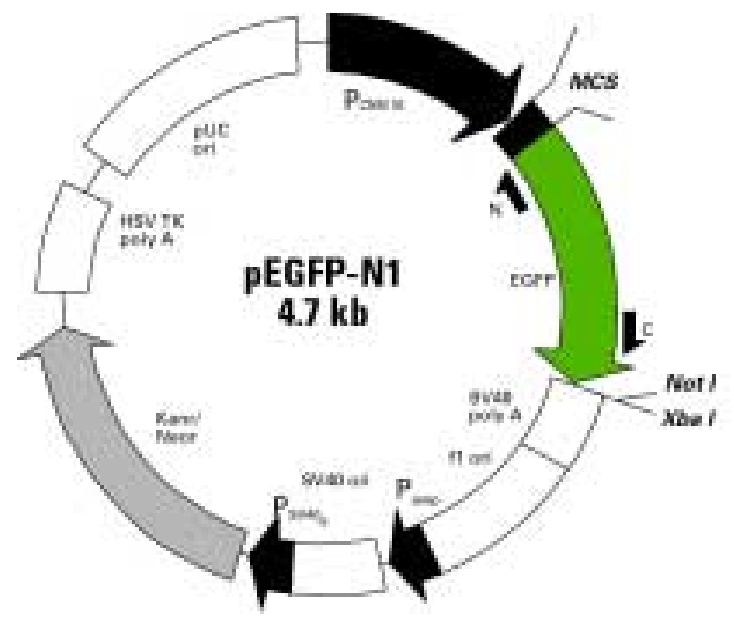

Abb. 1: Vereinfachte Genkarte des pEGFP-N1 N-terminaler ProteinFusions-Vektor

pEGFP eignet sich zur Konstruktion von EGFPFusionsgenen. Fremdgene können über die MCS am N-Terminus der EGFP-Sequenz inseriert werden und müssen ein Startcodon zur Expression als EGFP-Fusionsprotein enthalten. 


\subsection{HBT-L}

Als Expressionsvektor zur Lokalisationsbestimmung rekombinanter ATPase-GFP-Proteine in Tabak-Protoplasten diente der binäre Vektor HBT-L. Er wurde freundlicherweise von der Arbeitsgruppe Prof. Gatz (Albrecht-von-Haller-Institut der Universität Göttingen) zur Verfügung gestellt. Grundlage des HBT-L ist der Klonierungsvektor pUC18. Er enthält zwischen den Schnittstellen EcoR I und Hind III das HBT-sGFPS65T-NOS-Fragment.

sGFP-S65T ist eine GFP-Mutante mit einer für menschliche Gene optimierten CodonPräferenz, die in Pflanzenzellen gute Expressionsergebnisse zeigt, da die bevorzugte Codon-Präferenz zwischen menschlichen Genen und denen höherer Pflanzen oftmals ähnlich ist (HAAS et al. 1996, WADA et al. 1991). Diese Mutante führt zu einer 20-fach höheren Proteinexpression und einem verstärkten Fluoreszenzsignal im Vergleich zum Wildtyp-GFP (SHEEN et al. 1995). Zahlreiche Restriktionsschnittstellen und ein potentielles kryptisches Intron (HASELOFF et al. 1997) wurden eliminiert. Die Substitution von Ser ${ }^{65}$ zu Thr im Chromophor des sGFP-S65T führt zu einer Unterdrückung der Absorption bei $395 \mathrm{~nm}$ und zu einem Absorptionsmaximum bei 488 nm (CUBITT et al. 1995, HEIM et al. 1995) sowie zu einer schnelleren Bildung des Chromophors. Das Emissionsmaximum liegt bei $510 \mathrm{~nm}$. Die Expression des GFP erfolgt unter der Kontrolle des chimären Promotors HBT (SHEEN 1993, SHEEN et al. 1995). Er besteht aus den ersten 400 bp des 35S-Promotors und der TATA-Box sowie der 5'-untranslatierten Region (5'-UTR) aus dem Maisgen C4PPDK. Der 5'-UTR enthält einen universellen Transkriptions-Verstärker, der die Promotor-Aktivität um ein 10- bis 80-faches steigert. Am 3'-Ende des SGFP-S65T ist der NOS-Transkriptionsterminus aus Agrobacterium tumefaciens angefügt.

Durch zusätzliche Insertion der MCS des Klonierungsvektors pBluescript II SK(+) in den HBT-L-Vektor unmittelbar vor die sGFP-S65T-Sequenz, sind N-terminale Fusionen mit sGFP-S65T über die Schnittstellen Bam HI und Kpn I möglich. HBT-L enthält außerdem ein Ampicillinresistenzgen, das das Wachstum transformierter Bakterien auf Selektivagar ermöglicht.

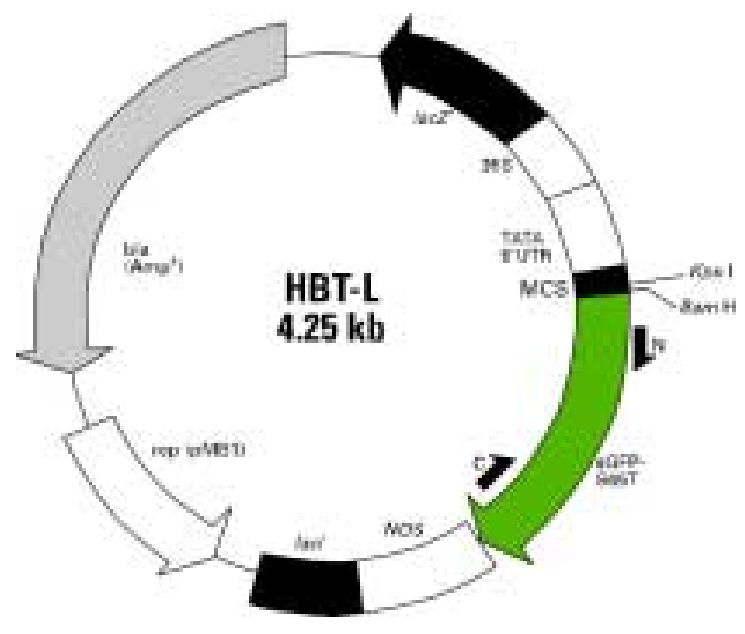

\begin{abstract}
Abb. 2: Vereinfachte Genkarte des Klonierungsvektors HBT-L

Fremdgene können über die zusätzlich eingefügte MCS am N-Terminus der SGFP-S65TSequenz inseriert werden und müssen ein Startcodon zur Expression als sGFP-S65TFusionsgen enthalten.
\end{abstract}




\subsubsection{Oligonukleotide}

Die folgenden Oligonukleotide wurden für Polymerasekettenreaktion (PCR) und Sequenzierung von DNA-Fragmenten eingesetzt.

Sie wurden über die Firmen Naps (Göttingen), Roth (Karlsruhe) und Clontech (Palo Alto, USA) bezogen.

\begin{tabular}{|l|l|}
\hline 0ligonukleotide & Sequenz $\left(5^{\prime} \rightarrow \mathbf{3}^{\prime}\right)$ \\
\hline DCA-M1 & GGTCTCGAGCACCATGGTGAGCCACGCTTCATCAGG \\
\hline DCA-M2 & GGTCTCGAGCACCATGGTGACCTGGCCTTGGAT \\
\hline DCA-M3 & GGTCTCGAGCACCATGCAGGACGCCTACTCCAGTG \\
\hline rDCAC1 & GGAATCAGCTGCAGCTGGCCAT \\
\hline DBH-M1 & GGTCTCGAGCACCATGGCGGACATCAAGGAAGGA \\
\hline DBH-M2 & GGTCTCGAGCACCATGATCAAGGAGCCCCTCACA \\
\hline rDBH & GCAGCTCGAGTCACAATGGCACCATCTCGCA \\
\hline rDBH2 & GTCACTGCAGCACAATGGCACCATCTCGCA \\
\hline DBCAT-M1 & TGATGGTACCCTTGAATGGTGAGC \\
\hline DBCAT-M2 & TGATGGTACCTGGAATGGTGTACCTG \\
\hline DBCAT-M3 & TGATGGTACCTTGGAATGCAGGACGCC \\
\hline rDBCAT & AGTCGGATCCATTCCGGAGCACTGTGGC \\
\hline DBHT-M1 & TGACGGTACCGCAACATGGCGGACATC \\
\hline DBHT -M2 & TGACGGTACCGGTGGACATGATCAAGGAG \\
\hline rDBHT & TGACGGATCCATCTCGCACGACCAT \\
\hline
\end{tabular}

Tab. 2: Primer für die Amplifikation des $\mathrm{N}$-Terminus und der ersten beiden Transmembransegmente aus der cDNA der $\mathrm{Ca}^{2+}$-ATPase DBCA1 und der $\mathrm{H}^{+}$-ATPase DBPMA1 aus Dunaliella bioculata

Die Startcodons sind durch Fettdruck hervorgehoben, die Kozak ConsensusSequenz kursiv dargestellt und die Schnittstellen sind unterstrichen.

\begin{tabular}{|l|l|}
\hline Oligonukleotide & Sequenz $\left(\mathbf{5}^{\mathbf{\prime}} \boldsymbol{\rightarrow} \mathbf{3}^{\mathbf{}}\right.$ ) \\
\hline rGFP & TTACGTCGCCGTCCAGCTCGAC \\
\hline rLGYMW & CCACATGTATCCAAGGGA \\
\hline rQQARI & TTGATGCGGGCCTGCTGC \\
\hline HBT-L-f & CAGGCGCGGGGCGGTCACGTAGTA \\
\hline
\end{tabular}

Tab. 3: Primer für die Sequenzierung der rekombinanten pEGFP-N1 und HBT-L-Vektoren 


\subsubsection{Chemikalien, Enzyme und Reaktionssysteme}

Chemikalien und Reaktionssysteme wurden über die Firmen Biomol (Ilvesheim), BioRad (München), Boehringer (Mannheim), DIFCO-Laboratories (Detroit, USA), Gibco BRL (Eggenstein), Invitrogen (San Diego, USA), Merck (Darmstadt), Pharmacia (Freiburg), Qiagen (Hilden), Serva (Heidelberg) und Sigma-Aldrich GmbH (München) bezogen.

Wenn nicht anders angegeben, wurden bei der Verwendung von Reaktionssystemen stets die Angaben des Herstellers befolgt.

Für Restriktionsanalysen wurden Restriktionsendonukleasen der Hersteller Boehringer (Mannheim), Eurogentec (Seraing, Belgien), MBI Fermentas GmbH (St. Leon-Rot), Pharmacia (Freiburg) verwendet.

\subsubsection{Mikroskopie}

\subsubsection{Fluoreszenzmikroskopie}

Die visuelle Überprüfung von Genexpression und Proteinlokalisation des fluoreszierenden Genmarkers GFP wurde mit einem Olympus BH-2 Mikroskop, bestückt mit den Filterblöcken BH2-DMV und BH2-DMBV, durchgeführt. Für Auflicht-FluoreszenzMikroskopie wurden zusätzlich ein vertikaler Auflicht-Fluoreszenz-Kondensor (BH-2-RFA), fluoreszenzfreie UV-0bjektive mit 10-, 40- und 100-facher Vergrößerung und eine $100 \mathrm{~W}$ Quecksiberdampflampe verwendet.

Für die Mikrofotografie war am Fototubus eine Automatik-Kleinbildkamera mit Handschaltgerät (Olympus, PM-10AK) angebracht. Als Filmmaterial dienten 200, 400 und 800 ASA Diafilme der Firmen Kodak und Revue.

\subsubsection{Konfokale Fluoreszenzmikroskopie}

Konfokale Aufnahmen von GFP-transfizierten COS-7-Zellen und Tabak-Protoplasten wurden mit dem inversen konfokalen Laser Scanning Mikroskop LSM 410 invert (Zeiss, Göttingen) gemacht. Es besteht als Grundeinheit aus dem Mikroskop Axiovert 135 M, das Fluoreszenz- und Durchlichtmikroskopie ermöglicht. Angegliedert sind die Einrichtungen für die konfokale Mikroskopie, die Steuerung des Gerätes, ein PC und die digitale Bildverarbeitung.

Die GFP-Expression wurde bei inverser Fluoreszenzmikroskopie mit dem FITC-Filtersatz (Extinktionsfilter 470 - 490 nm, Dichroider Spiegel 510 nm, Emissionsfilter $510-540 \mathrm{~nm}$ ) untersucht. Bei konfokaler Mikroskopie erfolgte die Anregung mit einem externen Argon-Ionen Laser bei einer Anregungswellenlänge von $488 \mathrm{~nm}$. Das Emissionslicht wurde durch einen 510 - 520 nm Bandpassfilter gefiltert. Die digitale Bildverarbeitung erfolgte mit dem Programm LSM Version 3.95 (Zeiss, Göttingen). 
Die Nutzung des konfokalen Fluoreszenzmikroskopes wurde freundlicherweise von der Abteilung Membranbiophysik am Max-Planck-Institut für Biophysikalische Chemie in Göttingen ermöglicht.

\subsubsection{Software}

Für DNA-Analyse:

ABI PRISM ${ }^{T M}$ Sequencing Analysis 3.0 (PE Applied Biosystems)

Mac Vector and AssemblyLign (IBI)

Für Bildanalyse und -bearbeitung:

NIH Image 1.61

Adobe Photoshop 5.0

LSM Version 3.95 (Zeiss)

\subsection{Methoden}

\subsubsection{Kultivierung von Escherichia coli}

Stammkulturen von Escherichia coli (E. coli) wurden als Glycerinsuspension (40\%) bei $-70^{\circ} \mathrm{C}$ gelagert und bei Bedarf auf Agarplatten ausgestrichen (1,5\% Agar in NZY-Medium).

$$
\begin{array}{llll}
\text { NZY-Medium: } & 1,0 \%(\mathrm{w} / \mathrm{v}) & \text { NZ-Amine } \\
& 0,5 \%(\mathrm{w} / \mathrm{v}) & \text { Hefeextrakt } \\
& 5,0 \%(\mathrm{w} / \mathrm{v}) & \mathrm{NaCl}
\end{array}
$$

Übernachtkulturen von $E$. coli wurden in autoklavierten $10 \mathrm{ml}$ Reagenzgläsern mit Aluminiumkappen gezogen. Dazu wurden in der Regel $2 \mathrm{ml}$ NZY-Medium bei Bedarf mit Ampicillin $(75 \mathrm{mg} / \mathrm{ml})$ oder Kanamycin $(30 \mathrm{mg} / \mathrm{ml})$ versetzt und mit einer einzelnen Bakterienkolonie von einer Agarplatte beimpft. Die Kulturen wurden $12-14 \mathrm{~h}$ bei $37^{\circ} \mathrm{C}$ und $250 \mathrm{Upm}$ in einem Schüttelinkubator (GFL 3032) gezogen. 


\subsubsection{Transformation von E. coli mit Calciumchlorid}

Für Standard-Transformationen wurden E. coli Zellen mit Calciumchlorid für die Aufnahme von Plasmid-DNA kompetent gemacht (COHEN et al. 1972, Protokoll nach SAMBROOK et al. 1989).

Zur Transformation wurden bis zu $10 \mu \mathrm{l}$ Plasmid-DNA mit einem Volumen von $200 \mu \mathrm{l}$ kompetenten Zellen vermischt und 30 min auf Eis inkubiert. Nach kurzem Erhitzen (90 s) auf $42^{\circ} \mathrm{C}$ wurde die Suspension anschließend auf Eis gekühlt und die Zellen zur Expression der Antibiotikaresistenz mit $800 \mu \mathrm{l}$ NZY-Medium 30 min bei $37^{\circ} \mathrm{C}$ geschüttelt. Nach der Inkubation wurden die Zellen durch kurze Zentrifugation im unteren Bereich des Reaktionsgefäßes konzentriert, vom Großteil des Mediums befreit und auf Selektivagar ausplattiert.

\subsubsection{Plasmidisolierung}

Plasmidisolierung wurde sowohl im präparativen als auch im analytischen Maßstab durchgeführt. Sie erfolgte nach der Methode von BIRNBOIM \& DOLY (1979).

Zur Analyse von Plasmid-DNA aus transformierten Bakterien wurden Übernachtkulturen angezogen. Jeweils 1,5 ml der Kultur wurden in 1,5 ml Reaktionsgefäße überführt und $10 \mathrm{~s}$ bei $12.000 \mathrm{~g}$ zentrifugiert. Das Zentrifugat wurde dekantiert und das Reaktionsgefäß zum Abtropfen 5 min kopfüber auf Fließpapier gestellt. Das Zellpellet wurde in $100 \mu \mathrm{l} \mathrm{TE-Puffer} \mathrm{mit} \mathrm{RNase} \mathrm{A} \mathrm{(P1-Puffer)} \mathrm{suspendiert} \mathrm{und} \mathrm{mit} 200 \mu \mathrm{l}$ alkalischer SDS-Lösung (P2-Puffer) versetzt. Nach 5-minütiger Inkubation bei RT wurden $150 \mu$ leiskalte Kaliumacetatlösung (P3-Puffer) zugegeben und das Gemisch 10 min auf Eis inkubiert. Nach 20-minütiger Zentrifugation bei $12.000 \mathrm{~g}$ wurde das Zentrifugat mit der Plasmid-DNA und den löslichen Proteinen einer Phenol-Chloroform-Extraktion unterworfen (2.2.4.1). Die DNA wurde mit Natriumacetat und Ethanol 30 min gefällt (2.2.4.3) und anschließend bei $12.000 \mathrm{~g}$ pelletiert. Der Überstand wurde verworfen und das verbleibende Ethanol im Heizblock bei $50^{\circ} \mathrm{C}$ abgedampft. Das DNA-Pellet wurde in $20-50 \mu \mathrm{l}$ autoklaviertem HPLC-Wasser gelöst und zur weiteren Verarbeitung bei $-20^{\circ} \mathrm{C}$ gelagert.

Zur präparativen Plasmidisolierung wurden $200 \mathrm{ml}$ steriles NZY-Medium mit einem Antibiotikum versetzt und mit $2 \mathrm{ml}$ einer Übernachtkultur des entsprechenden Klons beimpft. Die Kultur wurde über Nacht bei $37^{\circ} \mathrm{C}$ im Schüttelinkubator bei $250 \mathrm{Upm}$ angezogen. Die Bakterien wurden $15 \mathrm{~min}$ bei $2.500 \mathrm{~g}$ (4.000 Upm, GSA-Rotor, SORVALL RC-5B) pelletiert und anschließend in $10 \mathrm{ml}$ P1-Puffer resuspendiert. Die Zellsuspension wurde mit $10 \mathrm{ml}$ P2-Puffer vermischt und 5 min bei RT inkubiert. Anschließend wurden $10 \mathrm{ml}$ P3-Puffer hinzugegeben, das Gemisch vorsichtig geschwenkt und 20 min auf Eis inkubiert. Das Pelletieren der Zelltrümmer erfolgte durch Zentrifugation für 30 min bei 13.000 g (10.000 Upm, HB-4 Rotor, Sorvall 
RC-5B). Zur Reinigung der DNA wurde der Überstand auf eine Einweg-Anionenaustauschersäule (Qiagen-tip 500, Qiagen) gegeben, die zuvor mit $10 \mathrm{ml}$ QBT-Puffer äquilibriert worden war. Die Säule mit gebundener DNA wurde zweimal mit je $30 \mathrm{ml}$ QC-Puffer gewaschen, und die DNA durch Erhöhung der NaCl- Konzentration in einer Stufe mit $15 \mathrm{ml}$ QF-Puffer eluiert. Die eluierte DNA wurde mit 0,7 Vol Isopropanol bei RT gefällt und das Präzipitat durch einen weiteren Zentrifugationsschritt bei 13.000 g (10.000 Upm, HB-4-Rotor, SORVALL RC-5B) 30 min pelletiert. Die DNA wurde mit $70 \%$-igem Ethanol gewaschen, bei $50^{\circ} \mathrm{C}$ kurz getrocknet und in $500 \mu \mathrm{l}$ Wasser aufgenommen.

Die isolierten und aufgereinigten Plasmide wurden mit unterschiedlichen Restriktionsendonukleasen geschnitten (2.2.6), um neue DNA-Fragmente in das Plasmid zu ligieren, oder bereits eingeführte Fragmente mit Hilfe der Gelelektrophorese (2.2.7) auf ihre Größe hin zu überprüfen.

\begin{tabular}{|c|c|c|c|}
\hline P1-Puffer: & 50 & $\mathrm{mM}$ & Tris/HCl, pH 8,0 \\
\hline & 10 & $\mathrm{mM}$ & EDTA \\
\hline & 0,1 & $\%(w / v)$ & RNase A \\
\hline P2-Puffer: & 200 & $\mathrm{mM}$ & $\mathrm{NaOH}$ \\
\hline & 1,0 & $\%(w / v)$ & SDS \\
\hline P3-Puffer: & 3,0 & M & $\mathrm{KOAc} / \mathrm{HOAc}, \mathrm{pH} \mathrm{5,5}$ \\
\hline QBT-Puffer: & 750 & $\mathrm{mM}$ & $\mathrm{NaCl}$ \\
\hline & 50 & $\mathrm{mM}$ & MOPS, pH 7,0 \\
\hline & 15 & $\%(\mathrm{v} / \mathrm{v})$ & Ethanol \\
\hline & 0,15 & $\%(\mathrm{v} / \mathrm{v})$ & Triton-X-100 \\
\hline QC-Puffer: & 1,0 & $M$ & $\mathrm{NaCl}$ \\
\hline & 50 & $\mathrm{mM}$ & MOPS, pH 7,0 \\
\hline & 15 & $\%(\mathrm{v} / \mathrm{v})$ & Ethanol \\
\hline QF-Puffer: & 1,2 & M & $\mathrm{NaCl}$ \\
\hline & 50 & $\mathrm{mM}$ & MOPS, pH 8,0 \\
\hline & 15 & $\%(v / v)$ & Ethanol \\
\hline
\end{tabular}




\subsubsection{Reinigung und Konzentrierung von Nukleinsäuren}

Folgende Methoden wurden bei der Isolation von Plasmid-DNA und zur Reinigung von PCR- und Restriktionsfragmenten eingesetzt.

\subsubsection{Phenol-Chloroform-Extraktion}

Phenol-Chloroform-Extraktion wurde bei allen DNA-Präparationen außer der Plasmidisolation mit dem QIAfilter Plasmid Midi/Maxi Kit eingesetzt, um Proteine und andere organische Komponenten aus der Lösung zu entfernen.

Wassergesättigtes Phenol (P) wurde mit dem Antioxidationsmittel Hydroxychinolin versetzt und mit Tris-Base auf pH 8,0 eingestellt. Chloroform wurde im Verhältnis 24:1 mit Isoamylalkohol (I) versetzt, um Schaumbildung bei der Phasentrennung zu vermeiden. Die Extraktion erfolgte durch einmaliges Ausschütteln der DNA-Lösung mit dem gleichen Volumenanteil einer Phenol/Chloroform/Isoamylalkohol-Mischung im Verhältnis 25:24:1.

Eine Durchmischung von organischer und wässriger Phase wurde durch Schütteln erreicht, die Trennung durch 2-minütige Zentrifugation bei $11.000 \mathrm{~g}$ beschleunigt. Nach der Zentrifugation wurde die wässrige Phase abgenommen und durch alkoholische Fällung von Phenolresten befreit (2.2.4.3).

\subsubsection{Schleudersäulen-Chromatographie}

Alternativ zur Fällung wurden kleine Volumina von DNA-Suspensionen $(50-100 \mu \mathrm{l})$ über Sephacryl Schleudersäulen (S-200, S-300, S-400, Pharmacia, Freiburg) gereinigt. Diese Methode wurde zum Pufferwechsel, zum Entfernen von Nukleotiden und Primern nach der PCR und zur Beseitigung von Phenolresten nach der Phenol-Chloroform-Extraktion eingesetzt.

\subsubsection{Alkoholische Fällung von DNA}

DNA wurde zur Abscheidung von Proteinen und/oder niedermolekularen Substanzen aus wässrigen Lösungen mit Hilfe von Salz/Alkohol Kombinationen ausgefällt. Die DNA wurde dazu durch Zugabe von 2,5 Vol $98 \%$-igem Ethanol und 0,1 Vol $3 \mathrm{M}$ Natriumacetat pH 5,3 mindestens 20 min bei $-20^{\circ} \mathrm{C}$ gefällt und anschließend 30 min bei $13.000 \mathrm{~g}$ (10.000 Upm, HB4 Rotor, Sorvall RC-5B) zentrifugiert. Bei geringem Probenvolumen wurde eine Eppendorf Zentrifuge (5415 C, Eppendorf) bei $12.000 \mathrm{~g}$ eingesetzt. Alle Zentrifugationen fanden bei einer Temperatur von $4^{\circ} \mathrm{C}$ statt. Das erhaltene Pellet wurde mit $70 \%$-igem Ethanol gewaschen und erneut für 15 min bei gleicher g-Zahl wie zuvor zentrifugiert, um die DNA am Boden des Reaktionsgefäßes zu sammeln. Der Überstand wurde verworfen und das verbleibende Ethanol bei $50^{\circ} \mathrm{C}$ kurz abgedampft. Die DNA wurde in einer geeigneten Menge auto- 
klaviertem HPLC-Wasser durch kurzes Erwärmen auf $50^{\circ} \mathrm{C}$ resuspendiert und bis zur weiteren Verarbeitung bei $-20^{\circ} \mathrm{C}$ gelagert.

\subsubsection{Konzentrationsbestimmung}

Konzentrationen von wässrigen DNA-Lösungen wurden photometrisch anhand der Absorption bei 260 nm mit einem Gene Quant II Photometer (Pharmacia, Freiburg) ermittelt. Dabei wurde eine optische Dichte $\left(0 D_{260}\right)$ von 1 einer Konzentration von $50 \mu \mathrm{g}$ doppelsträngiger DNA gleichgesetzt (Schichtdicke der Küvette $1 \mathrm{~cm}$ ). Die Reinheit der Nukleinsäuren wurde durch das Verhältnis der Absorption bei $260 \mathrm{~nm}$ und $280 \mathrm{~nm}$ abgeschätzt (WARBURG \& CHRISTIAN 1942). Ein Verhältnis von $>1,8$ für DNA-Lösungen wurde als Indiz für geringe Verunreinigungen durch Proteine gewertet (SAMBROOK et al. 1989).

\subsubsection{Enzymatische Fragmentierung von DNA}

Für die Restriktionsanalyse wurden Restriktionsendonukleasen und Puffer verschiedener Hersteller einzeln und in Kombination eingesetzt. Standard-Spaltungen von Plasmid-DNA wurden mit 10 Einheiten (Units) des Enzyms pro $\mu \mathrm{g}$ DNA durchgeführt. Die Inkubationszeit betrug bei $37^{\circ} \mathrm{C}$ eine bis mehrere Stunden. Vor der Weiterverarbeitung der geschnittenen DNA wurden die Enzyme für 10 min bei $60^{\circ} \mathrm{C}$ inaktiviert. Die Ergebnisse wurden durch Gelelektrophorese (2.2.7) kontrolliert.

\subsubsection{Gelelektrophorese}

Analytische Gelelektrophoresen von Aliquots der Versuchsansätze wurden routinemäßig zur Erfolgskontrolle eingesetzt. Die Trennung der DNA erfolgte nach Größe der Fragmente im elektrischen Feld.

Zur analytischen Gelelektrophorese wurden 0,8 - 2,0 \%-ige Agarosegele in TBE-Puffer verwendet. Die Agarose wurde in TBE-Puffer aufgekocht und nach Abkühlung auf ca. $50^{\circ} \mathrm{C}$ in Elektrophoresekammern (Eigenbau K. Unger, Albrecht-von-Haller-Institut, Universität Göttingen) gegossen.

Vor dem Auftragen auf das Gel wurden die DNA-Proben mit 1/10 Volumen Probenpuffer versetzt. 


$\begin{array}{rrl}\text { Probenpuffer: } & 180 \mathrm{mM} & \text { Tris-Base } \\ & 180 \mathrm{mM} & \text { Borsäure } \\ 5 \mathrm{mM} & \text { EDTA } \\ 40,0 \%(\mathrm{w} / \mathrm{v}) & \text { Saccharose } \\ 0,25 \%(\mathrm{w} / \mathrm{v}) & \text { Bromphenolblau } \\ 0,25 \%(\mathrm{w} / \mathrm{v}) & \text { Xylencyanol FF }\end{array}$

$\begin{array}{lrl}\text { TBE-Puffer: } & 90 \mathrm{mM} & \text { Tris-Base } \\ & 90 \mathrm{mM} & \text { Borsäure } \\ & 2,5 \mathrm{mM} & \text { EDTA }\end{array}$

Die elektrophoretische Trennung der DNA-Fragmente erfolgte für $1-2 \mathrm{~h}$ bei einer Feldstärke von $5 \mathrm{~V} / \mathrm{cm}$. Zur Bestimmung der DNA-Fragmentgröße und zur Abschätzung der Konzentration wurden DNA-Längenstandards mit Fragmenten definierter Größe und bekannter Konzentration aufgetragen. Neben kommerziell erhältlichen DNA-Längenstandards wurden selbsterstellte Plasmid-Standards von A.H. Wolf und M. Giersberg eingesetzt (Längen in bp).

A-Standard: $6.991,5.086,3.992,2.999,2.357,1.652,1.389,1.077,516$

M-Standard: 710, 498, 404, 367, 242, 190, 147, 118, 110, 67, 57

Zur Detektion separierter DNA-Fragmente wurde eine Ethidiumbromid-Behandlung durchgeführt (SHARP et al. 1973). Die Agarosegele wurden für 15 min in ein Wasserbad mit $0,5 \mu \mathrm{g} / \mathrm{ml}$ Ethidiumbromid gelegt und anschließend gewässert. Die Trennung der DNA-Fragmente wurde auf einem UV-Leuchttisch (LKB 2011 MACP Transillumin, Pharmacia, Freiburg) kontrolliert sowie gegebenenfalls mittels einer Polaroidkamera (Polaroid DS-34 Direct Screen Instant Camera) mit Rotfilter fotografiert.

\subsubsection{Ligation von DNA-Fragmenten}

Rekombinante Plasmide wurden durch Verknüpfung (Ligation) von Vektor-DNA und Fremd-DNA mit T4-DNA-Ligase (Pharmacia, Freiburg; Gibco BRL, Eggenstein) hergestellt.

Um Fragmente mit kohäsiven Enden zu erzeugen, wurden PCR-Produkt und VektorDNA jeweils mit zwei Restriktionsendonukleasen geschnitten (2.2.6). Die Reinigung 
der Ansätze erfolgte durch Phenol-Chloroform-Extraktion (2.2.4.1) und Sephacryl S-200 Schleudersäulen (2.2.4.2). Für die Ligation wurden Fremd-DNA und VektorDNA im Verhältnis von 2:1 (v/v) eingesetzt. Die Ligationsansätze wurden entweder $4 \mathrm{~h}$ bei $10^{\circ} \mathrm{C}$ oder $2 \mathrm{~h}$ bei $16^{\circ} \mathrm{C}$ inkubiert.

\subsubsection{Polymerasekettenreaktion (PCR)}

PCR (nach SAIKI et al. 1988) wurde zur Amplifikation genomischer DNA und zur DNASequenzierung eingesetzt. Die Methode beruht auf dem Prinzip zyklischer Wiederholungen von Denaturierung der template-DNA, Anlagerung sequenzspezifischer Primer und Synthese einer komplementären DNA-Kopie durch die thermostabile TaqPolymerase. Bei Durchführung mehrere Zyklen kommt es zu einer exponentiellen Vervielfältigung der Zielsequenz.

\subsubsection{Amplifikation von Fragmenten aus cDNA}

Die Reaktionsansätze enthielten eine Primer-Konzentration von $1 \mu \mathrm{M}$, je $200 \mu \mathrm{M}$ Desoxyribonukleotide (dNTP) und $10 \mathrm{ng}$ template-DNA. Die Ansätze hatten ein Volumen von $100 \mu \mathrm{l}$ und wurden nach Zugabe aller Reagenzien mit einem Tropfen Mineralöl überschichtet und kurz zentrifugiert. Die thermostabile Taq-DNA-Polymerase (Gibco BRL, Eggenstein) wurde erst nach einem anfänglichen Denaturierungsschritt durch die Ölschicht hindurch zum Reaktionsgemisch pipettiert.

PCR-Protokoll für die Amplifikation der ATPase-Fragmente:

Zyklus A (1x) $5 \min 95^{\circ} \mathrm{C}$ (Denaturierung)

Zyklus B (25x) $60 \mathrm{~s} \quad 98^{\circ} \mathrm{C}$ (Denaturierung)

$60 \mathrm{~s} \quad 50^{\circ} \mathrm{C}$ (Primer-Anlagerung)

$90 \mathrm{~s} \quad 72^{\circ} \mathrm{C}$ (Polymerisierung)

Zyklus C (1x) $10 \min 72^{\circ} \mathrm{C}$ (Polymerisierung)

\subsubsection{Sequenzierung}

Bei der Didesoxy-Sequenzierungsmethode (nach SANGER et al. 1977) werden Primer eingesetzt, die an der DNA-Matrize eine Einzelstrangsynthese initiieren. Die Synthese findet unter Verwendung von vier Desoxynukleotiden statt, die mit unterschiedlichen Fluoreszenzfarbstoffen markiert sind. Durch Zusatz von Didesoxynukleotiden 
werden Kettenabbrüche erzeugt, so daß DNA-Fragmente unterschiedlicher Längen entstehen. Die DNA-Fragmente wurden mit einer automatischen Sequenzieranlage (ABI PRISM $^{\top M}$ 310, Perkin Elmer Applied Biosystems, Weiterstadt) elektrophoretisch aufgetrennt, wobei die Fluoreszenzsignale durch einen Laserstrahl induziert und dem computergesteuerten Auswertungsprogramm ABI PRISM ${ }^{\top M}$ Sequencing Analysis 3.0 übermittelt wurden.

Zur Sequenzierung von Plasmid-DNA wurde das ABI PRISM ${ }^{T M}$ dRhodamin Terminator Cycle Sequencing Ready Reaction Kit und das DYEnamic ET Cycle Sequencing Kit (beide Kits von Perkin Elmer Applied Biosystems, Weiterstadt) eingesetzt. Die verwendeten Didesoxynukleotide sind mit fluoreszierenden dRhodamin-Farbstoffen gekoppelt. Für die Reaktion wurden 200 - 500 ng Plasmid-DNA eingesetzt. Die Primer-Konzentrationen betrugen 2 - 5 pmol. Das Reaktionsvolumen wurde auf die Hälfte, der Reaktionsmix auf ein Viertel des im Herstellerprotokoll angegebenen Volumens reduziert.

Standard-PCR-Protokoll für ABI PRISM ${ }^{T M}$ dRhodamin Terminator Cycle Sequencing Ready Reaction Kit:

$1 \min 96^{\circ} \mathrm{C}$ (Denaturierung)

$30 \mathrm{~s} \quad 50^{\circ} \mathrm{C}$ (Primer-Anlagerung)

$4 \min 60^{\circ} \mathrm{C}$ (Polymerisierung)

25 Zyklen

Standard-PCR-Protokoll für DYEnamic ET Cycle Sequencing Kit:

$$
\begin{aligned}
10 \mathrm{~s} & 96^{\circ} \mathrm{C} \text { (Denaturierung) } \\
5 \mathrm{~s} & 50^{\circ} \mathrm{C} \text { (Primer-Anlagerung) } \\
4 \mathrm{~min} & 60^{\circ} \mathrm{C} \text { (Polymerisierung) }
\end{aligned}
$$

25 Zyklen

Die Aufreinigung der Sequenzierungsansätze erfolgte durch alkoholische Fällung. Bei Verwendung des ABI PRISM ${ }^{\mathrm{TM}}$ dRhodamin Terminator Cycle Sequencing Ready Reaction Kits wurde der Reaktionsansatz mit $37 \mu \mathrm{l} 70 \%$-igem Ethanol/0,5 mM MgCl für 15 min bei RT präzipitiert. Nach 20-minütiger Zentrifugation bei $12.000 \mathrm{~g}$ (14.000 Upm Eppendorf-Tischzentrifuge, 5415C) und RT wurde der Überstand verworfen und das Pellet bei $90^{\circ} \mathrm{C}$ für 1 min im Heizblock getrocknet. 
Sequenzierungsreaktionen mit dem DYEnamic ET Cycle Sequencing Kit durchgeführt, wurden durch alkoholische Fällung mit Natriumacetat/EDTA-Puffer aufgereinigt.

$$
\begin{array}{llll}
\text { Natrium-Acetat/EDTA-Puffer: } & 1,5 \mathrm{M} & \text { Natriumacetat } \\
& 250 \mathrm{mM} & \text { EDTA }
\end{array}
$$

Die Pellets wurden in $17 \mu \mathrm{l}$ TSR (Template Suppression Reagent, Perkin Elmer Applied Biosystems, Weiterstadt) resuspendiert. Zum Denaturieren wurden die Proben für 2 min auf $95^{\circ} \mathrm{C}$ erhitzt und anschließend sofort auf Eis gestellt. Bis zur Elektrophorese wurden sie auf Eis aufbewahrt.

\subsubsection{Kultivierung von HeLa-Zellen}

Die Anzucht der HeLa-Zellen erfolgte nach den Anweisungen des Lieferanten (DSM $\mathrm{GmbH}$, Braunschweig) in MEM-Medium (Gibco BRL, Eggenstein) bei $37^{\circ} \mathrm{C}$ in einem $5 \%-\mathrm{CO}_{2}$-Milieu.

$$
\begin{array}{lll}
\text { MEM-Medium: } & \text { MEM-Medium versetzt mit } \\
& 10 \mu \mathrm{g} / \mathrm{ml} & \text { Na-Pyruvat } \\
50 \mu \mathrm{g} / \mathrm{ml} & \text { Penicillin } \\
50 \mu \mathrm{g} / \mathrm{ml} & \text { Streptomycin } \\
10 \%(\mathrm{w} / \mathrm{v}) & \text { fötales Kälberserum (FKS) (Biochrom, Berlin) }
\end{array}
$$

Die Weiterzüchtung bereits aktiver Kulturen erfolgte in MEM- oder RPMI 1640-Medium (Biochrom KG, Berlin). Die Teilung des Zellgutes erfolgte alle drei Tage unter Zugabe frischen Mediums.

Nach Stabilisierung der Zellen in RPMI 1640-Medium (Biochrom KG, Berlin) wurden Monolayerkulturen in $250 \mathrm{ml}$ Kulturflaschen angelegt und diese bei $37^{\circ} \mathrm{C}$ und $5 \%-\mathrm{CO}_{2}$ inkubiert. Das Medium wurde jeden dritten Tag gewechselt und die Zellen passagiert, sobald sie auf dem Kulturflaschenböden konfluente Zellschichten bildeten. Dazu wurden neue Kulturflaschen mit $1-2 \times 10^{5}$ Zellen in $15 \mathrm{ml}$ Medium angesetzt.

\subsubsection{Bestimmung der Zellzahl}

Zur Bestimmung der Zellzahl wurde der Trypan-Blau-Exklusionstest angewendet (HOSKINS et al. 1956). Trypan-Blau färbt defekte und durchlässige Zellen, intakte und somit teilungsfähige Zellen bleiben hell. Die Ermittlung der Lebend-Zellzahl erfolgte mit einer Fuchs-Rosenthal-Zählkammer. $200 \mu \mathrm{l}$ Zellsuspension wurden mit 
$200 \mu \mathrm{l}$ steril filtrierter Farblösung vermischt, mit einer Pasteurpipette auf die Zählkammer gegeben und ausgezählt.

$$
\begin{array}{llll}
\text { Trypan-Blau-Lösung: } & 150 \mathrm{mM} & \mathrm{NaCl} \\
& 0,3 \%(w / v) & \text { Trypan-Blau (Merk, Darmstadt) }
\end{array}
$$

\subsubsection{Anzucht auf Objektträgern}

Zur Transfektion wurden die HeLa-Zellen auf Objektträgern bis zu einer Konfluenz von 60 - $80 \%$ angezüchtet. Zur Anzucht der Zellen auf Objektträgern wurden Flexiperm-Slides (Heraeus-Biotechnologie, Hanau) in Kombination mit Objektträgern verwendet. Das Flexiperm-Slide bildet die Wände, der Objektträger den Boden eines Blocks von acht Gewebekulturkammern mit je $300 \mu \mathrm{l}$ Fassungsvermögen. Objektträger und Flexiperm-Slides wurden für $1 \mathrm{~h}$ in $75 \%$-igem Alkohol desinfiziert und anschließend getrocknet. Die Flexiperm-Slides wurden unter Druck auf die Objektträger gepreßt, so daß pro Objektträger acht Kammern entstanden. In jede Kammer wurde $100 \mu$ verdünntes ECM-Gel (Sigma, Deisenhofen) gegeben. Das Gel trocknete 30 min und wurde dann mit $300 \mu \mathrm{l}$ HBSS-Puffer (Gibco BRL, Eggenstein) gewaschen. Am Tag vor der Transfektion (2.2.13) wurde jede Kammer mit $300 \mu \mathrm{l}$ Zellsuspension $\left(4 \times 10^{5}\right.$ Zellen) der Monolayerkultur befüllt und über Nacht bei $37^{\circ} \mathrm{C}$ und $5 \%$ $\mathrm{CO}_{2}$-Gehalt inkubiert.

\subsubsection{Liposomentransfektion von HeLa-Zellen}

Die Transfektion von HeLa-Zellen mit rekombinanter Plasmid-DNA erfolgte mittels Liposomentransfektion (RUYSSCHAERT et al. 1994). Das verwendete ClonfectinTransfektionsreagenz (Clontech, USA) ist ein amphiphiles Lipid, dessen kationischer Anteil mit der Plasmid-DNA interagiert und hydrophobe Komplexe bildet. Der Clonfectin/DNA-Komplex assoziiert mit der Zelloberfläche und ermöglicht so den Transfer der DNA durch Endocytose in die Zelle. Am Tag der Transfektion wurde die Liposomenlösung frisch angesetzt. $90 \mu \mathrm{LBS}$-Puffer wurden auf $55^{\circ} \mathrm{C}$ erhitzt und tropfenweise zur Clonfectin-Stammlösung gegeben (Endkonzentration $1 \mu \mathrm{g} / \mu \mathrm{l}$ ). Die Lösung wurde geschüttelt und auf Eis gekühlt. Für jeden Transfektionsansatz von $2 \mathrm{ml}$ wurde eine Plasmid- (Lösung A) und eine Clonfectin-Lösung (Lösung B) hergestellt:

Lösung A: $\quad 4 \mu \mathrm{g}$ Plasmid-DNA

$100 \mu \mathrm{l}$ serumfreies Medium 
Lösung B: $\quad 4 \mu \mathrm{g}$ Clonfectin $(1 \mu \mathrm{g} / \mu \mathrm{l}$ in HEPES-NaCl-Puffer, $\mathrm{pH} 7,4)$ $100 \mu \mathrm{l}$ serumfreies Medium

Lösungen $A$ und $B$ wurden vermischt und 30 min bei RT inkubiert. Anschließend wurde pro Ansatz 1,8 $\mathrm{ml}$ serumfreies Medium zugegeben. Das Medium der Übernachtkulturen wurde entfernt, die Transfektionslösung wurde auf die HeLa-Zellen pipettiert und diese für $4 \mathrm{~h}$ bei $37^{\circ} \mathrm{C}$ und $5 \%-\mathrm{CO}_{2}$ im Brutschrank inkubiert. Nach $4 \mathrm{~h}$ wurden die Zellen mit PBS-Puffer gewaschen, frisches Kulturmedium dazugegeben und erneut unter den gleichen Bedingungen wie oben angegeben inkubiert. Nach 24 - 48 h wurden Zellen mit transienter Genexpression mittels Fluoreszenzmikroskopie selektiert.

\begin{tabular}{|c|c|c|}
\hline \multirow[t]{2}{*}{ HBS-Puffer: } & $\begin{array}{r}150 \mathrm{mM} \\
20 \mathrm{mM}\end{array}$ & $\begin{array}{l}\mathrm{NaCl} \\
\text { HEPES }\end{array}$ \\
\hline & \multicolumn{2}{|c|}{ pH 7,3; autoklaviert } \\
\hline Kulturmedium: & $\begin{array}{l}\text { RPMI } 1640- \\
2 \mathrm{mM} \\
10 \mu \mathrm{g} / \mathrm{ml} \\
2 \mathrm{mg} / \mathrm{ml} \\
0,35 \mu \mathrm{l} / \mathrm{ml} \\
100 \mu \mathrm{g} / \mathrm{ml} \\
50 \mu \mathrm{g} / \mathrm{ml}\end{array}$ & $\begin{array}{l}\text { Medium (Biochrom KG, Berlin) versetzt mit } \\
\text { L-Glutamin } \\
\text { Na-Pyruvat } \\
\mathrm{NaHCO}_{3} \\
\beta \text {-Mercaptoethanol } \\
\text { Penicillin } \\
\text { Streptomycin }\end{array}$ \\
\hline
\end{tabular}

PBS-Puffer: $\quad 10 \quad \mathrm{mM} \quad \mathrm{Na}_{2} \mathrm{HPO}_{4}$

$1,8 \mathrm{mM} \quad \mathrm{KH}_{2} \mathrm{PO}_{4}$

$137 \mathrm{mM} \quad \mathrm{NaCl}$

$2,7 \mathrm{mM} \quad \mathrm{KCl}$

$\mathrm{pH} \mathrm{7,2;} \mathrm{steril} \mathrm{filtriert}$

\subsubsection{Morphologische Präparate}

Zur Herstellung einer Fixierlösung wurde Paraformaldehyd 3,7 \%-ig in PBS-Puffer unter Rühren auf $60^{\circ} \mathrm{C}$ erhitzt und der pH auf 7,4 eingestellt. Objektträger mit HeLa-Zellen wurden für 10 min in die Lösung getaucht und anschließend dreimal 
mit PBS-Puffer gewaschen. Je nach Verwendungszweck wurde eventuell noch eine Kernfärbung (2.2.15) durchgeführt. Abschließend wurde mit Wachs ein Deckglas auf dem Objektträger fixiert.

\subsubsection{Kernfärbung mit H33342}

Der Hoechst-Farbstoff H33342 interkaliert mit der DNA im Kern lebender Zellen. Die Zellkerne lebender Zellen fluoreszieren dadurch nach Anregung mit $460 \mathrm{~nm}$ blau (PREISLER 1987). Die H33342-Stammlösung wurde 1:1000 mit PBS verdünnt und auf Zellen gegeben, die zuvor vom Medium befreit wurden. Nach zweimaligem Waschen mit PBS wurden die Zellen bei einer Wellenlänge von $460 \mathrm{~nm}$ im Fluoreszenzmikroskop untersucht und ausgewertet.

\subsubsection{Kultivierung von COS-7-Zellen}

Zur Vorbereitung der Transfektion wurden COS-7-Zellen auf einer $10 \mathrm{~cm}$ Kulturschale ausplattiert und im Brutschrank bei $37^{\circ} \mathrm{C}$ in einem $5 \%-\mathrm{CO}_{2}$-Milieu kultiviert. Sobald sich eine konfluente Zellschicht gebildet hatte, wurden die Zellen mit PBSPuffer gewaschen und durch Behandlung mit Trypsin vom Kulturschalenboden abgelöst. Die abgelösten Zellen wurden in ein Einweg-Polypropylenreagenzröhrchen überführt und 30 min bei $800 \mathrm{~g}$ zentrifugiert. Der Überstand wurde verworfen und das Pellet in $30 \mathrm{ml}$ Kulturmedium resuspendiert. Jeweils $2 \mathrm{ml}$ Zellsuspension wurde auf 3,5 cm Kulturschalen verteilt und im Brutschrank bis zu einer Konfluenz von ca. $80 \%$ angezüchtet.

Kulturmedium: DMEM High Glucose (Gibco BRL, Eggenstein), versetzt mit

$$
\begin{array}{lll}
10 & \%(\mathrm{w} / \mathrm{v}) & \text { FKS (Biochrom, Berlin) } \\
2 & \mathrm{mM} & \text { L-Glutamin } \\
100 \mathrm{mg} / \mathrm{l} & \text { Penicillin } \\
100 & \mathrm{mg} / \mathrm{l} & \text { Streptomycin }
\end{array}
$$

\subsubsection{Liposomentransfektion von COS-7-Zellen}

Die Transfektion von COS-7-Zellen mit rekombinanter Plasmid-DNA erfolgte wie bei HeLa-Zellen mittels Liposomentransfektion (2.2.13). Jeder Transfektionsansatz enthielt $5 \mu \mathrm{g}$ Plasmid-DNA. 
Für Transfektionsansätze von je $1 \mathrm{ml}$ wurden eine Plasmid- (Lösung A) und eine Lipofectamin-Lösung (Lösung B) hergestellt.

$\begin{array}{ll}\text { Lösung A: } & \begin{array}{l}5 \mu \mathrm{g} \\ \text { ad } 100 \mu \mathrm{l} \text { mit serumfreiem Medium aufgefüllt }\end{array} \\ & \\ \text { Lösung B: } & 6 \mu \mathrm{l} \quad \text { Lipofectamin (Gibco BRL, Eggenstein) } \\ & 94 \mu \mathrm{l} \quad \text { serumfreies Medium }\end{array}$

Serumfreies Medium: DMEM High Glucose versetzt mit

2 mM L-Glutamin

Lösungen $A$ und $B$ wurden vermischt und 30 min bei RT inkubiert. Anschließend wurden $800 \mu \mathrm{l}$ serumfreies Medium hinzugefügt.

Vor der Transfektion der COS-7-Zellen wurde das Kulturmedium abgesaugt, die Zellen mit serumfreien Medium gewaschen und anschließend der Lipofectamin-DNA-Mix auf die Zellen pipettiert. Die Inkubation erfolgte $5-6 \mathrm{~h}$ bei $37^{\circ} \mathrm{C}$ in $5 \%$-igem $\mathrm{CO}_{2}$-Milieu. Anschließend wurde jedem Transfektionsansatz $1 \mathrm{ml}$ Kulturmedium versetzt mit 20 \% FKS zugegeben. Am nächsten Morgen erfolgte ein Wechsel in Standard-Kulturmedium.

Vor Überprüfung der Genexpression unter dem konfokalen Fluoreszenzmikroskop wurden die Zellen auf sterile, Gelatine-beschichteten Objektträger übertragen.

\subsubsection{Fixierung von COS-7-Zellen}

Die mit Zellen behafteten Objektträger wurden zur Fixierung mehrmals mit Methanol gespült und mit Eukitt (Novoglas, Bern) eingedeckt.

\subsubsection{Axenische Kulturen von Tabakpflanzen}

Axenische Kulturen wurden aus Tabaksamen der Sorte Nicotiana tabacum L. cV Samsun NN angezogen. Als Anzuchtgefäß dienten autoklavierte Einweckgläser (Weck, Wehr), die mit 120 - 200 ml Murashige \& Skoog Nährmedium gefüllt wurden. Zur Desinfektion der Samen wurden diese für 20 min in $10 \%$-iger Natriumhypochloridlösung, die zum Abbau der Oberflächenspannung mit einem Tropfen Tween 20 Detergenz versetzt wurde, leicht geschwenkt und anschließend fünfmal mit sterilem 
Wasser gewaschen. Pro Einweckglas wurde je ein Samen auf das Nährmedium gelegt und die Deckel mit Parafilm verschlossen. Alle Schritte wurden steril durchgeführt. Die Anzucht erfolgte im Klimaschrank (I-36LLVL, Percival Scientific, Perry, Iowa, USA) bei einem Licht/Dunkel Rhythmus mit Temperaturveränderungen von $16 \mathrm{~h}$ bei $24,1^{\circ} \mathrm{C}$ und $8 \mathrm{~h}$ bei $21^{\circ} \mathrm{C}$.

Murashige \& Skoog Nährmedium:

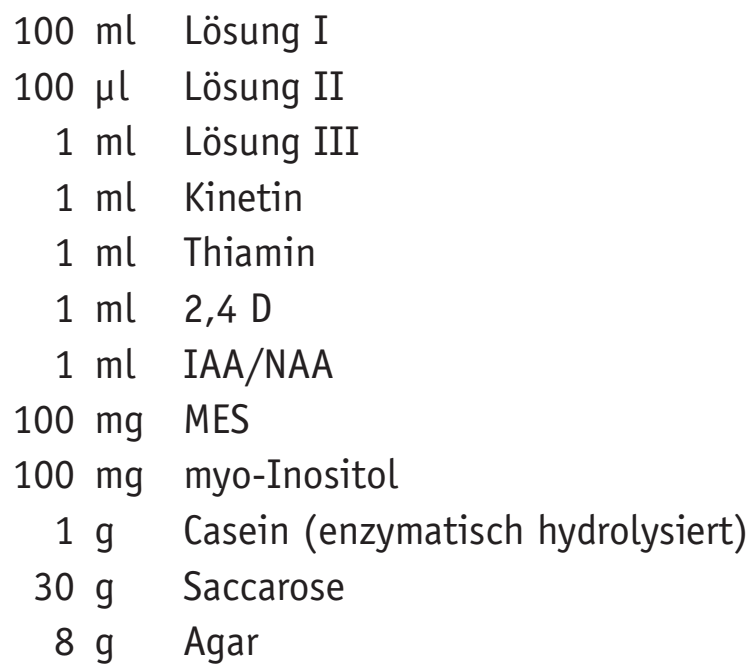

ad $1.000 \mathrm{ml} \mathrm{H}_{2} \mathrm{O}$-Bidest, pH 5,4; autoklaviert

Murashige \& Skoog Basismedium (Lösung I):

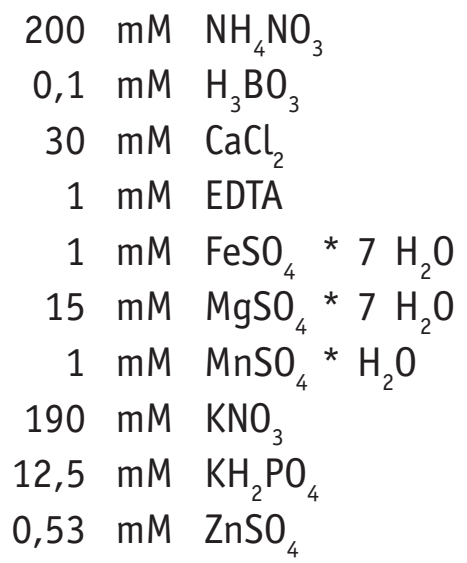

Cobalt/Kupfer-Lösung (Lösung II):

$1 \mathrm{mM} \mathrm{CoCl}$

$1 \mathrm{mM} \mathrm{CuSO}_{4}$

Molybdän/Jod-Lösung (Lösung III):

$1 \mathrm{mM} \mathrm{Na} \mathrm{MoO}_{4}$

$5 \mathrm{mM} \mathrm{KJ}$ 


\subsubsection{Präparation von Tabak-Protoplasten}

Die Blätter von drei in axenischer Kultur gewachsenen 10 - 12 Wochen alten Tabakpflanzen wurden auf der Unterseite mit einem Skalpell in Abständen von 1 - 2 mm eingeritzt und die Mittelrippen entfernt. Die so behandelten Blätter wurden mit der Blattunterseite nach unten in Petrischalen mit $7 \mathrm{ml}$ Enzymlösung gelegt und über Nacht im Dunkeln bei $24,1^{\circ} \mathrm{C}$ inkubiert. Macerozyme verdauen dabei die Mittellamellen, Cellulasen entfernen die Zellwände und die Protoplasten werden freigesetzt.

Am nächsten Morgen wurden die Petrischalen leicht geschwenkt, um die Protoplasten aus den Zellfragmenten zu lösen. Nach 30-minütiger Inkubation wurde die Protoplastensuspension anschließend über ein $125 \mu \mathrm{m}$-Sieb gegeben. Das Sieb wurde mit Elektroporationspuffer nachgespült und die erhaltene Protoplastensuspension in $50 \mathrm{ml}$ Einweg-Polypropylenröhrchen für $20 \mathrm{~min}$ bei $64 \mathrm{~g}$ im Vollausschwingrotor (\#2252M, Megafuge 1.0R, Heraeus Instruments, Hanau) bei RT und ausgeschalteter Rotorbremse zentrifugiert. Lebende Protoplasten sammelten sich an der Lösungsoberfläche, tote mit den Zelltrümmern am Boden des Polypropylenröhrchens. Mit Hilfe einer peristaltischen Pumpe (Cyclo I, Roth, Karlsruhe) wurden Pellet und Lösung vorsichtig abgesaugt. Die lebenden Protoplasten wurden in $40 \mathrm{ml}$ Elektroporationspuffer aufgenommen und 15 min bei $115 \mathrm{~g}$ unter den oben beschriebenen Bedingungen zentrifugiert. Pellet und Lösung wurden erneut abgesaugt und die Protoplasten in $25 \mathrm{ml}$ Elektroporationspuffer aufgenommen. Nach dem letzten Aufreinigungsschritt (115 g, 5 min) wurden die Protoplasten erneut in Elektroporationspuffer aufgenommen. Alle Präparationsschritte erfolgten unter sterilen Bedingungen. Die Protoplastenzahl wurde mit einer Jessen-Zählkammer bestimmt.

$$
\begin{array}{ll}
\text { Enzymlösung : } & 0,4 \%(w / v) \text { Cellulase (Onozuka R10, Tokio, Japan) } \\
0,2 \%(w / v) \text { Macerozyme }
\end{array}
$$

in TEX-Puffer gelöst, 30 min gerührt und 5 min zum Entfernen unlöslicher Partikel bei $2500 \mathrm{~g}$ zentrifugiert. Der Überstand wurde steril filtriert.

TEX-Puffer: Gamborg's B-5 Basis Salz Mix für 1 l (Sigma-Aldrich, Deisenhofen) versetzt mit
$2,5 \mathrm{mM}$
MES
$6,7 \mathrm{mM}$ $\mathrm{CaCl}_{2}$
$3,1 \mathrm{mM} \quad \mathrm{NH}_{4} \mathrm{NO}_{3}$
$0,4 \mathrm{M} \quad$ Saccarose

$\mathrm{pH} 5,7$; steril filtriert 


\begin{tabular}{lrll} 
Elektroporationspuffer: & $0,4 \mathrm{M}$ & Saccarose \\
$10 \mathrm{mM}$ & $\mathrm{HEPES}$ \\
$80 \mathrm{mM}$ & $\mathrm{KCl}$ \\
$5,4 \mathrm{mM}$ & $\mathrm{CaCl}_{2}$ \\
\hline
\end{tabular}

$\mathrm{pH} 7,2$; steril filtriert

\subsubsection{Elektroporation von Tabak-Protoplasten}

Die Transfektion von Vektor-DNA in Tabak-Protoplasten erfolgte durch Elektroporation. $500 \mu \mathrm{l}$ der Protoplastenlösung (2 $-5 \times 10^{6}$ Protoplasten $\left./ \mathrm{ml}\right)$ wurden in sterilen Einweg-Elektrodenküvetten (0,4 cm Elektrodenabstand, Bio-Rad, München) mit $30-100 \mu \mathrm{g}$ Vektor-DNA (in $100 \mu \mathrm{l}$ Elektroporationspuffer) gemischt und 5 min bei RT bis zur Transfektion inkubiert. Zur Elektroporation wurde eine Gerätekombination der Firma Biorad, bestehend aus Pulsgenerator (Gene Pulser II) und parallel geschaltetem Pulskontrollgerät (Puls Controller) benutzt. Die Elektroporation erfolgte bei $925 \mu \mathrm{F}$ und $160 \mathrm{~V}$. Nach dem Strompuls wurden die Protoplasten $30 \mathrm{~min}$ bei RT inkubiert und anschließend in $2 \mathrm{ml}$ TEX-Puffer überführt. Die mikroskopische Analyse der Genexpression erfolgte 24 und $48 \mathrm{~h}$ nach Transfektion. Bis dahin wurden die Protoplasten bei $24,1^{\circ} \mathrm{C}$ im Dunkeln inkubiert. 


\section{Ergebnisse}

\subsection{Klonierungsstrategie für die Expression von ATPase-GFP-Fusionsvektoren in Tabak-Protoplasten}

Ausgangspunkt der Arbeit bildeten die beiden Plasmide pDL20/14 und pDL10. pDL20/14 enthielt cDNA des Aminoterminus des Proteins DBCA1, eine aus Dunaliella bioculata isolierte putative Ca ${ }^{2+}$-ATPase (RASCHKE \& WOLF 1996). Plasmid pDL10 kodiert für den Aminoterminus der aus Dunaliella bioculata isolierten putativen $\mathrm{H}^{+}$-ATPase DBPMA1 (WOLF 1993, WOLF et al. 1995).

Zur in vivo Lokalisation der ATPasen DBCA1 und DBPMA1 in heterologen Expressionssystemen bietet sich die Fusion mit dem Reportergen GFP an. Bei N-terminaler Fusion des GFP mit den beiden ATPasen wird das Startcodon der ATPase als Translationsstart des Fusionsgens benutzt. Daher werden von der Expression der ATPaseGFP-Fusionsproteine Hinweise über die subzelluläre Lokalisation von DBCA1 und DBPMA1 erhofft. Ferner können durch diese Strategie die tatsächlich genutzten Startcodons und N-terminale Signalsequenzen analysiert werden.

Welche Sequenzbereiche der ATPasen für ihre subzelluläre Lokalisation verantwortlich sind, ist weitestgehend unbekannt. Immunofluoreszenzuntersuchungen mit tierischen rekombinanten Chimären einer $\mathrm{Ca}^{2+}$-ATPase aus dem Sarkoplasmatischen Retikulum (SER) und einer $\mathrm{Ca}^{2+}$-ATPase der Plasmamembran (PM) haben jedoch gezeigt, daß die Zielsteuerungssignale der SER-ständigen $\mathrm{Ca}^{2+}$-ATPasen durch Aminosäuresequenzen im ersten Transmembransegment festgelegt sind und auch die plasmamembranständige $\mathrm{Ca}^{2+}$-ATPase rSERCA1 N-terminale Signalsequenzbereiche besitzen könnte (FOLETTI et al. 1995).

Aufgrund der Ergebnisse von FOLETTI et al. (1995) wurde angenommen, daß am $\mathrm{N}$-Terminus gelegene Sequenzbereiche, einschließlich der ersten beiden Transmembransegmente von DBCA1 und DBPMA1, für das Targeting von ATPase-Reporterprotein-Chimären ausreichen.

Die Lokalisation der $\mathrm{H}^{+}$-ATPase in der Plasmamembran kann aufgrund von $78 \%$ Identität und $87 \%$ Ähnlichkeit zur Primärstruktur der plasmamembranständigen $\mathrm{H}^{+}$-ATPase aus Dunaliella acidophila als gesichert angesehen werden. Daher kann die subzelluläre Lokalisation der N-terminal GFP-markierten Sequenzbereiche als interner Standard zur Interpretation der Lokalisation der $\mathrm{Ca}^{2+}$-ATPase-GFP-Chimären angesehen werden.

Die Transfektion von Dunaliella ist trotz ausführlicher Versuchsreihen in unserem Labor bis jetzt nicht gelungen (B. EBERT, persönliche Mitteilung). Daher dienten in der vorliegenden Arbeit Tabak-Protoplasten als pflanzliches Expressionssystem. Als Expressionsvektor wurde HBT-L verwendet (Abb. 2). Er enthält eine für pflanzliche Systeme optimierte GFP-Sequenz mit verstärktem Fluoreszenzsignal bei $510 \mathrm{~nm}$ 
(CHIU et al. 1996, HAAS et al. 1996). Die GFP-Variante sGFP-S65T bietet darüber hinaus den Vorteil, ein in den längerwelligen Lichtbereich verschobenes Anregungsmaximum zu haben. Photochemische Schäden des zu untersuchenden Pflanzenmaterials werden so vermindert bzw. vermieden und die starke Autofluoreszenz des Pflanzenmaterials unter UV-Licht-Anregung wird minimiert. Fusionen am N-Terminus des sGFP-S65T ermöglichten Expressionsstudien der Fusionsproteine unter Berücksichtigung möglicher ATPase-Translationsstartcodons. Die Expression der Fusionsproteine fand unter Kontrolle des starken HBT-Promotors statt (SHEEN 1993).

\subsubsection{Analyse der Translationsstartsignale der $\mathrm{H}^{+}$- und $\mathrm{Ca}^{2+}$-ATPase aus Dunaliella bioculata}

Mehrere ATG-Tripletts, die als Translationsstart interpretiert werden könnten, befinden sich im jeweils längsten offenen Leserahmen der Nukleinsäuresequenz der $\mathrm{Ca}^{2+}$ - und $\mathrm{H}^{+}$-ATPase aus Dunaliella bioculata.

Im 5'-Bereich des $\mathrm{Ca}^{2+}$-ATPase-Gens liegen drei mögliche Startcodons. Das erste ATG befindet sich an Position 48 - 50, weitere Methionin-kodierende Basentripletts sind an Position 96 - 98 und 117 - 119 lokalisiert (Abb. 3). Die H+-ATPase DBPMA1 enthält im 5'-Bereich an Position 23 - 25 und 72 - 74 jeweils ein ATG (Abb. 4).

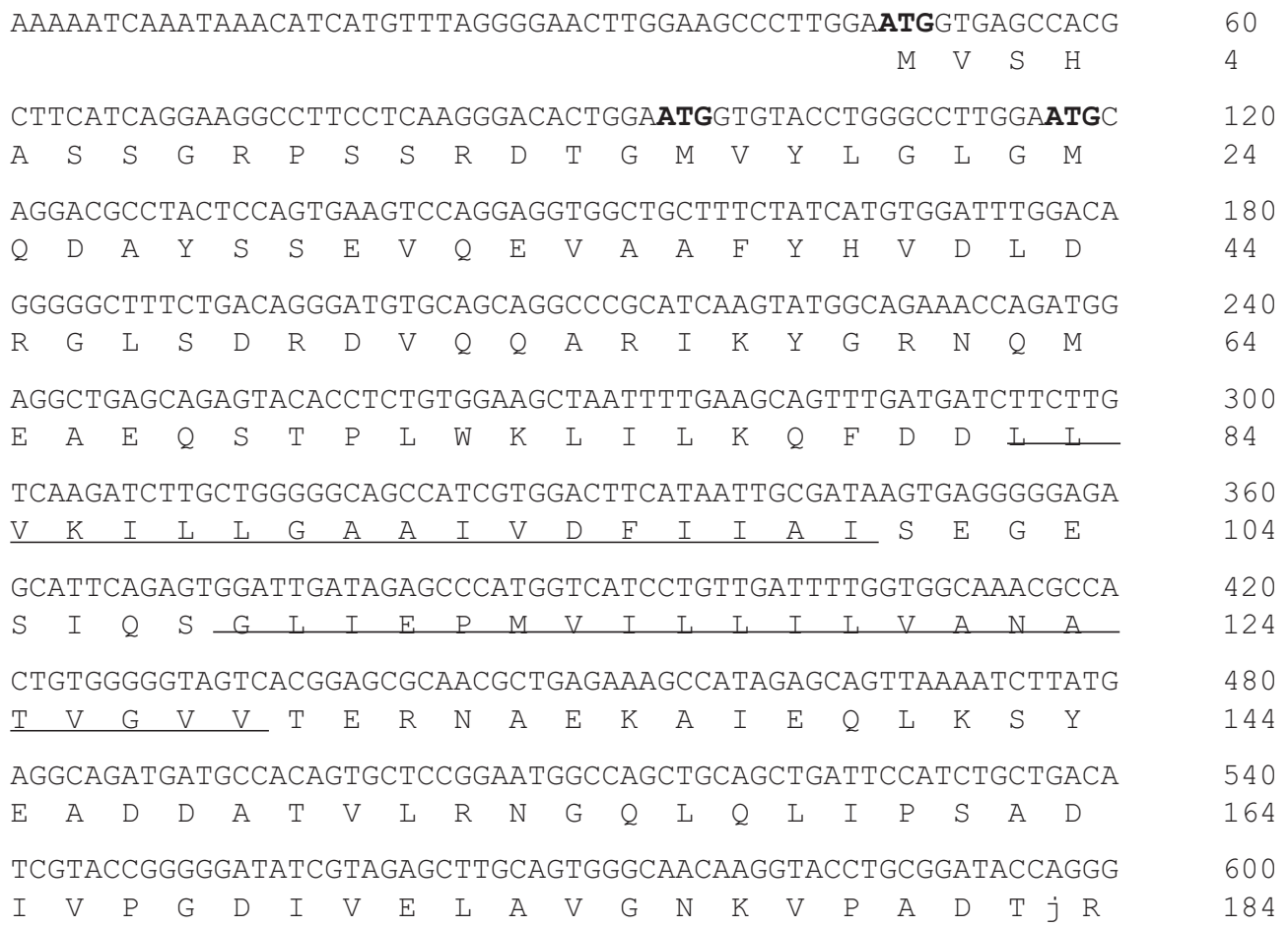

\section{Abb. 3: Aminoterminale Nuklein- und Aminosäuresequenz von DBCA1}

Die Nukleotidsequenz des Klons pDL20/14 ist in $5^{\prime} \rightarrow 3^{\prime}$ Orientierung angegeben. Die daraus abgeleitete Aminosäuresequenz ist darunter abgebildet. Die beiden Transmembransegmente sind unterstrichen. Die drei als mögliche Startcodons in Frage kommenden ATG-Tripletts sind durch Fettdruck hervorgehoben. 


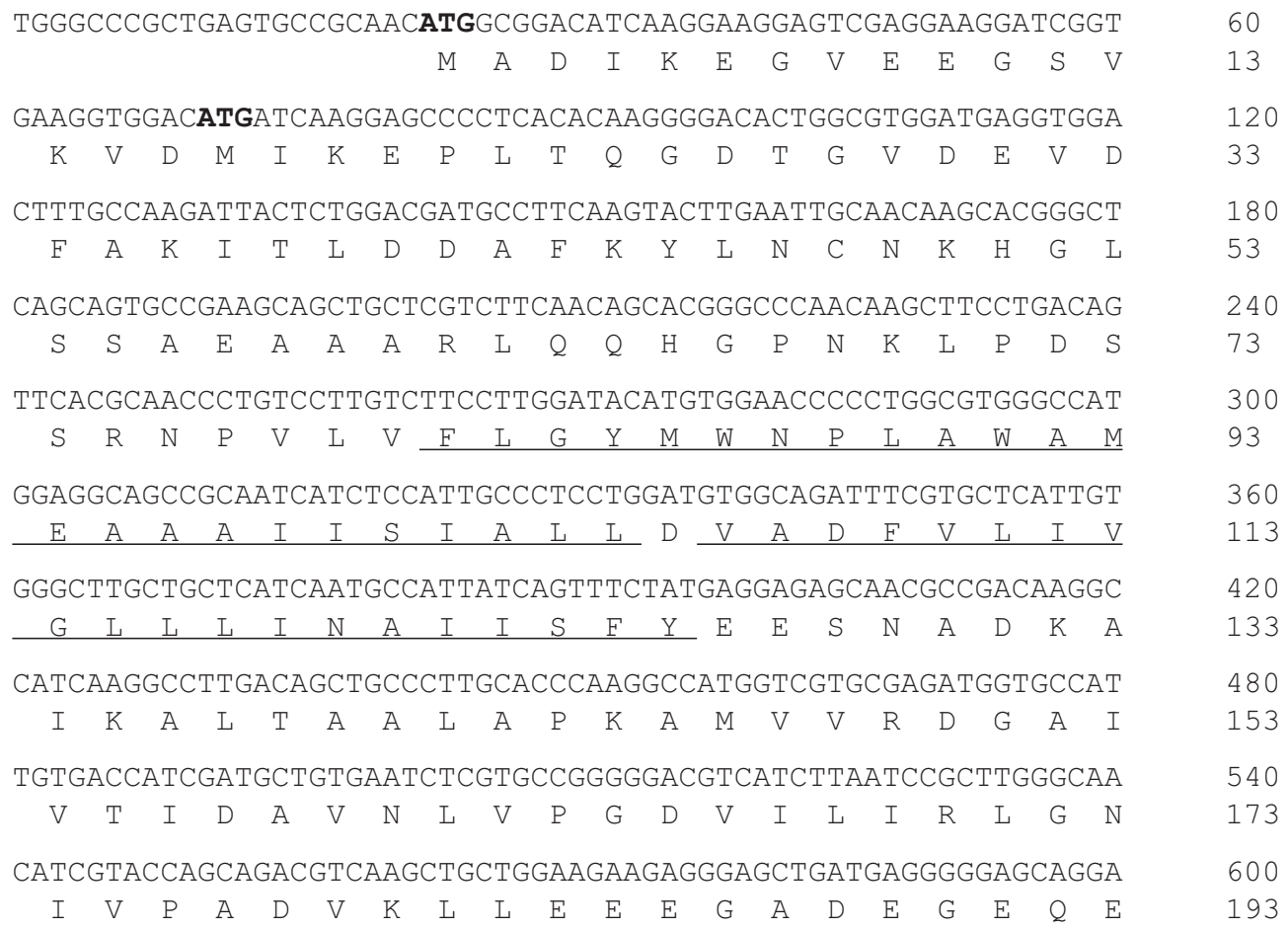

\section{Abb. 4: Aminoterminale Nuklein- und Aminosäuresequenz von DBPMA1}

Die Nukleotidsequenz des Klons pDL10 ist in $5^{\prime} \rightarrow 3^{\prime}$ Orientierung angegeben. Die daraus abgeleitete Aminosäuresequenz ist darunter abgebildet. Die beiden Transmembransegmente sind unterstrichen. Die zwei als mögliche Startcodons in Frage kommenden ATG-Tripletts sind durch Fettdruck hervorgehoben.

Vergleiche der Basensequenzen in nächster Umgebung tatsächlicher Statcodons lassen bei Eukaryonten in der Regel Rückschlüsse auf das als Translationsstart genutzte ATG-Triplett zu (KOZAK 1987, LÜTCKE et al. 1987).

Ein Vergleich der Basen in unmittelbarer Umgebung der beiden ATG-Motive an Position 23 - 25 und 72 - 74 der Nukleinsäuresequenz von DBPMA1 mit den für tierische und pflanzliche Transkripte ermittelten Consensus-Sequenzen zeigte größte Übereinstimmungen zwischen der Umgebung des ersten ATG am 5'-Terminus und der tierischen Kozak Consensus-Sequenz (Tab. 4). Es wurde daher vermutet, daß die Translation am ersten ATG beginnt (WOLF 1993).

\begin{tabular}{|l|rrrrrrrrrr|}
\hline Position & -4 & -3 & -2 & -1 & 1 & 2 & 3 & 4 & 5 & 6 \\
\hline M1 (Position 23- 25) & C & $\underline{A}$ & A & C & $\underline{\mathbf{A}}$ & $\underline{\mathbf{I}}$ & $\underline{\mathbf{G}}$ & $\underline{\mathrm{G}}$ & $\underline{\mathrm{C}}$ & $\mathrm{G}$ \\
\hline M2 (Position 72 - 74) & $\mathrm{G}$ & $\mathrm{G}$ & $\mathrm{A}$ & $\mathrm{C}$ & $\underline{\mathbf{A}}$ & $\mathbf{I}$ & $\underline{\mathbf{G}}$ & $\underline{\mathrm{G}}$ & $\mathrm{A}$ & $\mathrm{T}$ \\
\hline Pflanzliche Consensus-Sequenz & $\mathrm{A}$ & $\mathrm{A}$ & $\mathrm{C}$ & $\mathrm{A}$ & $\mathrm{A}$ & $\mathrm{T}$ & $\mathrm{G}$ & $\mathrm{G}$ & $\mathrm{C}$ & \\
\hline Tierische Consensus-Sequenz & $\mathrm{C}$ & $\mathrm{A}$ & $\mathrm{C}$ & $\mathrm{C}$ & $\mathrm{A}$ & $\mathrm{T}$ & $\mathrm{G}$ & & & \\
\hline
\end{tabular}

\section{Tab. 4: Umgebung der Translationsstartcodons von pma1}

Die Bezeichnung der Nukleinsäuresequenz von DBPMA1 ist pma1. Übereinstimmungen der Basen in unmittelbarer Umgebung der am Aminoterminus befindlichen ATG-Tripletts mit den pflanzlichen Consensus-Sequenzen sind unterstrichen, Übereinstimmungen mit den tierischen ConsensusSequenzen sind durch Fettdruck gekennzeichnet. 
Für die $\mathrm{Ca}^{2+}$-ATPase DBCA1 ergab ein Sequenzvergleich der Basen in unmittelbarer Umgebung der drei ATG-Tripletts am N-Terminus mit den tierischen und pflanzlichen Consensus-Sequenzen keine Hinweise auf das als Startcodon genutzte ATG. So sind die Basensequenzen vor dem jeweiligen ATG bei allen drei identisch, zeigen aber zu den Consensus-Sequenzen keine oder nur geringe Übereinstimmungen. Nur bei dem ersten und zweiten an Position 48 - 50 und 96 - 98 gelegenen ATG-Tripletts zeigte sich nach dem jeweiligen ATG mit der für pflanzliche Transkripte ermittelten Consensus-Sequenz in der Base Guanin eine Übereinstimmung (Tab. 5).

\begin{tabular}{|l|cccccccccc|}
\hline Position & -4 & -3 & -2 & -1 & 1 & 2 & 3 & 4 & 5 & 6 \\
\hline M1 (Position 48-50) & T & G & G & $\underline{A}$ & $\underline{\mathbf{A}}$ & $\underline{\mathbf{I}}$ & $\underline{\mathbf{G}}$ & $\underline{G}$ & $\mathrm{~T}$ & $\mathrm{G}$ \\
\hline M2 (Position 96-98) & $\mathrm{T}$ & $\mathrm{G}$ & $\mathrm{G}$ & $\underline{\mathrm{A}}$ & $\underline{\mathbf{A}}$ & $\underline{\mathbf{I}}$ & $\underline{\mathbf{G}}$ & $\underline{\mathrm{G}}$ & $\mathrm{T}$ & $\mathrm{G}$ \\
\hline M3 (Position 117- 119) & $\mathrm{T}$ & $\mathrm{G}$ & $\mathrm{G}$ & $\underline{\mathrm{A}}$ & $\underline{\mathbf{A}}$ & $\underline{\mathbf{I}}$ & $\underline{\mathbf{G}}$ & $\mathrm{C}$ & $\mathrm{T}$ & $\mathrm{G}$ \\
\hline Pflanzliche Consensus-Sequenz & $\mathrm{A}$ & $\mathrm{A}$ & $\mathrm{C}$ & $\mathrm{A}$ & $\mathrm{A}$ & $\mathrm{T}$ & $\mathrm{G}$ & $\mathrm{G}$ & $\mathrm{C}$ & \\
\hline Tierische Consensus-Sequenz & $\mathrm{C}$ & $\mathrm{A}$ & $\mathrm{C}$ & $\mathrm{C}$ & $\mathrm{A}$ & $\mathrm{T}$ & $\mathrm{G}$ & & & \\
\hline
\end{tabular}

\section{Tab. 5: Umgebung der Translationsstartcodons von dca1}

Die Bezeichnung der Nukleinsäuresequenz von DBCA1 ist dca1. Übereinstimmungen der Basen in unmittelbarer Umgebung der am Aminoterminus befindlichen drei ATG-Tripletts mit dem pflanzlichen Consensus sind unterstrichen, Übereinstimmungen mit dem tierischen Consensus sind durch Fettdruck gekennzeichnet.

Da die unmittelbare Nähe der ATG-Tripletts keine Ähnlichkeiten zu ConsensusSequenzen zeigte, die Aufschluß über den Translationsstart hätten geben können, wurden Aminosäuresequenzvergleiche mit Typ IIA Ca ${ }^{2+}$-ATPasen des ER (Abb. 5) und verschiedenen tierischen $\mathrm{Ca}^{2+}$-ATPasen des (S)ER (RASCHKE 1996) im Hinblick auf das Translationsstartcodon durchgeführt.

Die Konservierung bestimmter Aminosäuresequenzen ist ein typisches Merkmal von P-Typ ATPasen. Sechs Aminosäuresequenzen lassen sich definieren, die in allen eukaryontischen P-Typ ATPasen vollständig konserviert sind und an nahezu identischen Positionen in der Aminosäureabfolge vorkommen (GREEN 1989, SERRAN0 1989).

Im parallelen Mehrfachabgleich zeigte sich, daß die Anzahl an Aminosäuren zwischen dem ersten Methionin und den konservierten Bereichen der ersten und zweiten Transmembrandomäne bei sechs der acht tierischen und pflanzlichen Typ IIA ATPasen nahezu identisch ist.

Bei fünf der sieben ATPasen stimmte die Position ihres Startcodons mit dem an Position 24 befindlichen Methionin von DBCA1 genau überein. Ab dieser Position an zeigt DBCA1 größte Ähnlichkeiten zu anderen Typ IIA ATPasen, denen im Vergleich zu DBCA1 ein verlängerter N-Terminus fehlt.

Eine Ausnahme bildet ACA3 aus Arabidopsis thaliana, dessen Startcodon mit dem 
an Position 1 liegenden Methionin von DBCA1 zwar übereinstimmt, aber wenig Sequenzhomologien zu den anderen Typ IIA $\mathrm{Ca}^{2+}$-ATPasen in den N-terminalen Aminosäuren aufweist.

Aufgrund der Aminosäuresequenzvergleiche läßt sich das an Position 24 befindliche Methionin von DBCA1 als Translationsstartcodon favorisieren.

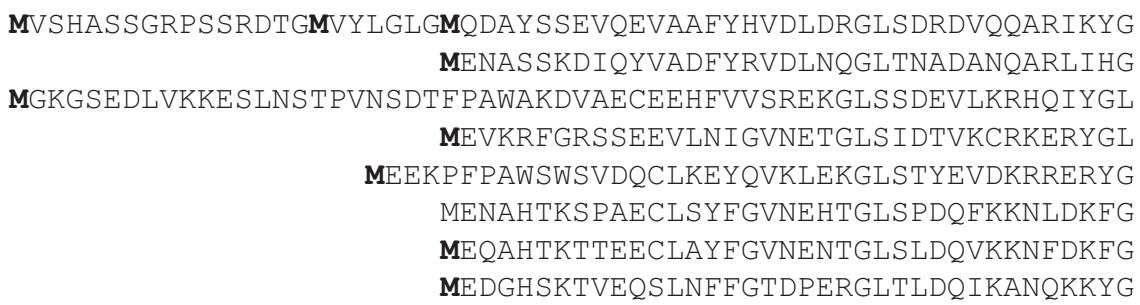

(1) RNQMEAEQSTPLWKLILKQFDDLLVKILLGAAIVDFIIAI-SEGESI---QSGLIEPMVI 120

(2) NNEIAADPGTPLWKLILKLLVKLLVKILIVAAIVDLVIS-FAEGGIG---LSAVIEPGVI 120

(3) NELEKPEGTSIFKLLILEQFNDTLVRILLAAAVISFVLAFFDGDEGGEMGITAFVEPLVI 120

(4) NNELFFEEGKTVRSLVLEQFHDILVKILLNAAYISFVLAYIEEGEAGFTAYVEPIVIFLI 120

(5) LNELEKEKGKPLWRLVLEQFDDTLVKILLGAAFISFVLAYVNQDETGESGFEAYVEPLVI 120

(6) YNELPAEEGKSIWDLIVEQFEDLLVRILLLAACISFVLAWFEEGEETITAFVEPFVILLI 120

(7) PNELPAEEGKSLWELVAEQFEDLLVRILLLAAI ISFVLAWFEEGEETVTAFVEPFVILLL 120

(8) PNELPTEEGKSIWQLVLEQFDDLLVKILLLAAIISFVLALFEEHEETFTAFVEPLVILLI 120

\section{Abb. 5: Vergleich der Primärstrukturen pflanzlicher und tierischer $\mathrm{Ca}^{2+}$-ATPasen des (S)ERs}

Der parallele Mehrfachabgleich setzt sich aus den $\mathrm{N}$-terminalen Aminosäurensequenzen verschiedener Typ IIA Ca ${ }^{2+}$-ATPasen unterschiedlicher Organismen zusammen. (1) Dunaliella bioculata DBCA1 (X73901), (2) Acetabularia acetabulum AACA1 (RASCHKE 1996), (3) Arabidopsis thalina ACA3 (U93845), (4) Oryza sativa (U82966), (5) Lycopersicon esculentum (M96324), (6) Makaira nigricans (U65228), (7) Rana esculenta SERCa1 (X63009), (8) Drosophila melanogaster (P22700). Die Methionine sind durch Fettdruck hervorgehoben, die ersten beiden Transmembransegmente sind grau unterlegt. Unter den in Klammern angegebenen Zugangsnummern sind die vollständigen Aminosäuresequenzen der Klone in der Datenbank des NCBI aufgeführt.

\subsubsection{Konstruktion von ATPase-sGFP-S65T-Fusionsvektoren für die Transfektion von Tabak-Protoplasten}

Bei der $\mathrm{H}^{+}$-ATPase konnte das erste an Position 23 - 25 befindliche ATG (Position 1 in der Aminosäuresequenz von DBPMA1) aufgrund der Homologie seiner umgebenden Basen zur tierischen Consensus-Sequenz als Startcodon favorisiert werden (Tab. 4).

Bei dem Aminosäure-Sequenzvergleiche von DBCA1 mit verschiedenen Typ IIA $\mathrm{Ca}^{2+}$-ATPasen im Hinblick auf das Translationsstartcodon (Abb. 5) wurde angenommen, daß das Methionin an Position 24 (Position 117 - 119 in der Nukleinsäure- 
sequenz von pma1) als Startcodons fungiert. Wie bereits erwähnt, werden Signalsequenzen bzw. Signalsequenzbereiche für das Protein-Targeting am N-Terminus einschließlich der ersten beiden Transmembransegmente der beiden ATPasen vermutet. Die genauen Targeting-Motive und ihre Lokalisation in der Aminosäuresequenz sind unbekannt.

Da sich zwischen den Position 48 und 117 der Ca ${ }^{2+}$-ATPase und Position 23 und 78 der $\mathrm{H}^{+}$-ATPase keine weiteren Stopcodons in der Nukleotidsequenz befinden, konnte nicht grundsätzlich ausgeschlossen werden, daß die Translation in Dunaliella bioculata doch am jeweils ersten bzw. zweiten ATG beginnt.

Es sollte sicher gestellt werden, daß alle Sequenzbereich, die für das ProteinTargeting, zwischen dem ersten und zweiten ATG bei DBPMA1 bzw. ersten und dritten ATG von DBCA1 liegen könnten, berücksichtigt werden. Daher wurden mit PCR aus dem cDNA-Klon pDL20/14 der $\mathrm{Ca}^{2+}$-ATPase drei, aus dem Klon pDL10 der $\mathrm{H}^{+}$-ATPase zwei Genfragmente mit unterschiedlich langen N-Termini amplifiziert.

Mit den Primern DBCAT-M1, DBCAT-M2, DBCAT-M3 und dem reversen Primer rDBCAT wurden aus dem CDNA-Klon pDL20/14 der $\mathrm{Ca}^{2+}$-ATPase aus Dunaliella bioculata die drei Fragmente M1-Ca $a^{2+}-\mathrm{T}, \mathrm{M} 2-\mathrm{Ca}^{2+}-\mathrm{T}$ und $\mathrm{M3}-\mathrm{Ca}^{2+}-\mathrm{T}$ amplifiziert. Sie hatten eine Länge von 487, 438 und 416 bp. Vor den jeweiligen Startcodons wurde der Basenkontext bezüglich der für höhere Pflanzen postulierten Consensus-Sequenz (LÜTCKE et al. 1987) nicht optimiert. Die natürliche Umgebung bis zur Base -6 relativ zum A des ATG der Nukleinsäuresequenz von DBCA1 wurde beibehalten. Mit den Primern DBHT-M1, DBHT-M2 und dem reversen Primer rDBHT wurden aus dem cDNA-Klon pDL10 der $\mathrm{H}^{+}$-ATPase von Dunaliella bioculata zwei DNA-Fragmente amplifiziert und mit $\mathrm{M} 1-\mathrm{H}^{+}-\mathrm{T}$ und $\mathrm{M} 2-\mathrm{H}^{+}-\mathrm{T}$ bezeichnet. Sie hatten eine Länge von 475 und $429 \mathrm{bp}$. Auch bei diesen Fragmenten wurde auf eine zusätzliche Anpassung der ConsensusSequenz um das jeweils ersten AGT verzichtet und die natürliche Basenumgebung der beiden ATG-Motive bis zur Base -6 beibehalten .

Die in den Reaktionen verwendeten Primer waren mit Erkennungssequenzen der Restriktionsendonukleasen Bam HI und Kpn I ausgestattet. Die fünf PCR-Fragmente und der Expressionsvektor HBT-L wurden mit Bam HI und Kpn I geschnitten und ihre überhängenden komplementären Enden durch eine Ligationsreaktion miteinander verknüpft. Die so konstruierten Plasmide wurden nach ihren PCR-Fragmenten M1-Ca ${ }^{2+}-T-s G F P-S 65 T$, M2-Ca ${ }^{2+}-T-s G F P-S 65 T, M 3-C a^{2+}-T-s G F P-S 65 T, M 1-H^{+}-T-s G F P-S 65 T$ und M2-H'-T-sGFP-S65T benannt.

M1-Ca ${ }^{2+}-\mathrm{T}-$ Fragment kodierte für den $\mathrm{N}$-Terminus der $\mathrm{Ca}^{2+}$-ATPase, beginnend am ersten ATG, einschließlich der ersten beiden Transmembransegmente. Es wurde mit den Primern DBCAT-M1 und rDBCAT-C1 amplifiziert und hatte eine Länge von $487 \mathrm{bp}$. 

M2-Ca ${ }^{2+}-$ T-Fragment kodierte für den bis zum zweiten ATG verkürzten $\mathrm{N}$-Terminus von DBCA1, einschließlich der ersten beiden

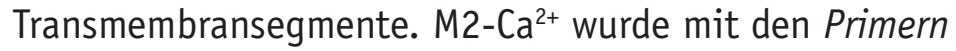 DBCAT-M2 und rDBCAT-C1 amplifiziert und hatte eine Länge von $438 \mathrm{bp}$.

\author{
M3-Ca ${ }^{2+}$-T-Fragment kodierte für den bis zum dritten ATG verkürzten \\ $\mathrm{N}$-Terminus von DBCA1, einschließlich der ersten beiden \\ Transmembransegmente. Es wurde mit den Primern \\ DBCAT-M3 und rDBCAT-C1 amplifiziert und hatte eine \\ Länge von $416 \mathrm{bp}$.
}

M1- $\mathrm{H}^{+}$-T-Fragment kodierte für den kompletten $\mathrm{N}$-Terminus und die ersten beiden Transmembransegmente von DBPMA1, beginnend am ersten ATG. Es wurde mit den Primern DBHT-M1 und rDBHT amplifiziert und hatte eine Länge von 475 bp.
M2- $\mathrm{H}^{+}-\mathrm{T}$-Fragment kodierte für den bis zum zweiten ATG verkürzten $\mathrm{N}$-Terminus von DBPMA1, einschließlich der ersten beiden Transmembransegmente, und wurde mit den Primern DBHT-M2 und rDBHT amplifiziert. Es hatte eine Länge von $429 \mathrm{bp}$.

\title{
3.2 Expression von ATPase-GFP-Fusionsproteinen in Tabak-Protoplasten
}

Die Transfektion der Tabak-Protoplasten fand mittels Elektroporation statt. Pro Ansatz wurden $1-3 \times 10^{6}$ Protoplasten mit $30-150 \mu \mathrm{g}$ Plasmid-DNA transfiziert. Als Positivkontrolle wurde der Vektor HBT-L verwendet, der unter Kontrolle des chimären HBT-Promotors natives SGFP-S65T exprimiert. Als Negativkontrolle dienten nicht-transfizierte Protoplasten und solche, die mit $100 \mu$ l Elektroporationspuffer ohne Plasmid-DNA elektroporiert wurden. 


\subsubsection{Cytoplasmatische und nukleare Lokalisation von SGFP-S65T in Tabak-Protoplasten}

$24 \mathrm{~h}$ nach Transfektion des Vektors HBT-L als Positivkontrolle wurden die Protoplasten in 0,1 mm dünnen Microslids (Camlab, Cambridge, England) im WeitfeldFluoreszenz- und konfokalen Laser Scanning Mikroskop (CLSM) betrachtet. Eine Expression des SGFP-S65T unter Kontrolle des chimären Promotors HBT-L konnte in nur fünf Prozent aller lebenden Protoplasten beobachtet werden (Abb. 6 und 7). Die von SHEEN et al. (1995) bei Verwendung des gleichen Vektors erhaltene Transfektionsrate von $50 \%$ in Mais-Protoplasten und mehr als $80 \%$ in Tabak-Protoplasten (CHIU et al. 1996) wurde auch durch längere Inkubationszeiten von 48 bis $60 \mathrm{~h}$ und einer Erhöhung der pro Transfektionsansatz eingesetzten Plasmidmenge auf bis zu $150 \mu \mathrm{g}$ nicht erreicht.

Mit nativem SGFP-S65T transfizierte Protoplasten zeigten eine starke gelb-grünliche Fluoreszenz (Abb. 7), die sich von der Fluoreszenz nicht-transfizierter Protoplasten deutlich unterschied (Abb. 8). Das gesamte Cytoplasma fluoreszierte und bis auf den Zellkern ließen sich keine weiteren fluoreszierenden Zellorganellen identifizieren. Die Vakuolen zeigten im CLSM keine Emission im Lichtwellenbereich von 510 - 520 nm. In Pflanzen exprimiertes natives GFP ohne Signalsequenzen befand sich außerhalb aller durch Membranen abgeschlossener Kompartimente. Dies wurde auch von HASELOFF et al. (1997), GREBENOK et al. (1997) und KÖHLER et al. (1997) beobachtet. Abb. 7 b, c und d zeigen aber auch, daß eine scharfe Abgrenzung gegen das umgebende Außenmedium nicht vorhanden war. Eine Akkumulation des nativen sGFP-S65T in der Plasmamembran konnte somit ausgeschlossen werden. 

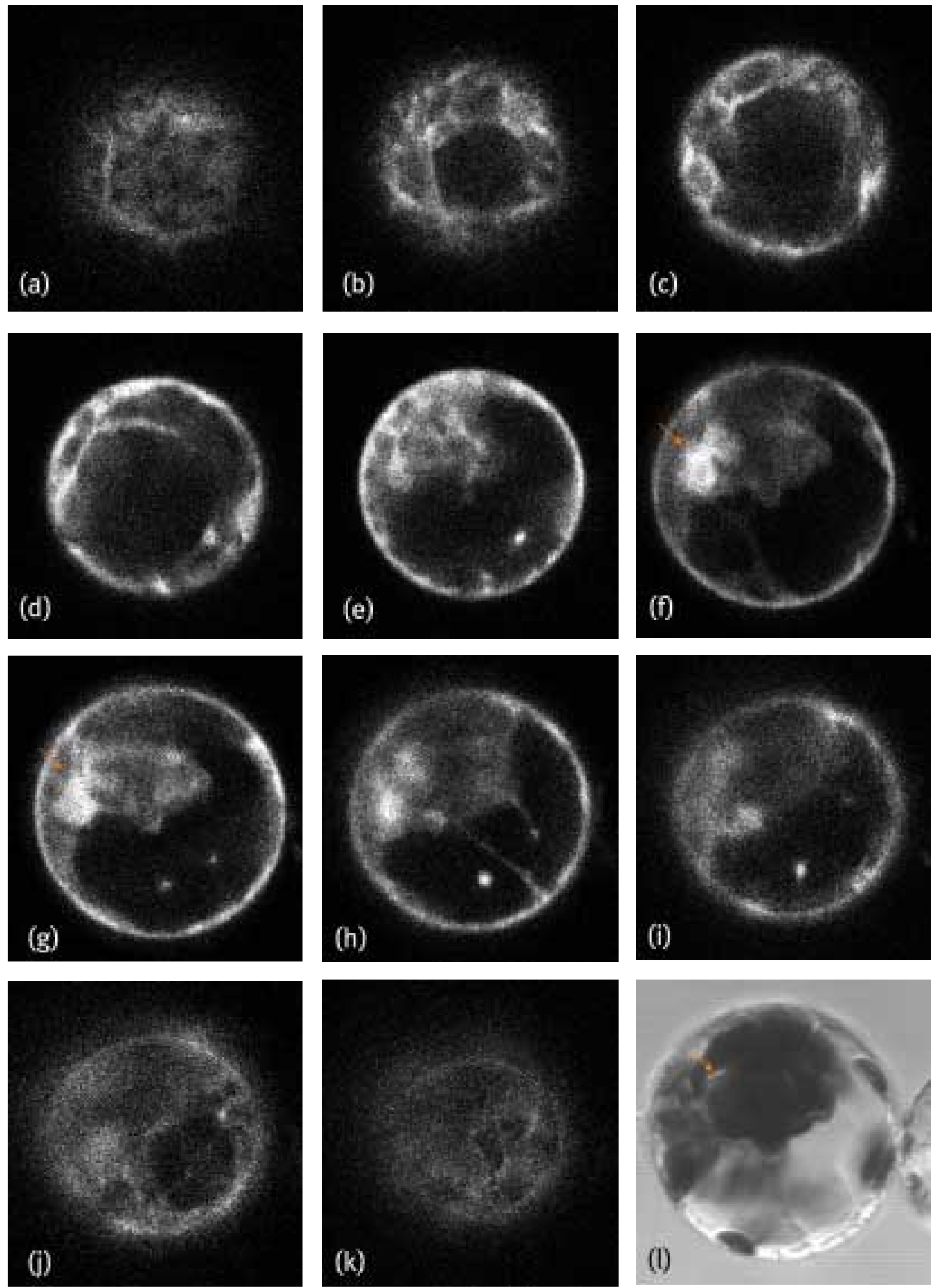

$15 \mu \mathrm{m}$

Abb. 6: Optische Schnittserie eines mit HBT-L transfizierten Tabak-MesophyllProtoplasten

Die CLSM-Aufnahmen wurden in Abständen von $4 \mu \mathrm{m}$ durch den $45 \mu \mathrm{m}$ großen Protoplasten erstellt. Auf den fluoreszierenden Zellkern in $(\mathrm{f}),(\mathrm{g})$ und $(\mathrm{h})$ wird durch Pfeile hingewiesen. $(\mathrm{l})$ zeigt dieselbe Bildebene wie $(\mathrm{g})$ im Durchlicht aufgenommen. 

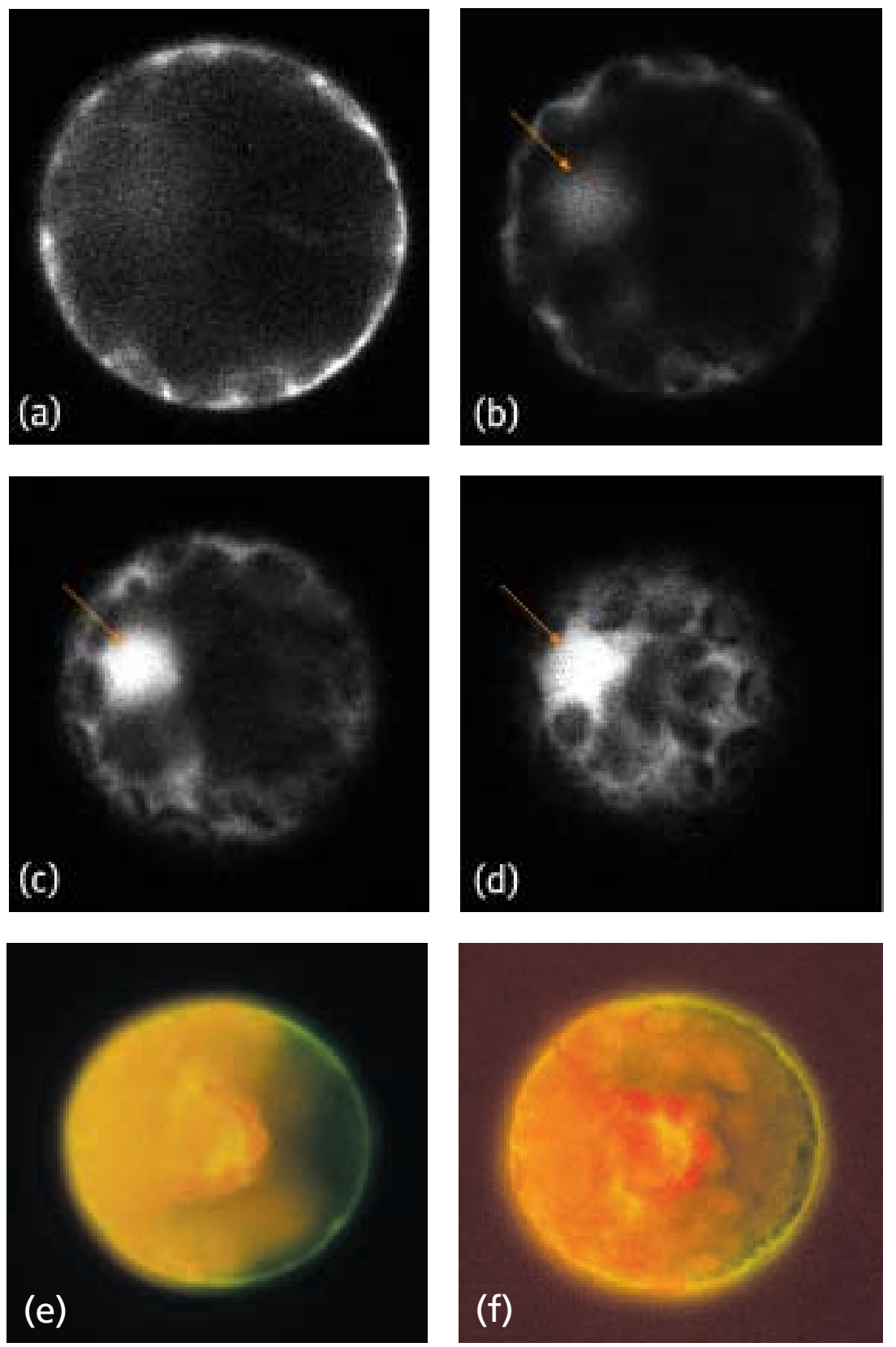

$10 \mu \mathrm{m}$

\section{Abb. 7: Ausschnitte eines mit HBT-L transfizierten Tabak-Protoplasten}

CLSM-Aufnahme durch das Zentrum eines mit HBT-L transfizierten Mesophyll-Protoplasten. Im Gegensatz zu Abb. 6 sind hier die Aussparungen nicht-fluoreszierender Zellorganellen deutlich erkennbar. (a) Im Cytoplasma des Protoplasten hat eine Akkumulation des GFP stattgefunden. In den Bildebenen (b) und (c), 5 und $15 \mu \mathrm{m}$ von der Aufnahme (a) entfernt, wird der fluoreszierende Zellkern (siehe Pfeil) und die unregelmäßige Struktur des Cytoplasmas erkennbar. Die im Zentrum des Protoplasten befindliche Zentralvakuole ist im Vergleich zum fluoreszierenden Cytoplasma dunkel (a), (b), (c) und am äußeren Protoplastenrand (d) so gut wie nicht mehr ersichtlich. (e) Weitfeld-Fluoreszenzmikroskopaufnahme eines transfizierten Protoplasten. Anregung mit $480 \mathrm{~nm}$ und Beobachtung mit Longpassfilter $510 \mathrm{~nm}$, (f) zusätzlich mit Durchlicht. Die gelbe Fluoreszenz ist bedingt durch die Überlagerung der roten Autofluoreszenz der Chloroplasten und der grünen Fluoreszenz des GFP. 


\subsubsection{Negativkontrollen}

Die Negativkontrollen wurden genauso wie die mit Plasmid-DNA elektroporierten Protoplasten behandelt und nach Inkubationszeiten von $24 \mathrm{~h}$ und $48 \mathrm{~h}$ unter dem Weitfeld-Fluoreszenzmikroskop und CLSM untersucht. Nicht-elektroporierte Protoplasten wurden nach 24-stündiger Inkubationszeit im Mikroskop betrachtet. Es zeigte sich, daß zwischen nicht-elektroporierten und ohne Plasmid-DNA elektroporierten Protoplasten keine Unterschiede in den Fluoreszenzeigenschaften auftraten. Lediglich der Anteil an Zelltrümmern war nach Elektroporation höher. Bei einigen Protoplasten beider Kontrollen zeigte sich im inversen Fluoreszenzmikroskop mit dem FITC-Filtersatz eine schwache diffuse gelblich-grüne Eigenfluoreszenz, die auch im CLSM auszumachen war (Abb. 8 a, b). In vielen Protoplasten trat außerdem nach Anregung mit 488 nm eine Emission der Chloroplasten im gleichen Emissionsspektrum, wie das des sGFP-S56T auf. Diese Emission konnte auch bei Verwendung eines 510 - 520 nm Bandpassfilters nicht eliminiert werden (Abb. 8 c, d). Tote Protoplasten zeigten vermutlich auf Grund von Abbauprodukten im Fluoreszenzmikroskop bei Beobachtung mit dem FITC-Filtersatz eine grünliche Fluoreszenz, die auch im CLSM auszumachen war (Abb. 8 e, f).

Durchlichtaufnahmen bestätigten, daß es sich bei den gelb-grünlich leuchtenden Negativkontrollen um lebende Protoplasten handelte.
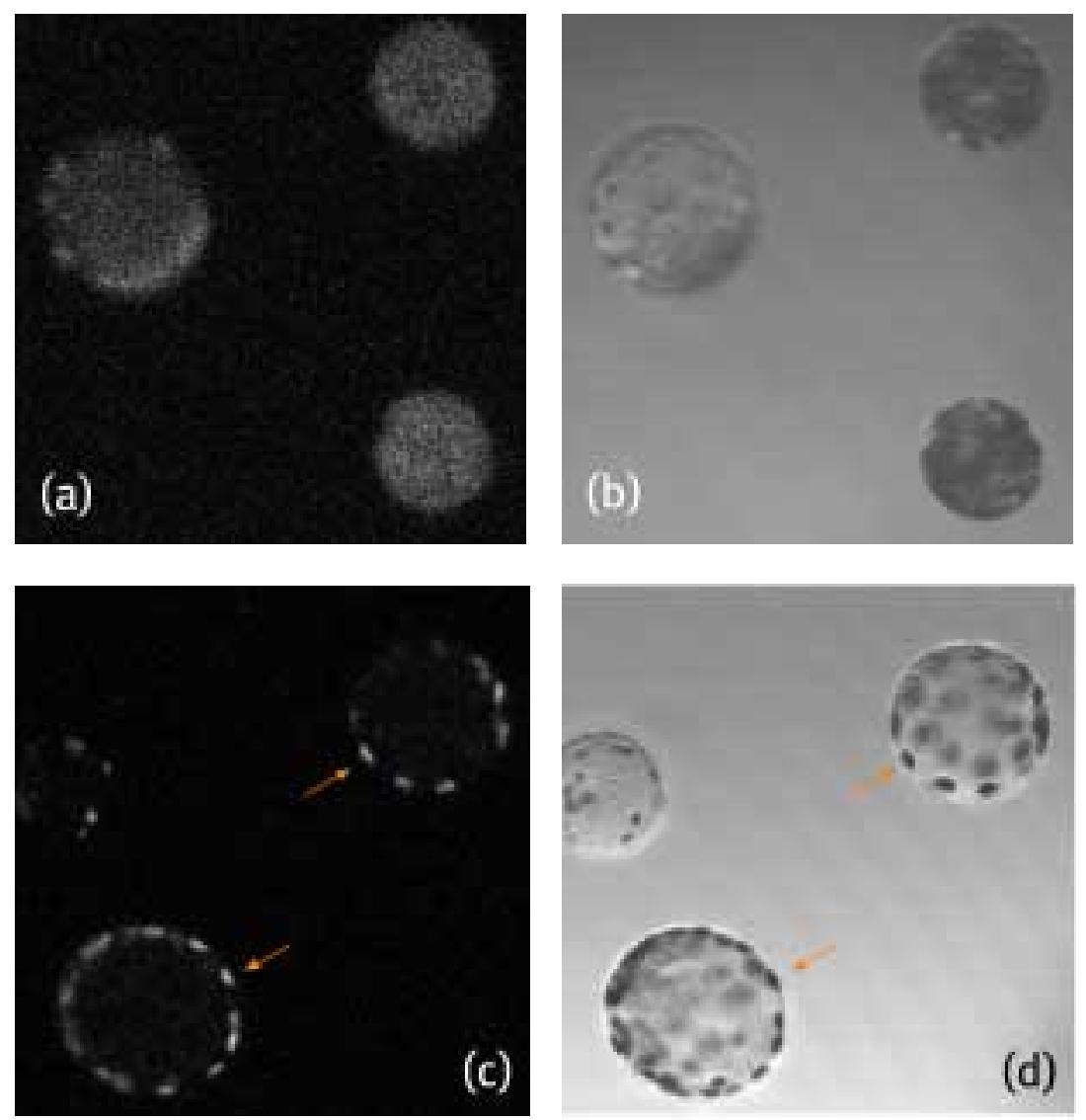

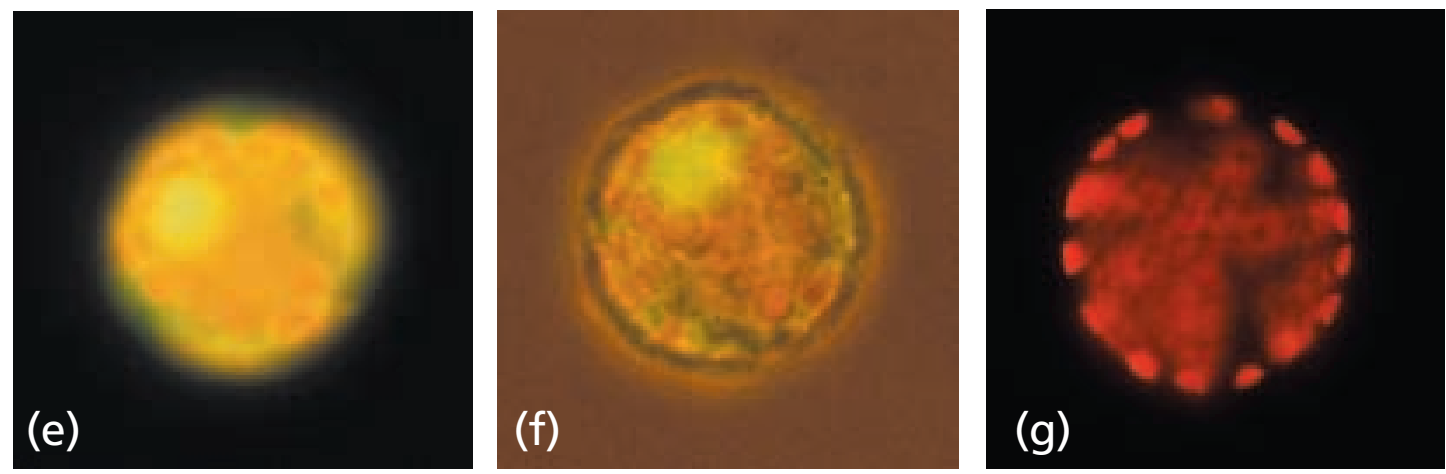

$15 \mu \mathrm{m}$

\section{Abb. 8: Negativkontrollen}

(a) Autofluoreszenz nicht-transfizierter Protoplasten im CLSM und (b) im Durchlicht. (c) Chloroplastenfluoreszenz (siehe Pfeile) lebender Protoplasten im konfokalen Fluoreszenzmikroskop und (d) im Durchlicht. (e) Autofluoreszenz toter Protoplasten, (f) im Durchlicht. (g) Weitfeldfluoreszenzmikroskopische Aufnahme nicht-transfizierter Protoplasten. Anregung mit 480 nm, Beobachtung mit Longpassfilter $510 \mathrm{~nm}$.

\subsubsection{Fehlende Expression der ATPase-sGFP-S65T-Fusionsproteine in Tabak-Protoplasten}

Die fünf rekombinanten Vektoren M1-Ca ${ }^{2+}-\mathrm{T}-$ sGFP-S65T, M2-Ca ${ }^{2+}-\mathrm{T}-\mathrm{sGFP}-\mathrm{S} 65 \mathrm{~T}$, M3-Ca ${ }^{2+}-\mathrm{T}-$-sGFP-S65T, M1-H+-T-sGFP-S65T und M2-H+-T-sGFP-S65T wurden durch Elektroporation in Tabak-Protoplasten eingeschleust. Es war bei Betrachtung im Weitfeld-Fluoreszenzmikroskop und im CLSM nach 24-, 48- und 60-stündiger Inkubation bei $24^{\circ} \mathrm{C}$ im Dunkeln unter Kontrolle des chimären HBT-Promotors, keine Expression der fünf Fusionsproteine in Tabak-Protoplasten festzustellen.

Jedes Plasmid wurde mehrere Male mit je zwei Kontrollansätzen in Tabak-Protoplasten transfiziert. Bei den Positivkontrollen war jedesmal eine Expression des nativen sGFP-S65T festzustellen. Eine Erhöhung der pro Transfektionsansatz eingesetzten Plasmidmenge auf bis zu $150 \mu \mathrm{g}$, die Inkubation der Protoplasten im Hellen und die Verwendung unterschiedlich alter Tabakpflanzen zur Protoplastengewinnung führte zu keinen anderen Ergebnissen. 


\subsection{Konstruktion der ATPase-EGFP-Fusionsvektoren für die Expression in HeLa- und COS-7-Zellen}

Die $\mathrm{Ca}^{2+}$-ATPase aus Dunaliella bioculata zeigt starke Homologien zu tierischen ATPasen des (Sarko-)Endoplasmatischen Retikulums auf (54\% Identität, $70 \%$ Ähnlichkeit, dagegen zu pflanzlichen Typ IIA ATPasen $44 \%$ Identität und $57 \%$ Ähnlichkeit). Aufgrund der fehlenden Expression in Tabak-Protoplasten und einer Codon-Präferenz, die der vieler tierischer Gene ähnlich ist, wurde für beide ATPasen im zweiten Schritt eine heterologe Expression in tierischen Systemen gewählt.

Für die Transfektion der ATPase-GFP-Fusionsvektoren waren tierspezifische Änderungen bei der Plasmidkonstruktion notwendig. Ausgangsmaterial zur Klonierung rekombinanter GFP Fusionsvektoren war der Vektor pEGFP-N1 (Clontech, Palo Alto, USA) und die cDNA Klone pDL10 der $\mathrm{H}^{+}$-ATPase DBPMA1 und pDL20/14 der $\mathrm{Ca}^{2+}-$ ATPase DBCA1 aus Dunaliella bioculata. pEGFP-N1 enthält ein für tierische Expressionssysteme optimiertes GFP. Es unterscheidet sich vom Wildtyp-GFP durch die Angleichung der Codons an die tierische Codon-Präferenz und eine verstärkte Fluoreszenzintensität durch Substitution von $\mathrm{Phe}^{64}$ zu Leu und $\mathrm{Ser}^{65}$ zu Thr im Chromophor (CLONTECH 1996). Die Expression der rekombinanten Fusionsproteine fand unter Kontrolle des CMV-Promotors statt.

Um eine effizientere Transkription und Translation der pflanzlichen ATPase-Fusionsgene in heterologen tierischen Systemen zu gewährleisten, wurde der Bereich des Translationsstartcodons des Fusionsgenes der tierischen Consensus-Sequenz angepaßt (KOZAK 1987, KOZAK 1996). Die ATPase-Fragmente wurden wie folgt amplifiziert:

M1-Ca ${ }^{2+}$-Fragment kodierte für den N-Terminus der Ca ${ }^{2+}$-ATPase, beginnend am ersten ATG, einschließlich der ersten beiden Transmembransegmente. Es wurde mit den Primern DCA-M1 und rDCAC1 amplifiziert und hatte eine Länge von 472 bp.

M2-Ca ${ }^{2+}$-Fragment kodierte für den bis zum zweiten ATG verkürzten $\mathrm{N}$-Terminus von DBCA1, einschließlich der ersten beiden

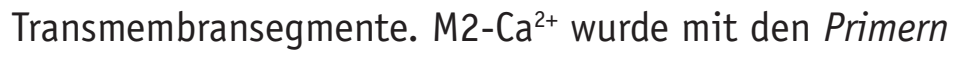
DCA-M2 und rDCAC1 amplifizierten und hatte eine Länge von $424 \mathrm{bp}$. 

M3-Ca ${ }^{2+}$-Fragment kodierte für den bis zum dritten ATG verkürzten $\mathrm{N}$-Terminus von DBCA1, einschließlich der ersten beiden Transmembransegmente. Es wurde mit den Primern DCA-M3 und rDCAC1 amplifiziert und hatte eine Länge von $403 \mathrm{bp}$.

\begin{abstract}
M1- $\mathrm{H}^{+}$-Fragment $\quad$ kodierte für den kompletten N-Terminus von DBPMA1, beginnend am ersten ATG einschließlich der ersten beiden Transmembransegmente. Es wurde mit den Primern DBH-M1 und rDBH2 amplifiziert und hatte eine Länge von $440 \mathrm{bp}$.

M2- $\mathrm{H}^{+}$-Fragment

kodierte für den bis zum zweiten ATG verkürzten $\mathrm{N}$-Terminus von DBPMA1 einschließlich der ersten beiden Transmembransegmente und wurde mit den Primern DBH-M2 und rDBH2 amplifiziert. Es hatte eine Länge von $397 \mathrm{bp}$.
\end{abstract}
M1-H+-TAG-Fragment kodierte für das gleiche Fragment wie $\mathrm{M1}-\mathrm{H}^{+}$mit dem Unterschied, daß sich vor der Schnittstelle Xho I im Leserahmen das Stopcodon TAG befand. Es hatte eine Länge von $441 \mathrm{bp}$ und wurde über die Primer DBH-M1 und rDBH amplifiziert.

Die in den Reaktionen verwendeten Primer waren mit Xho I und Pst I Schnittstellen ausgestattet. Die Basen um das jeweils erste Startcodon des Transkriptes waren der tierischen Consensus-Sequenz (KOZAK 1987a) angepaßt.

Die ATPase Fragmente und der Vektor pEGFP-N1 wurden mit den Restriktionsendonukleasen Pst I und Xho I geschnitten, aufgereinigt und ihre überhängenden komplementären Enden durch eine Ligationsreaktion miteinander verknüpft. Die korrekte Sequenz der Klone wurden durch DNA-Sequenzanalysen bestätigt. Bei der Klonierung der Fusionsvektoren wurde darauf geachtet, daß die Genfragmente im richtigen Leserahmen miteinander verbunden wurden, um eine durchgehende Translation der Fusionsgene zu ermöglichen. In vielen Fällen wurden Basendeletionen innerhalb der amplifizierten ATPase-Fragmente festgestellt. Klone ohne Mutationen wurden im präparativen Maßstab isoliert, aufgereinigt und für die Transfektion von HeLa- und COS-7-Zellen verwendet. 
Die rekombinanten Fusionsvektoren wurden entsprechend ihrer ATPase-Fragmenten

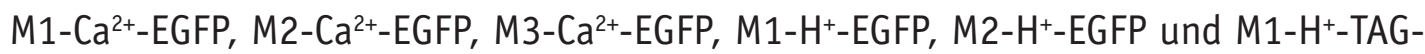
GFP benannt (Abb. 9).
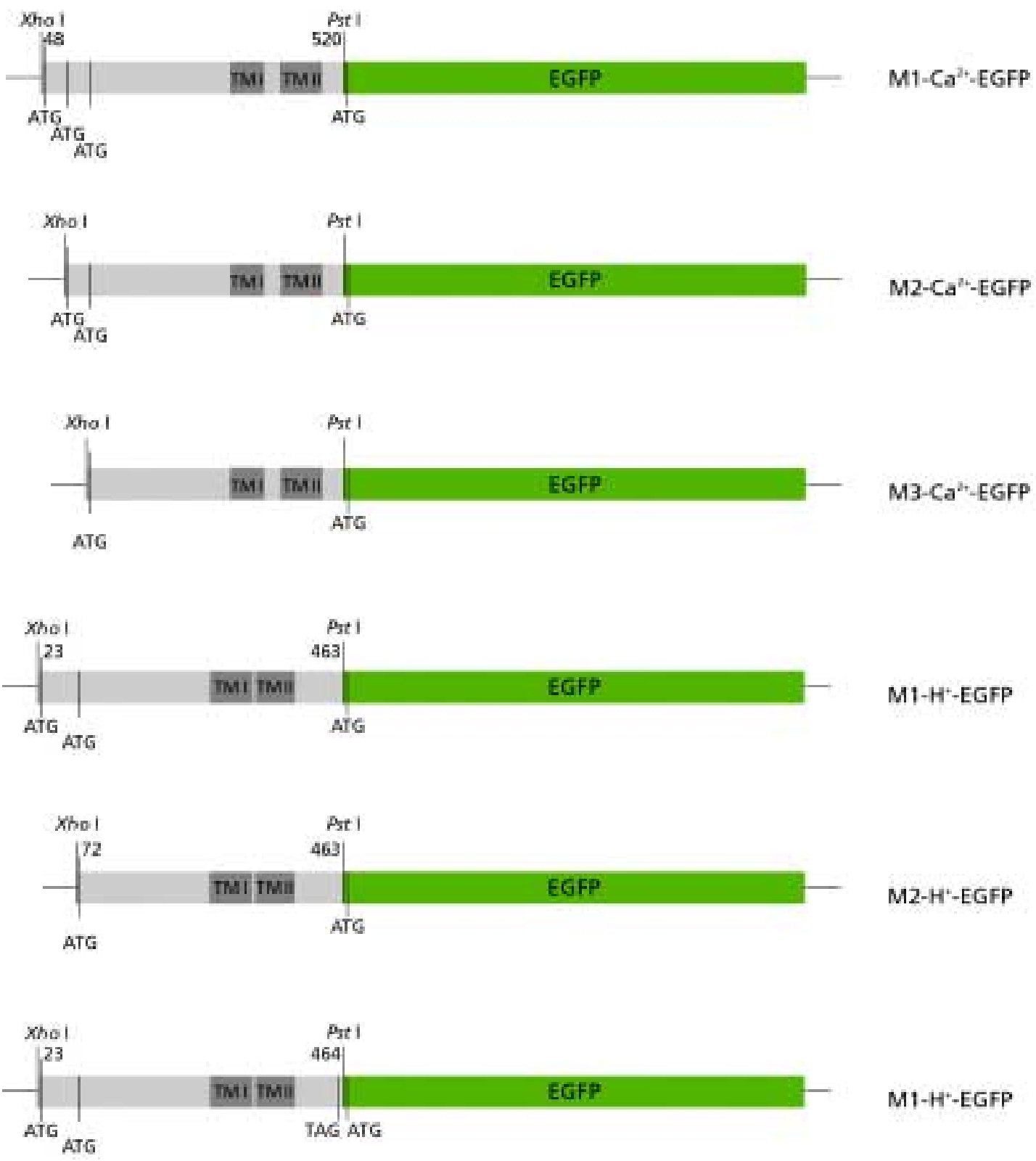

\section{Abb. 9: Konstruktion der rekombinanten EGFP-Fusionsvektoren}

Die EGFP-Sequenz ist grün, die ATPase-Sequenzen grau dargestellt. Die Bereiche der beiden Transmembransegmente sind dunkelgrau gezeigt und mit TM I und TM II gekennzeichnet. Die ATPaseFragmente wurden in die Multiple Klonierungstelle des pEGFP-N1 Vektors kloniert. Die Zahlen verweisen auf die Position der Nukleinsäuren von DBCA1 und DBPMA1. 


\subsection{Expression der ATPase-EGFP-Fusionsgene in HeLa-Zellen}

Die ersten klonierten Fusionsvektoren $\mathrm{M} 2-\mathrm{Ca}^{2+}$-EGFP und $\mathrm{M3}-\mathrm{Ca}^{2+}$-EGFP wurden mittels Liposomentransfektion in adhärente HeLa-Zellen eingeschleust. Mit diesen ersten Versuchen sollte überprüft werden, ob pflanzliche ATPase-GFP-Chimären in tierischen Expressionssystemen translatiert werden und eine subzelluläre Lokalisation der Fusionsproteine erkennbar ist.

Zur Überprüfung der Transfektionseffizienz wurde der Vektor pEGFP-N1 als Positivkontrolle verwendet. Als Negativkontrolle dienten Transfektionsansätze ohne DNA. Die Positivkontrollen ergaben sehr geringe Transfektionsraten. Um größere Transfektionsraten zu erzielen, wurden verschiedene Versuchsansätze durchgeführt, die im Bezug auf DNA-Konzentration, Liposomenkonzentration, Verhältnis von DNA zu Liposomen und Zellzahl variierten. Die höchste Transfektionsrate von $3-5 \%$ wurde bei einer Mischung von Liposomen und Plasmid-DNA im Verhältnis 1:1 erzielt. Verlängerte Inkubationszeiten von $48 \mathrm{~h}$ führten zwar zu einer 1,5-fach höheren Transfektionsrate, typische subzelluläre Lokalisationsmuster konnten aber aufgrund einer Überexpression der Proteine nicht mehr erkannt werden. Um zu zeigen, daß die Ergebnisse reproduzierbar sind, wurden die Versuche von jedem Plasmid sechsmal mit je zwei Kontrollen wiederholt.

\subsubsection{Positiv- und Negativkontrolle: Expression von EGFP in HeLa-Zellen}

Da das für die Kultivierung der HeLa-Zellen verwendete RPMI-Kulturmedium eine sehr hohe Eigenfluoreszenz aufweist, wurden alle HeLa-Zellen vor der fluoreszenzmikroskopischen Untersuchung in 1x PBS-Puffer aufgenommen.

Transfizierte HeLa-Zellen wurden $24 \mathrm{~h}$ nach der Transfektion im Weitfeld-Fluoreszenzmikroskop auf Expression des nativen EGFP untersucht. Eine Expression des nativen EGFP unter Kontrolle des CMV-Promotors konnte unter Verwendung eines FITC-Filtersatzes festgestellt werden (Abb. 10). Die Fluoreszenz war nicht kompartimentspezifisch und trat auch im Zellkern auf. Eine deutliche Abgrenzung der Zellen gegenüber dem Außenmedium war erkennbar. Ohne DNA transfizierte Negativkontrollen zeigten unter dem Weitfeld-Fluoreszenzmikroskop bei Verwendung des FITC-Filtersatzes keine Autofluoreszenz. 

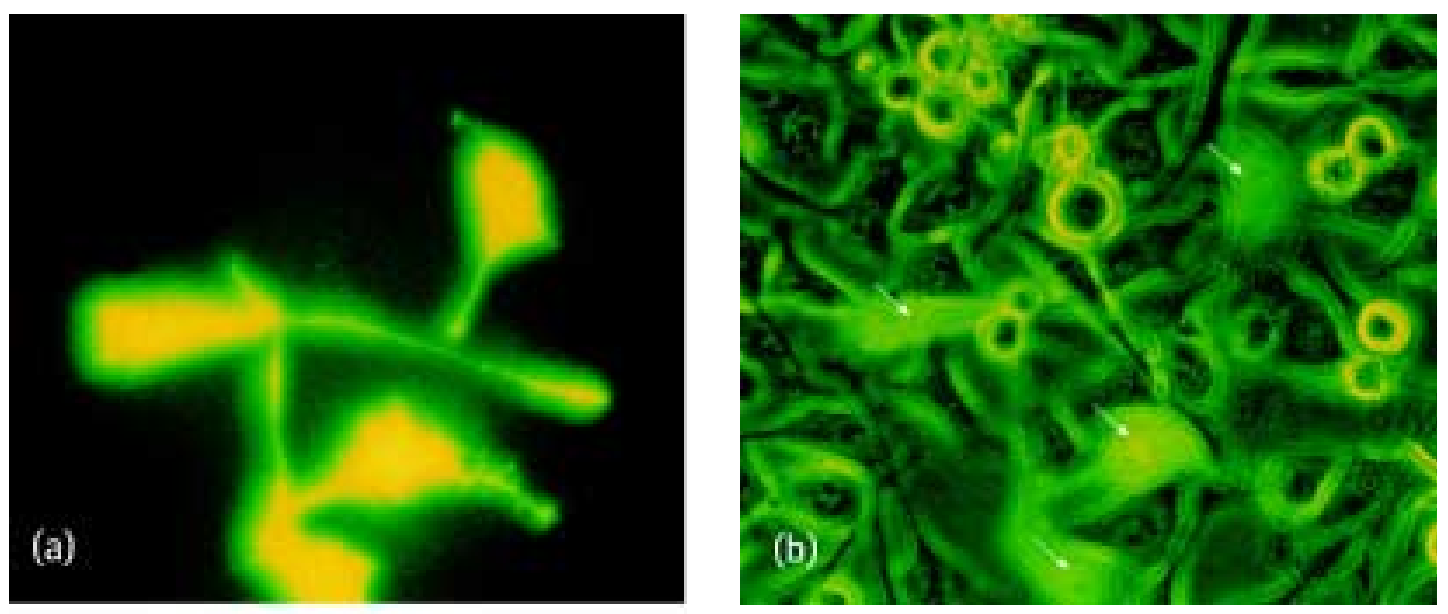

$15 \mu \mathrm{m}$

\section{Abb. 10: Expression des EGFP in HeLa-Zellen}

Fluoreszenzmikroskopische Aufnahmen von HeLa-Zellen nach Transfektion mit pEGFP-N1. (a) In transfizierten Zellen ist eine starke, nicht differenzierbare Fluoreszenz des gesamten Zellinhaltes zu sehen. Anregung und Beobachtung erfolgten mit einem FITC-Filtersatz. (b) Die Fluoreszenz der transfizierten Zellen war so stark, das sie auch unter Durchlicht, gekoppelt mit FITC-Anregung, erkennbar waren (siehe Pfeile). Ein Vergleich von (a) und (b) zeigt, daß untransfizierte Zellen mit FITC-Anregung keine Autofluoreszenz besitzen und nur im Durchlicht erkennbar waren.

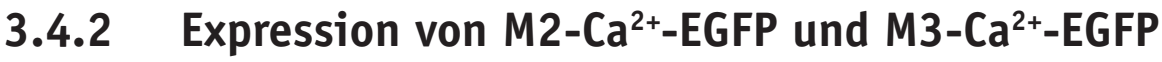 in HeLa-Zellen}

Nach Transfektion von M2-Ca ${ }^{2+}-E G F P$ und M3-Ca ${ }^{2+}-$ EGFP in HeLa-Zellen zeigte sich gegenüber der Positivkontrolle ein deutlich anderes Bild (Abb. 11). Die Fluoreszenzintensität beider Fusionsproteine war im Vergleich zum EGFP wesentlich geringer, was auf eine schwächere Expression der Fusionsproteine gegenüber dem nativen EGFP hinweisen könnte. Der Zellkern fluoresziert wesentlich schwächer, wodurch seine Lage innerhalb der Zelle im Gegensatz zur Positivkontrolle erkennbar war. Die Plasmide M2-Ca ${ }^{2+}$-EGFP und M3-Ca ${ }^{2+}$-EGFP zeigten die gleiche geringe Transfektionsrate wie die Positivkontrolle. Nach Kernfärbung dieser Zellen mit dem Lebendfarbstoff H33342 wurde deutlich, daß die Fluoreszenz beider Fusionsproteine verstärkt in perinukleären Bereichen und schwächer auch in Zellstrukturen auftrat, die das gesamte Cytoplasma durchziehen (Abb. 11). Die Zellgrenzen erschienen gegenüber dem Außenmedium diffuser als nach Expression des nativen EGFP.

Da die ATPase-GFP-Fusionsproteine ein anderes Expressionsmuster innerhalb der HeLa-Zellen zeigten als das native GFP, wurde die kompartimentspezifische Lokalisation der Fusionsproteine vermutlich durch die N-terminalen ATPase-Genbereiche bestimmt. Das Fluoreszenzmuster beider Fusionsproteine in HeLa-Zellen deutet auf eine ER-Lokalisation hin. Vergleiche mit pEYEP-ER und pECFP-ER (GFP-Varianten mit Targeting-Signalen in das ER) transfizierten HeLa-Zellen bestätigten diese Annahme 
(Clontech-Homepage, www.clontech.com). Durch die starke Fluoreszenz im kernnahen Bereich kann jedoch nicht ausgeschlossen werden, daß eine Akkumulation der Fusionsproteine auch in anderen Zellorganellen, wie dem Golgi-Apparat stattgefunden hat.

Beide ATPase-EGFP-Konstrukte wurden exprimiert, zeigten ein anderes Fluoreszenzmuster als das native EGFP und ließen keine deutlichen Unterschiede in der Fluoreszenzintensität erkennen. Eine Aussage darüber, ob das ATG an Position 96 - 98 oder 117 - 119 der Nukleinsäuresequenz von DBCA1 als tatsächliches Startcodon in Dunaliella bioculata fungiert, ließ sich nicht machen.
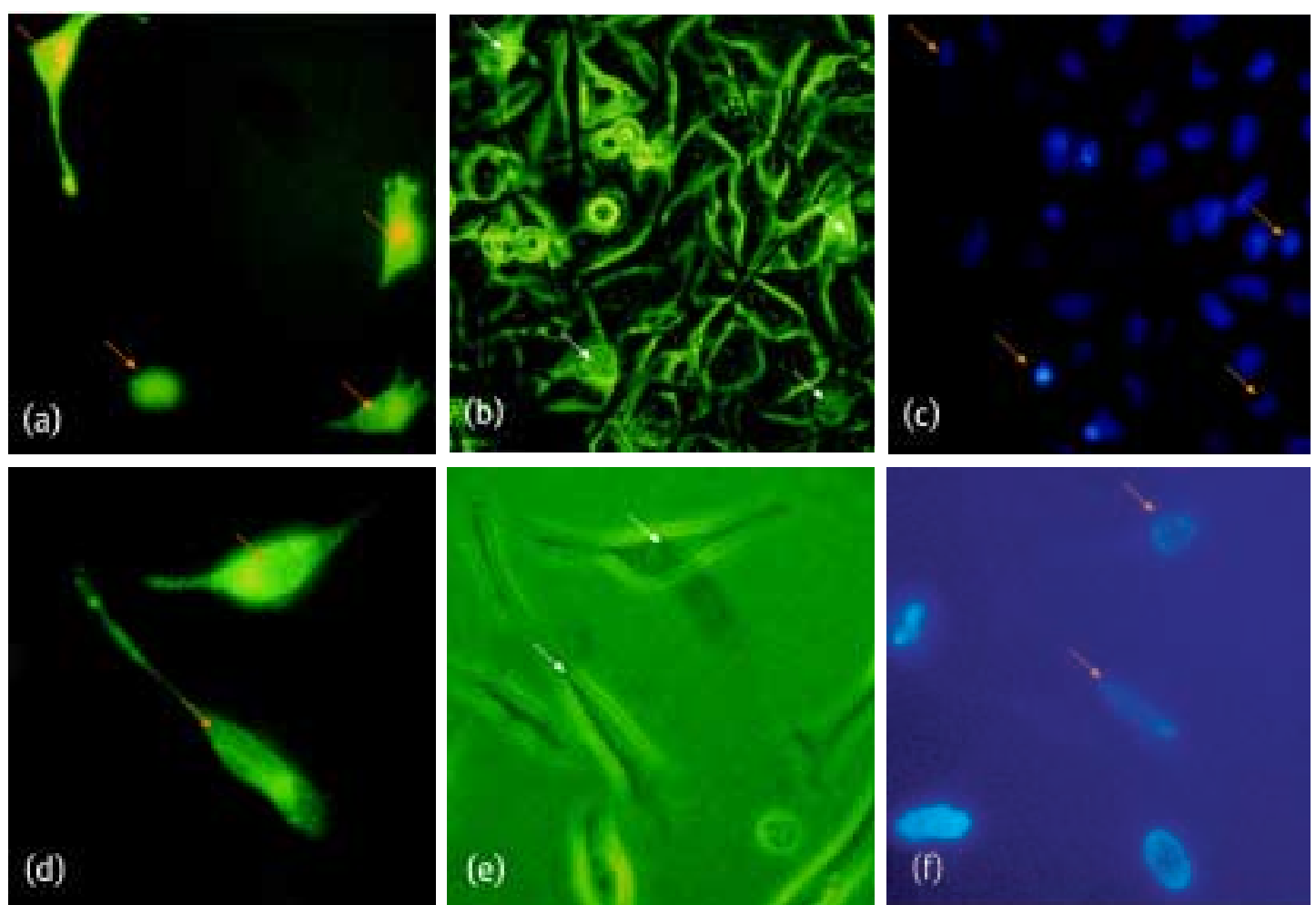

$10 \mu \mathrm{m}$

\section{Abb. 11: Expression von M2-Ca ${ }^{2+}$-EGFP und M3-Ca ${ }^{2+}-E G F P$ in HeLa-Zellen}

Weitfeldfluoreszenzmikroskopische Aufnahmen von HeLa-Zellen $24 \mathrm{~h}$ nach Transfektion mit M2-Ca ${ }^{2+}$ EGFP (a), (b) und M3-Ca ${ }^{2+}$-EGFP (d), (e) sowie Zellkernfärbung der transfizierten HeLa-Zellen mit H33342 (c), (f). Anregung und Beobachtung erfolgten bei (a), (b), (d) und (e) mit dem FITC-Filtersatz bei (b) und (e) zusätzlich mit Durchlicht. Nach Zellkernfärbung wurden die Zellen mit $365 \mathrm{~nm}$ angeregt. (a) und (d) zeigen, daß nicht das gesamte Cytoplasma, sondern nur Teilbereiche und verstärkt perinukleäre Strukturen leuchten. Vergleiche zwischen (c) und (f) machen dies deutlich. Orangefarbene Pfeile deuten auf die Zellkerne, weiße auf die im Durchlicht fluoreszierenden Zellen hin. 


\subsubsection{Expression von M1- $\mathrm{H}^{+}-\mathrm{TAG}-\mathrm{EGFP}$ in HeLa-Zellen}

Mit den Primern DBH-M1 und rDBH wurde das ATPase-Fragment M1- $\mathrm{H}^{+}-\mathrm{TAG}$ amplifiziert und mit dem Vektor pEGFP-N1 ligiert. Nach der Ligation der beiden Genfragmente bildeten diese durch Insertion eines Nukleotides keinen durchgängigen Leserahmen zueinander. Dadurch befand sich zwischen den Nukleinsäuresequenzen von DBPMA1 und EGFP ein Stopcodon (Abb. 9). Eine durchgehende Translation des Fusionsgens war somit nicht gewährleistet. Nach Transfektion in HeLa-Zellen konnte beobachtet werden, daß wider Erwarten das GFP sowohl im Cytoplasma als auch im Zellkern fluoreszierte (Abb. 11). Das translatierte Protein zeigte das gleiche Fluoreszenzmuster wie natives EGFP (Abb. 10, Abb. 12) und wurde genauso stark exprimiert. Es ist daher anzunehmen, daß bei $\mathrm{N}$-terminaler Fusion mit EGFP das Startcodon der EGFP-Sequenz auch weiterhin als Translationsstart erkannt wird.
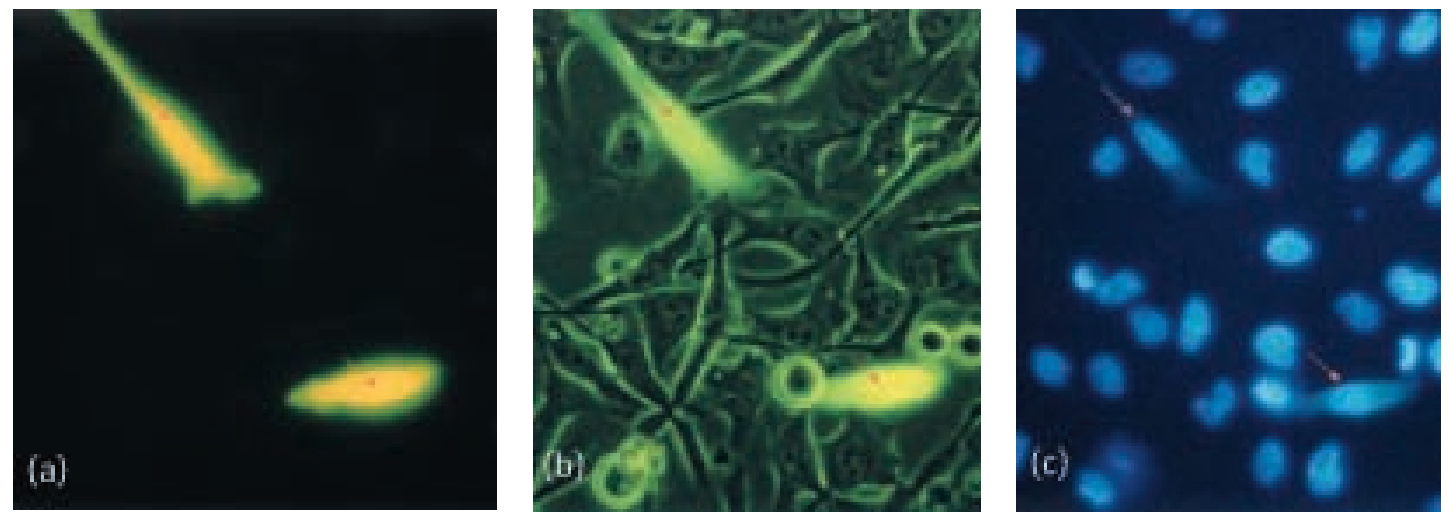

$10 \mu \mathrm{m}$

\section{Abb. 12: Lokalisation von M1-H+-TAG-EGFP im Cytoplasma und Zellkern}

$24 \mathrm{~h}$ nach Transfektion konnte im Weitfeld-Fluoreszenzmikroskop mit dem FITC-Filtersatz eine Lokalisation des Proteins im Cytoplasma und dem Zellkern von HeLa-Zellen verzeichnet werden (a). Abbildung (b) wie (a), nur zusätzlich mit Durchlicht aufgenommen. (c) Zellkernfärbung mit H3334 nach Anregung mit 365 nm. Die Pfeile zeigen die grün fluoreszierenden Zellkerne.

\subsection{Expression der ATPase-EGFP-Fusionsproteine in COS-7-Zellen}

Weiterführende Experimente wurden in COS-7-Zellen durchgeführt, da bei Kontrolltransfektionen mit pEGFP-N1 in diesem Zellsystem Transfektionsraten von bis zu $30 \%$ erzielt wurden. In HeLa-Zellen lag diese nur bei drei bis fünf Prozent. Um statistische Schwankungen zu minimieren, wurden alle Versuche viermal mit je zwei Kontrollen wiederholt. In allen Wiederholungsversuchen zeigten sich die gleichen Ergebnisse. 


\subsubsection{Cytoplasmatische und nukleare Lokalisation von EGFP in COS-7-Zellen}

Als Positivkontrolle dienten mit nativem EGFP transfizierte Zellen, als Negativkontrolle nicht-transfizierte COS-7-Zellen. Die Aufnahmen am Weitfeld-Fluoreszenzmikroskop erbrachten wenig Aufschluß über die genaue subzelluläre Lokalisation der Fusionsproteine. Zur Verbesserung der räumlichen Auflösung wurden die Zellen daher sowohl im Weitfeld-Fluoreszenzmikroskop als auch im konfokalen Laser Scanning Mikroskop (CLSM) betrachtet.

Die Transfektion erfolgte wie bei den HeLa-Zellen durch Liposomentransfektion. Pro Transfektionsansatz wurden $5 \mu \mathrm{g}$ Plasmid-DNA eingesetzt. Nach 24-stündiger Inkubation konnte eine starke Expression des GFP in COS-7-Zellen unter Kontrolle des CMV-Promotors im CLSM festgestellt werden. Wie schon in HeLa-Zellen beobachtet (Abb. 10), trat die Fluoreszenz verstärkt im Cytoplasma, dem perinukleären Bereich und dem Zellkern auf (Abb. 13). Eine deutliche Abgrenzung der Zellen gegenüber dem Außenmedium war erkennbar. Nicht-transfizierte Zellen zeigten bei $488 \mathrm{~nm}$ Laseranregung keine Emission im permissiven Spektrum des 510 - 520 nm Bandpassfilters.

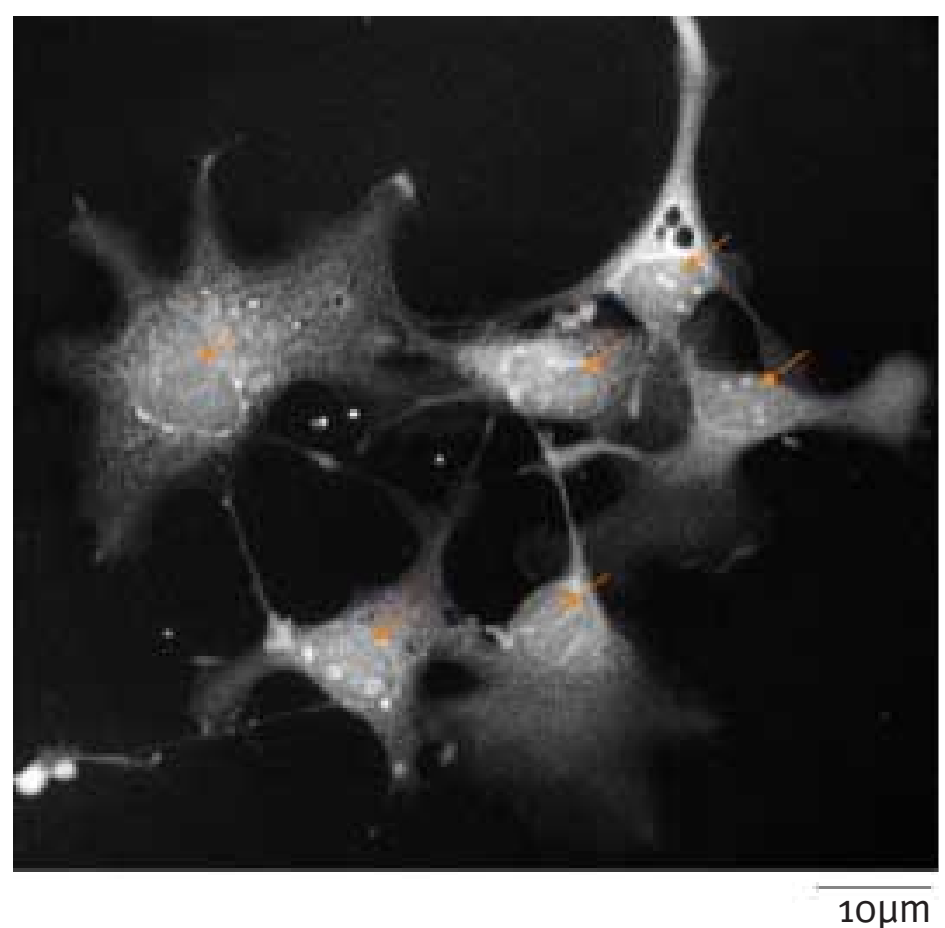

\footnotetext{
Abb. 13: Cytoplasmatische und nukleäre Lokalisation des EGFP

CLSM-Aufnahmen von COS-7-Zellen nach Transfektion mit pEGFP-N1. Es fluoreszierten Cytoplasma, Zellkern und perinukleäre Strukturen. Die Pfeile zeigen die Zellkerne. Anregung und Beobachtung erfolgte bei allen weiteren CLSM-Aufnahmen, sofern nicht anderes angegeben, mit $488 \mathrm{~nm}$ und einem 510 - 520 nm Bandpassfilter.
} 


\subsection{2 $\mathrm{Ca}^{2+}$-ATPase-EGFP-Fusionsproteine in COS-7 Zellen}

Die drei rekombinanten Vektoren M1-Ca ${ }^{2+}-E G F P, ~ M 2-\mathrm{Ca}^{2+}$-EGFP, M3-Ca ${ }^{2+}$-EGFP wurden ebenfalls mittels Liposomentransfektion in COS-7-Zellen eingeschleust. $24 \mathrm{~h}$ nach der Transfektion wurde eine Expression aller drei Fusionsproteine unter Kontrolle des CMV-Promotors in COS-7-Zellen festgestellt. Während mit EGFP Transfektionsraten von $30 \%$ erreicht wurden, lagen sie bei den ATPase-Fusionsvektoren nur bei durchschnittlich $10 \%$.

Im Fluoreszenzmikroskop sah man eine verstärkte Fluoreszenz bei allen drei Fusionsproteinen in netzartigen Strukturen innerhalb des Cytoplasmas und im perinukleären Bereich (Abb. 14). Die Fluoreszenz im Zellkern war im Vergleich zu den mit pEGFP-N1 transfizierten Zellen geringer.

Konfokale Untersuchungen erbrachten weitere Details zur subzellulären Verteilung der Proteine. Während im Weitfeld-Fluoreszenzmikroskop ein Auffinden der Fusionsproteine im Zellkern nicht eindeutig ausgeschlossen werden konnte (Abb. 14 a, C, e), machten konfokale Betrachtungen deutlich, daß keine Kernfluoreszenz vorhanden war. Die Konzentrierung des Fluoreszenzsignals im kernnahen ER-Bereich und der Kernmembran sowie die Ausdehnung netzartiger Strukturen bis zur Peripherie der Zelle ohne definierte Zellgrenzen, sind ein typisches Fluoreszenzmuster für Proteine des Endoplasmatischen Retikulums (FOLETTI et al. 1995). Durch die starke Fluoreszenz im kernnahen Bereich der COS-7-Zellen konnte auch bei konfokaler Betrachtung eine Akkumulation der Fusionsproteine in anderen kernnahen Zellorganellen, besonders dem Golgi-Apparat, nicht ausgeschlossen werden. Da bei diesen Konstrukten keine Fluoreszenz im Cytoplasma und dem Zellkern erkennbar war, die auf Expression des nativen EGFP schließen läßt, ist anzunehmen, daß bei durchgehender Translation der Fusionsgene das ATG des EGFP nicht als zusätzlicher Translationsstart fungiert. 

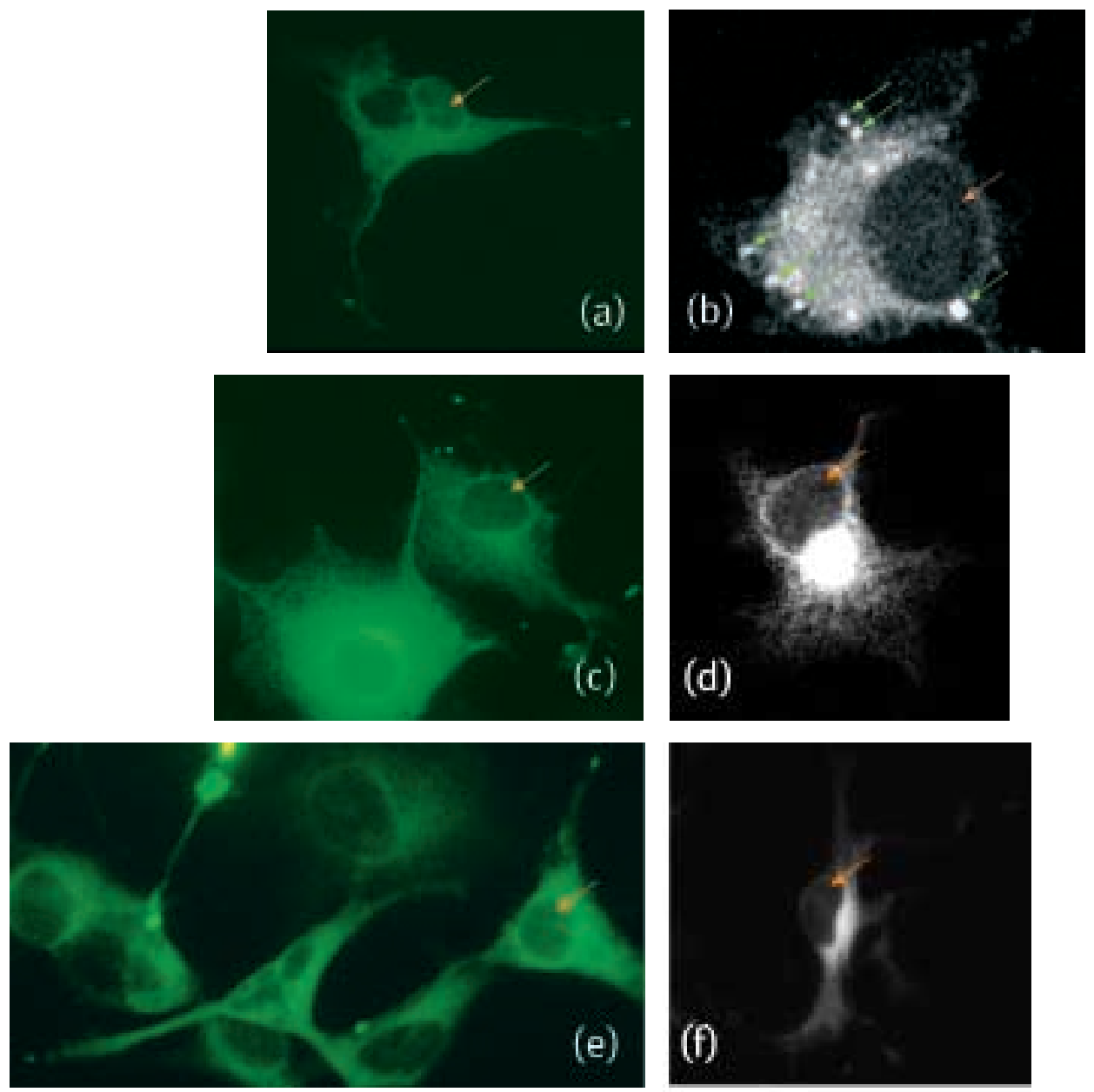

$25 \mu \mathrm{m}$

Abb. 14: Lokalisation der Ca ${ }^{2+}$-ATPase-EGFP-Fusionsproteine in COS-7 Zellen $24 \mathrm{~h}$ nach Liposomentransfektion der rekombinanten Fusionsvektoren M1-Ca ${ }^{2+}-E G F P(a),(b)$, M2-Ca ${ }^{2+}-E G F P(c),(d), M 3-C a^{2+}-E G F P(e)$, (f) konnte unter dem Weitfeld-Fluoreszenzmikroskop (a), (c), (e) und CLSM (b), (d), (f) eine Expression der EGFP-Fusionsproteine festgestellt werden. Die Aufnahmen zeigen, daß die netzartigen Strukturen des ER fluoreszieren. Verstärkte Fluoreszenz tritt zudem im perinukleären Bereich auf. Grüne Pfeile zeigen auf Proteinakkumulationen, die nach Transfektion mit M1-Ca ${ }^{2+}$-EGFP auftraten (b). Anregung und Beobachtung der EGFP-Fusionsproteine erfolgte im Weitfeld-Fluoreszenzmikroskop mit dem FITC-Filtersatz. Orangefarbene Pfeile zeigen auf die Zellkerne.

Im CLSM konnte in $5-20 \%$ aller COS-7-Zellen, in denen $\mathrm{Ca}^{2+}$-ATPase-EGFP-Fusionsproteinen exprimiert wurden, größere Ansammlungen fluoreszierender punktförmiger Strukturen (Abb. 15) beobachtet werden. Diese zeigten das gleiche Anregungs- und Emissionsspektrum wie GFP und waren im Weitfeld-Fluoreszenzmikroskop nicht erkennbar. Es ist anzunehmen, daß es sich bei diesen Strukturen um akkumulierte Fusionsproteine handelt. Während die Summe der COS-7-Zellen mit fluoreszierenden Partikeln nach Expression von M3-Ca ${ }^{2+}-$ EGFP nur bei $5 \%$ lag und die Anzahl der Partikel innerhalb der Zellen gering war, konnte nach Expression von M1-Ca ${ }^{2+}$-EGFP und 
M2-Ca ${ }^{2+}$-EGFP in $20 \%$ der transfizierten Zellen ein verstärktes Auftreten von punktförmigen Strukturen beobachtet werden (Abb. 15). So war bei den $20 \%$ mit M1- $\mathrm{Ca}^{2+}-$ EGFP transfizierten Zellen fast das gesamte exprimierte Protein in Proteinakkumulationen um den Zellkern abgelagert (Abb. 15 a, b). Bei M2-Ca²+EGFP fluoreszierten hingegen neben den hauptsächlich perinukleären Proteinakkumulationen auch noch subzelluläre Strukturen (Abb. 14 c, d).
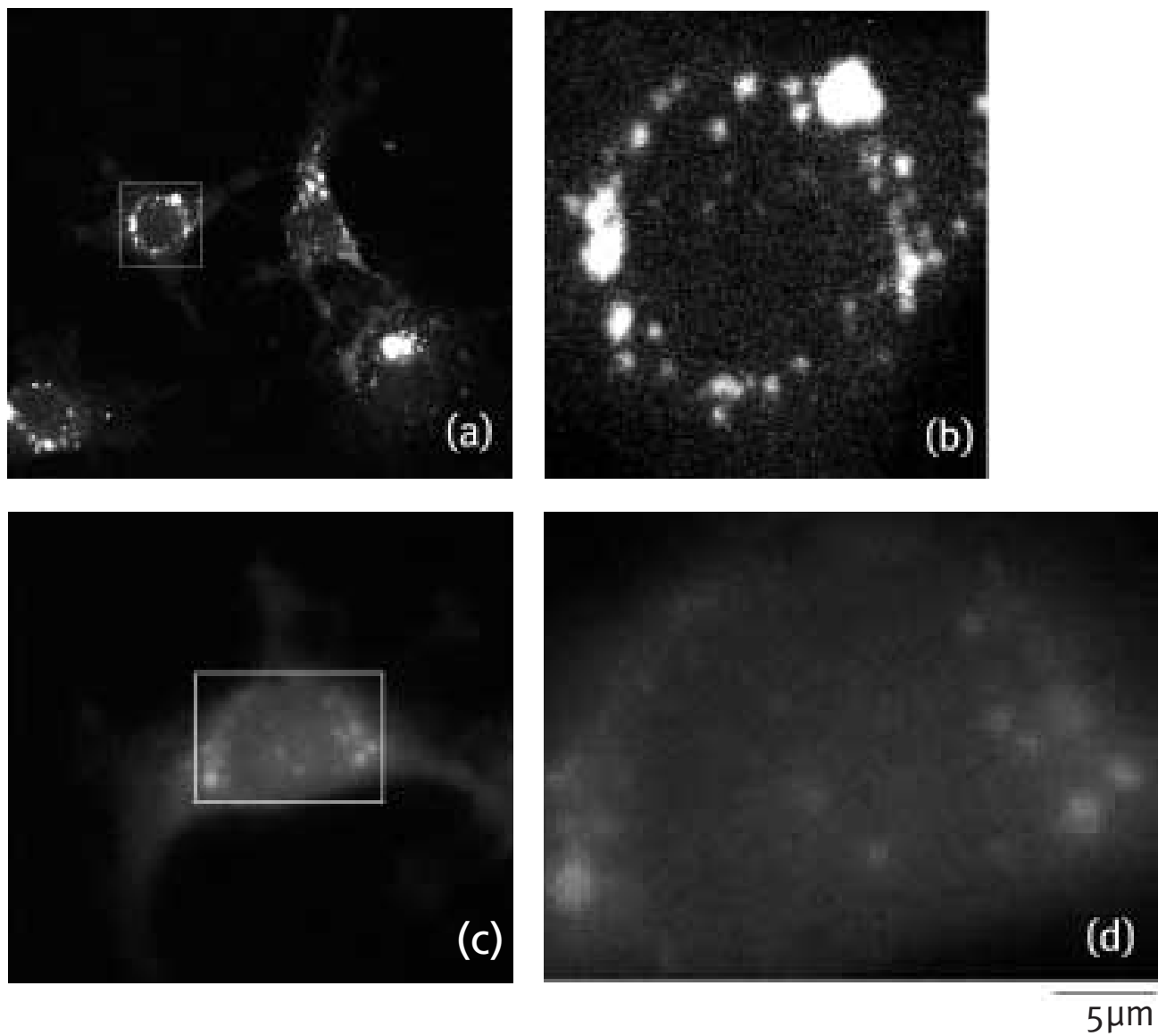

\section{Abb. 15: Proteinakkumulation bei M1-Ca ${ }^{2+}-E G F P$ und $M 2-\mathrm{Ca}^{2+}-E G F P$ im Cytoplasma von COS-7-Zellen}

CLSM-Aufnahme von mit M1-Ca ${ }^{2+}$-EGFP und M2-Ca ${ }^{2+}$-EGFP transfizierten COS-7-Zellen mit punktförmigen Strukturen. Während das Fusionsprotein M1-Ca ${ }^{2+}$-EGFP bei diesen Zellen fast ausschließlich in Proteinakkumulationen vorkam (a), (b) fluoreszierten nach Expression von M2-Ca ${ }^{2+}$-EGFP sowohl Proteinakkumulationen als auch subzelluläre Strukturen (c), (d). (b) und (d) zeigen vergrößerte Ausschnitte der Zellkerne mit verstärktem Vorkommen der Proteinakkumulationen in perinukleären Strukturen von (a) und (c). 


\subsubsection{Lokalisation der Fusionsproteine M1- $\mathrm{H}^{+}$-EGFP und $\mathrm{M} 2-\mathrm{H}^{+}$-EGFP im ER von COS-7-Zellen}

Zur Lokalisationsbestimmung der $\mathrm{H}^{+}$-ATPase wurden die Vektoren $\mathrm{M1}-\mathrm{H}^{+}$-EGFP und M2- $\mathrm{H}^{+}$-EGFP ebenfalls in COS-7-Zellen transfiziert. Sie enthielten als Fusionsgene den $\mathrm{N}$-Terminus und die ersten beiden Transmembransegmente der vermutlich plasmamembranständigen $\mathrm{H}^{+}$-ATPase aus Dunaliella bioculata, verknüpft mit dem Reportergen EGFP.

$24 \mathrm{~h}$ nach Liposomentransfektion der Fusionsvektoren wurde bei beiden Konstrukten unter Kontrolle des CMV-Promotors eine Expression festgestellt. Während die Lokalisation der Fusionsproteine nach Betrachtung im Weitfeld-Fluoreszenzmikroskop nicht eindeutig zu bestimmen war (Abb. 16 a, c), legten auch bei diesen Konstrukten erst CLSM Aufnahmen nähere Einzelheiten über die Proteinverteilung in den Zellen offen. Wie nach Expression der $\mathrm{Ca}^{2+}$-ATPase-EGFP-Fusionsproteine, trat die Fluoreszenz verstärkt in perinukleären Bereichen sowie in netzartigen Strukturen auf, die bis in die Peripherie der Zelle reichten. Dieses typische Fluoreszenzmuster zeigte, daß sich beide Fusionsproteine im Endoplasmatischen Retikulum befanden. Eine Lokalisation in der Plasmamembran der COS-7-Zellen konnte nicht festgestellt werden. Die Fluoreszenz im Zellkern war wie nach Expression der $\mathrm{Ca}^{2+}$-ATPase-EGFP-Fusionsproteine sehr gering. Unterschiede in der Translationseffizienz beider Konstrukte im Hinblick auf die Translationsstartcodons wurden optisch nicht festgestellt. Proteinakkumulationen wie nach Expression der Fusionsproteine M1-Ca ${ }^{2+}-E G F P$,

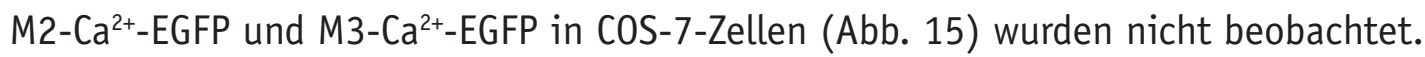



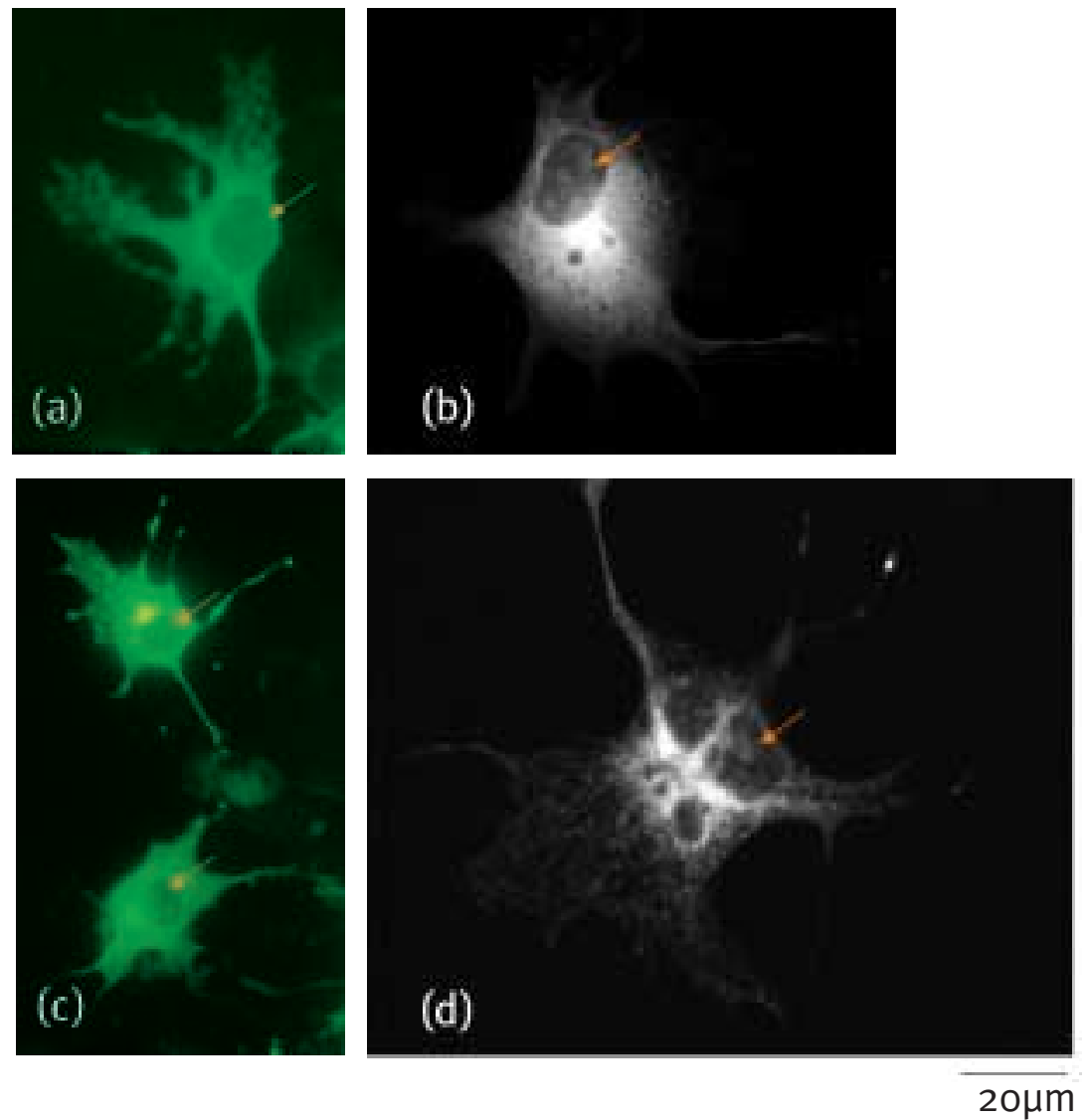

Abb. 16: Lokalisation von M1-H+-EGFP und M2-H ${ }^{+}$-EGFP im ER von COS-7-Zellen $24 \mathrm{~h}$ nach Liposomentransfektion der rekombinanten Expressionsvektoren M1- $\mathrm{H}^{+}$-EGFP (a), (b) und M2- $\mathrm{H}^{+}$-EGFP (c), (d) konnte die Lokalisation von beiden Fusionsproteinen im ER ausgemacht werden. Eine Proteinlokalisation im Zellkern konnte im Weitfeld-Fluoreszenzmikroskop nicht (a), (c), aber im CLSM ausgeschlossen werden (b), (c). Zellkerne sind durch orange Pfeile gekennzeichnet. Die Aufnahmen mit dem Weitfeld-Fluoreszenzmikroskop erfolgten mit einem FITC-Filtersatz.

\subsubsection{Quantitative Bestimmung der Fluoreszenzverteilung und Expressionsrate von EGFP und der Fusionsproteine in COS-7-Zellen}

Für eine Quantifizierung der Proteinverteilung und Expressionsrate der transfizierten Zellen wurden Intensitätsmessungen an den digitalen CLSM-Bilddaten durchgeführt. Jedes angeregte GFP-Molekül sendet eine bestimmte Lichtquantenmenge $(0,72-0,85)$ aus (STEIPE \& SKERRA 1997). Werden alle zu untersuchenden Zellen mit der gleichen Wellenlänge angeregt, besteht somit zwischen der Proteinmenge und der Lichtintensität eine lineare Korrelation. Die Stichprobe für jedes Fusionsprotein bestand aus je 10 COS-7-Zellen der verschiedenen Wiederholungsversuche. Die Intensitätsmessungen der Fluoreszenzverteilung im Cytoplasma und im Zellkern wurde für alle Zellen nach einem definierten Schema durchgeführt (Abb. 17). 


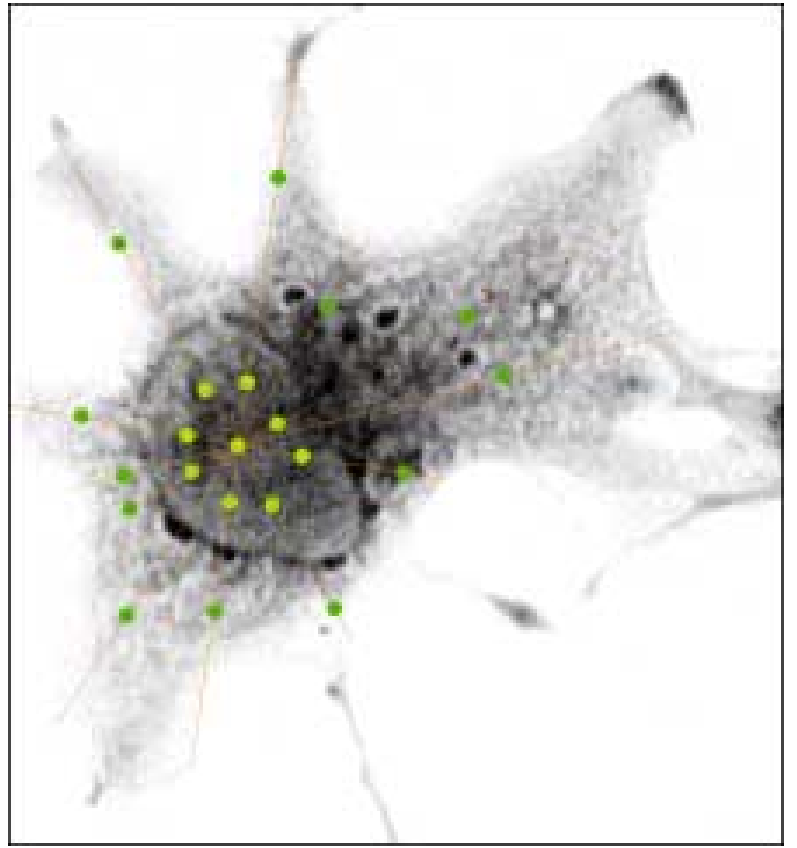

Abb. 17:

Schema der Meßpunkteverteilung Vom Mittelpunkt des Zellkerns ausgehend wurden 12 Geraden durch die Zelle bis zur Plasmamembran gelegt. Die Intensität im Zellkern (hellgrüne Punkte) wurde an 9 Meßpunkten bestimmt. Acht Meßpunkte lagen auf den Linien jeweils in der Mitte zwischen Kernmittelpunkt und Kernmembran, einer lag im Mittelpunkt. Die Fluoreszenzintensität im Cytoplasma (dunkelgrüne Punkte) wurde an 12 Punkten bestimmt, die jeweils auf der Hälfte der Geraden zwischen Kernmembran und Plasmamembran lagen. Die Bestimmung erfolgte mit dem Programm NIH-Image 1.61.

Aus den Meßwerten für Zellkern und Cytoplasma wurden für jede Zelle die Mittelwerte berechnet. Um Intensitätsunterschiede aufzudecken, die auf eine Ungleichverteilung des GFP zwischen Zellkern und Cytoplasma schließen lassen, wurden die Mittelwerte von Cytoplasma und Zellkern ins Verhältnis gesetzt. Damit wurden gleichzeitig die unterschiedlichen Helligkeitsintensitäten und Kontrasteinstellungen der verschiedenen CLSM-Aufnahmen standardisiert. Von allen Werten einer Stichprobe wurden Mittelwert und Standardabweichung ermittelt (Abb. 18).

Es zeigte sich, daß das Intensitätsverhältnis Cytoplasma/Zellkern bei Expression des EGFP in COS-7-Zellen <1 war. Das native EGFP ist somit sowohl im Zellkern als auch im Cytoplasma lokalisiert.

Anders bei der Expression der Fusionsproteine: Die Intensität der exprimierten Proteine war im Cytoplasma wesentlich größer als im Zellkern und die gemessenen Werte der Intensität des Zellkerns waren oft mit denen des Außenmediums identisch. Daraus kann geschlossen werden, daß keine oder nur eine sehr geringe Akkumulation der Fusionsproteine im Zellkern stattgefunden hat.

Bei den Proteinen M1-Ca ${ }^{2+}$-EGFP, M2-Ca ${ }^{2+}$-EGFP und M3-Ca ${ }^{2+}$-EGFP nahm mit Verkürzung des N-Terminus die relative Fluoreszenz im Cytoplasma zu. So war bei M3-Ca ${ }^{2+}$-EGFP eine $25 \%$ höhere Expressionsrate gegenüber M1-Ca ${ }^{2+}$-EGFP festzustellen. Von M1-Ca ${ }^{2+}-$ EGFP zu M2-Ca ${ }^{2+}-E G F P$ nahm sie um $18 \%$ zu. Die Zunahme der Expressionsrate zeigte sich auch bei $\mathrm{M} 1-\mathrm{H}^{+}$-EGFP und $\mathrm{M} 2-\mathrm{H}^{+}$-EGFP. Hier lagen die Unterschiede zwischen beiden Fusionsproteinen bei $40 \%$, bei jedoch sehr hoher Standardabweichung. 
Aus dem Versuch einer quantitativen Auswertung der Expressionsdaten läßt sich daher annehmen, daß die Startcodons an Position 96 - 98 und 117 - 119 der Nukleinsäuresequenzen von DBCA1 und an Position 72 - 74 von DBPMA1, scheinbar bessere Translationsinitiationsstellen darstellen, als das jeweils erste ATG am N-Terminus in $5^{\prime} \rightarrow 3^{\prime}$-Richtung.

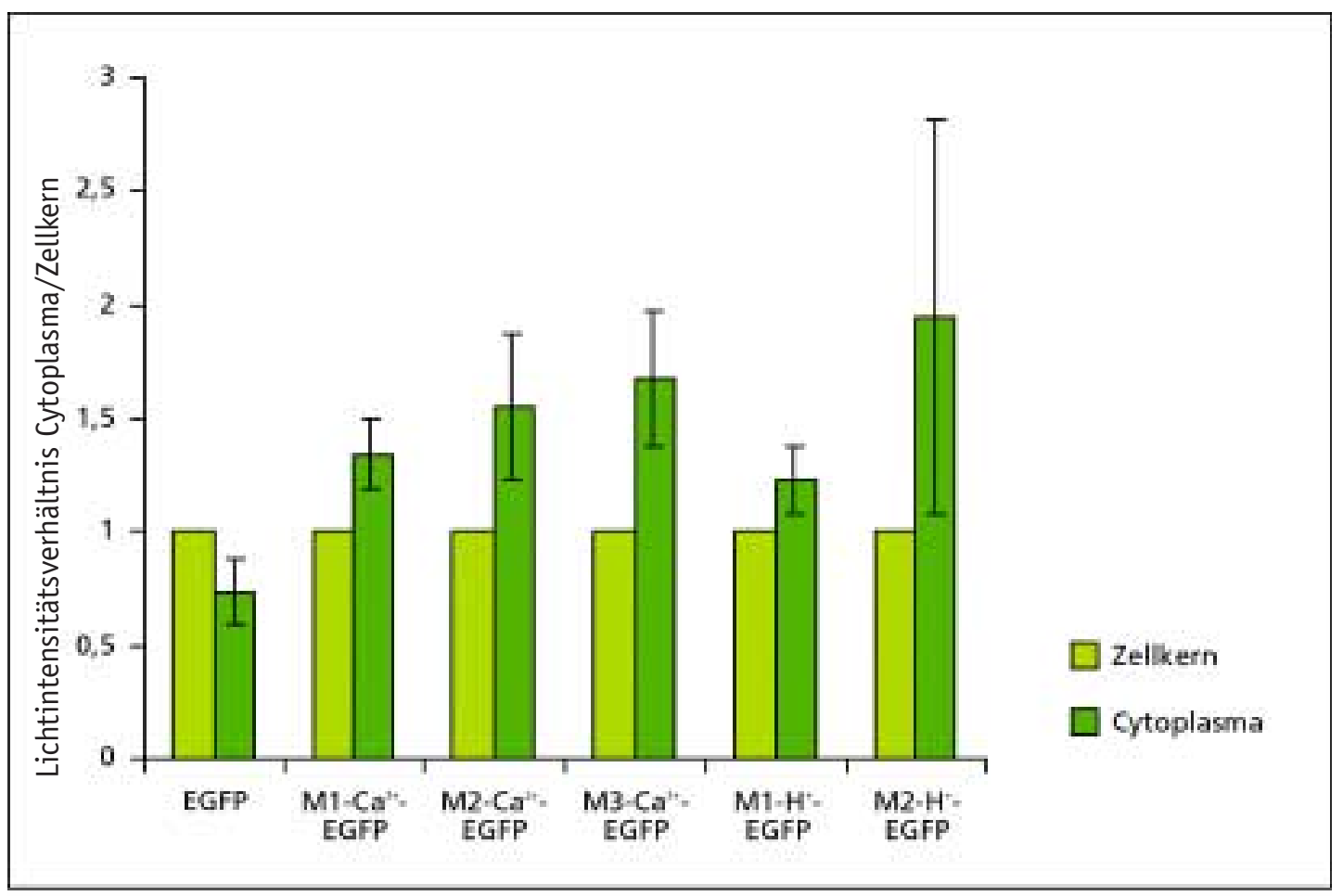

\section{Abb. 18: Statistische Verteilung der kompartimentspezifischen Fluoreszenz- intensität in COS-7-Zellen}

In einer Stichprobe von jeweils 10 transfizierten COS-7-Zellen wurde jeweils der Mittelwert des Lichtintensitätsverhältnisses Cytoplasma/Zellkern (dunkelgrün) errechnet und gegen den auf 1 normierten Wert für die Intensität des Zellkerns (hellgrün) aufgetragen. Die Standardabweichungen der errechneten Mittelwerte sind durch Meßbalken gekennzeichnet.

\subsubsection{Kozak-Mutante in COS-7-Zellen}

Eines der sequenzierten rekombinanten $\mathrm{M} 1-\mathrm{Ca}^{2+}$-EGFP Plasmide enthielt eine Punktmutation in der Consensus-Sequenz. Anstelle der durch Primer zusätzlich vor dem jeweils ersten ATG der Fusionsgene angefügten und auf Säugetierzellen abgestimmten Consensus-Sequenz CACC trat bei diesen Plasmid die Sequenzabfolge CCCC auf. Diese Mutante wurde benutzt, um den möglichen Einfluß der tierischen ConsensusSequenz auf die Translationseffizienz abzuschätzen. 
Dieser Klon wurde wie die anderen Fusionsvektoren mittels Liposomentransfektion in COS-7-Zellen transfiziert. Nach 24-stündiger Inkubationszeit wurden die Zellen im konfokalen Fluoreszenzmikroskop untersucht. Sie zeigten das gleiche Fluoreszenzmuster wie das der Fusionsproteine M1-Ca ${ }^{2+}-E G F P, ~ M 2-C a^{2+}-E G F P$ und M3-Ca ${ }^{2+}-E G F P$. Die netzartigen Strukturen des ER waren deutlich erkennbar. Im Gegensatz zu M1-Ca ${ }^{2+}$-EGFP war eine starke Akkumulation der Fusionsproteine in Einschlußkörpern bei veränderter Consensus-Sequenz nicht feststellbar. Auffällig war jedoch die starke Lichtemission des Fusionsproteins, vor allem in den perinukleären Bereichen, was auf eine erhöhte Translation des Proteins deuten könnte (Abb. 19).

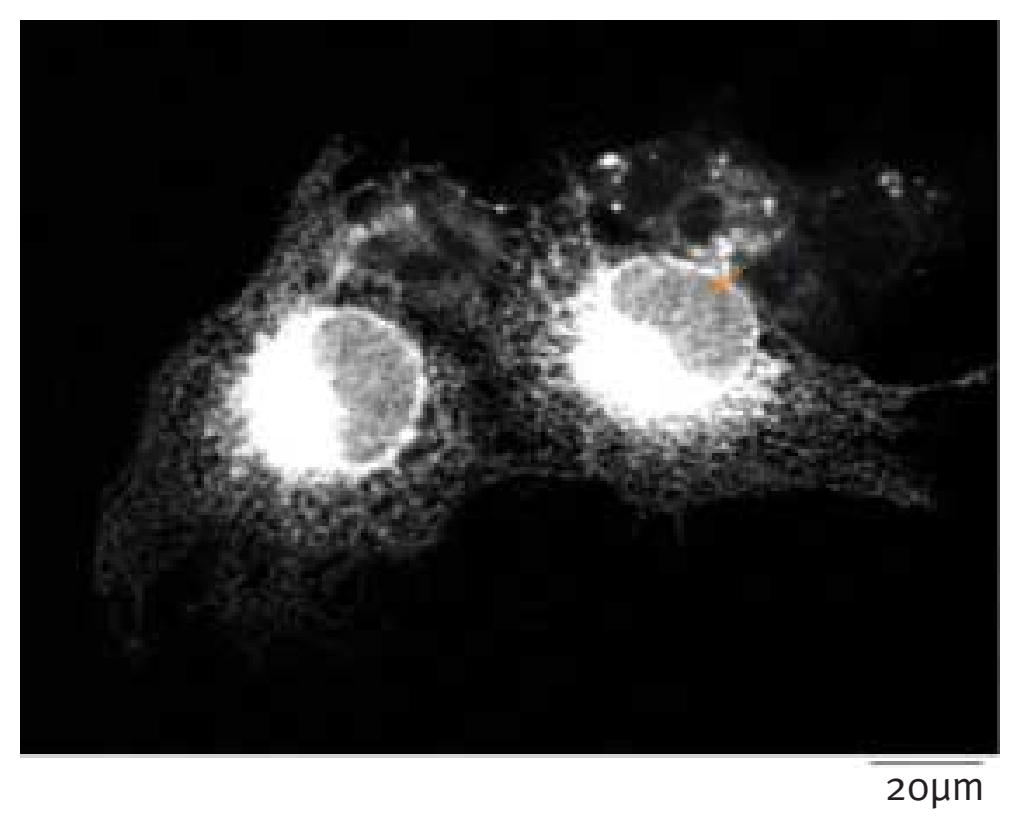

\section{Abb. 19: M1-Ca ${ }^{2+}-E G F P$ mit veränderter Kozak Consensus-Sequenz}

CLSM-Aufnahme $24 \mathrm{~h}$ nach Transfektion. Auf den Zellkern wird durch den Pfeil verwiesen. Anregung mit 488 nm, Beobachtung mit 510 - 520 nm Bandpassfilter.

Die Quantifizierung der mit dieser Mutante transfizierten COS-7-Zellen erfolgte nach demselben Schema, wie in Kapitel 3.5.4 beschrieben. Um Unterschiede in der Translationseffizienz aufzudecken, wurden die errechneten Werte für die M1-Ca ${ }^{2+}-E G F P-K o z a k-M u t a n t e ~ d e n e n ~ v o n ~ M 1-C a{ }^{2+}-E G F P$ gegenübergestellt (Abb. 20).

Der Vergleich beider Fusionsproteine zeigt eine um $60 \%$ gestiegene relative Lichtintensität im Cytoplasma von M1-Ca²+EGFP-Kozak-Mutante transfizierten COS-7Zellen. Die Steigerung der Translationseffizienz ist vermutlich auf den veränderten Translationsinitiationsbereich zurückzuführen. 


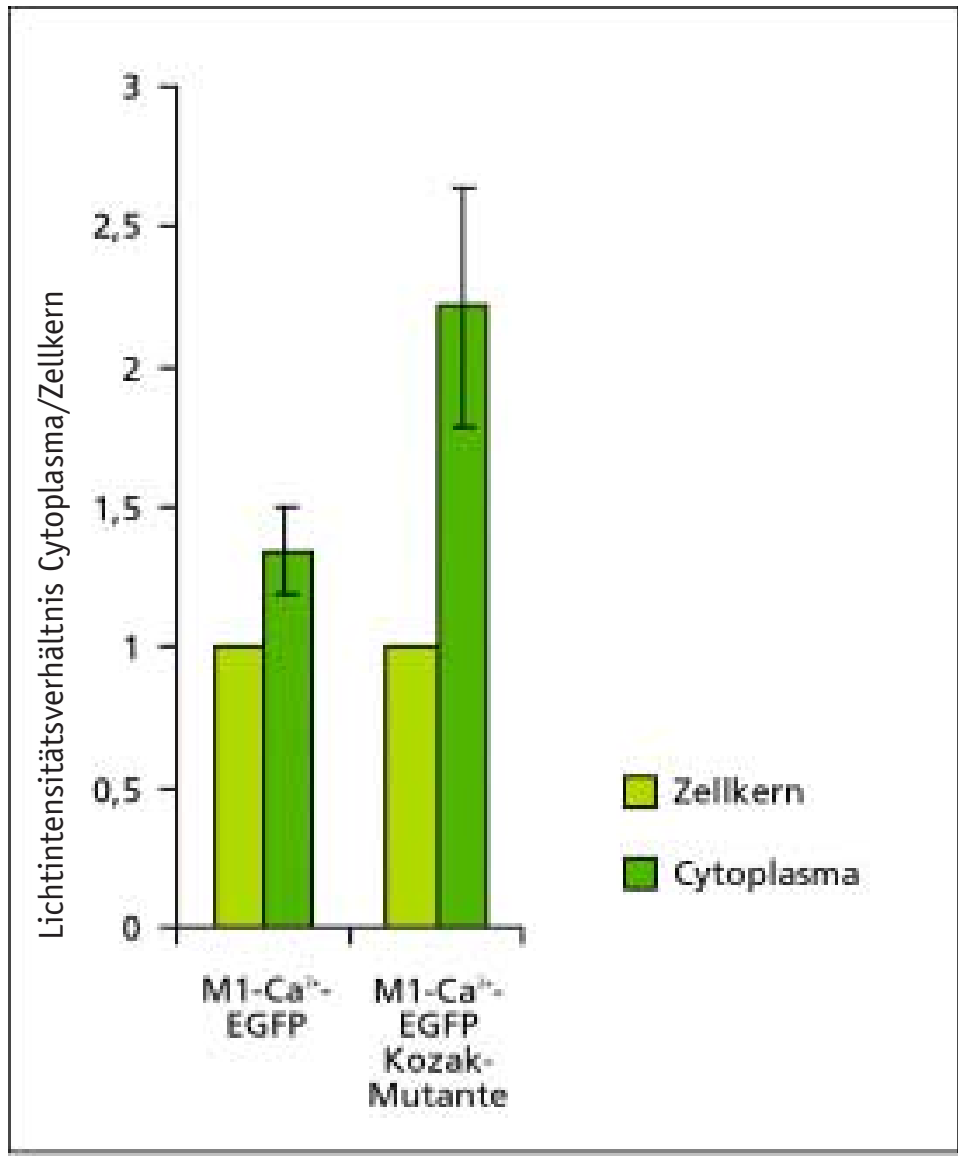

Abb. 20: Statistische Verteilung der kompartimentspezifischen Fluoreszenz-

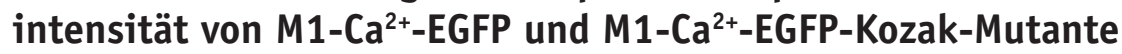

Die Werte zur Berechnung der Intensitätsverteilung wurden nach dem gleichen Schema ermittelt wie in Abb. 17 beschrieben und wie in 3.5.4 beschrieben errechnet. Der Unterschied in der Expressionsrate der beiden Fusionsgene M1-Ca ${ }^{2+}$-EGFP und M1-Ca ${ }^{2+}$-EGFP-Kozak-Mutante beträgt $60 \%$. 


\section{Diskussion}

Ziel der Arbeit war, die subzelluläre Lokalisation der beiden P-Typ ATPasen DBCA1 und DBPMA1 aus der Grünalge Dunaliella bioculata fluoreszenzoptisch zu bestimmen. Dabei sollte untersucht werden, ob N-terminale Sequenzbereiche der ATPasen ausreichen, das Protein-Targeting der ATPasen zu vermitteln.

Bisher wurde aufgrund von Sequenzvergleichen mit molekularbiologisch und immunocytologisch charakterisierten P-Typ $\mathrm{Ca}^{2+}$-ATPasen für DBCA1 eine Lokalisation in der Membran des ER angenommen. Die Lokalisation von DBPMA1 in der Plasmamembran gilt aufgrund der großen Sequenzhomologie zur plasmamembranständigen $\mathrm{H}^{+}$-ATPase aus Dunaliella acidophila als gesichert. So kann die Expression der $\mathrm{H}^{+}$-ATPase-GFP-Fusionsproteine als interner Standard zur Kontrolle der Versuchseffizienz gewertet werden.

Die ersten beiden Transmembransegmente der beiden ATPasen wurden mit GFP markiert und ihre lokale Expression in heterologen Expressionssystemen untersucht. Während nach Transfektion von Tabak-Protoplasten keine Expression der Fusionsproteine sichtbar war, waren in tierischen Zellen sowohl die $\mathrm{H}^{+}-$als auch die $\mathrm{Ca}^{2+}$-ATPase-GFP-Fusionsproteine im ER lokalisiert.

\subsection{Expression der ATPase-GFP-Fusionsproteine in Tabak-Protoplasten}

Dunaliella bioculata gehört zu den halophilen einzelligen Grünalgen. Aus ihr wurden die beiden P-Typ ATPasen DBCA1 und DBPMA1 molekularbiologisch charakterisiert (RASCHKE 1996, WOLF 1993).

Ausführliche Versuche, Dunaliella als pflanzliches Expressionssystem in unserem Labor zu etablieren, scheiterten (B. EBERT, persönliche Mitteilung). Die Versuche zur Lokalisation der ATPasen wurden daher in Tabak-Protoplasten, einem etablierten pflanzlichen Expressionssystem, durchgeführt.

Während nach Transfektion der Tabak-Protoplasten mit nativen sGFP-S65T unter Kontrolle des chimären HBT-Promotors eine Expression sichtbar war, konnte unter Kontrolle des gleichen Promotors bei keinem der $\mathrm{H}^{+}$- und $\mathrm{Ca}^{2+}$-sGFP-S65T-Fusionsproteine eine Expression in Tabak-Protoplasten festgestellt werden. Die Gründe für eine fehlende Fluoreszenz können vielfältig sein. Als mögliche Ursachen für die fehlende Fluoreszenz werden diskutiert:

- Konstruktion der Fusionsvektoren

- Unterbindung Translations aufgrund unterschiedlicher Codon-Präferenzen

- Aggregation der Fusionsproteine

- Proteinabbau durch Fehlfaltung der Fusionsproteine 


\subsubsection{Konstruktion der Fusionsvektoren}

Die Verwendung des Reporterproteins GFP in tierischen Zellen und höheren Pflanzen wurde anfangs durch ineffiziente Expression, geringe Fluoreszenz und eine langsame Chromophor-Bildung limitiert (CORMACK et al. 1996, Heim et al. 1994, HASELOFF \& AMOS 1995; HU \& CHENG 1995; REICHEL et al. 1996; SHEEN et al. 1995).

Die Verwendung universeller Transkriptions- und Translationsverstärker in Verbindung mit starken Promotoren und eine Anpassung der GFP-Sequenz (CHIU et al. 1996; PANG et al. 1996; REICHEL et al. 1996) an die Codon-Präferenz pflanzlicher und tierischer Systeme führt in der Regel zu höheren Expressionsraten (SHEEN et al. 1995, GALBRAITH et al. 1995, HASELOFF \& SIEMERING 1998).

Das in der vorliegenden Arbeit für die Transfektion in Tabak eingesetzte sGFP-S65T stellte bereits eine optimierte GFP-Variante dar. sGFP-S65T ist eine GFP-Variante mit einer für menschliche Gene optimierten Codon-Präferenz, die in Pflanzenzellen gute Expressionsergebnisse zeigte (CHIU et al. 1996, SHEEN et al. 1995). Ein potentielles kryptisches pflanzliches Intron (HASELOFF et al. 1997), das zum Spleißen der mRNA in Pflanzen führte, wurde durch Basenaustausch eliminiert.

Transfektionsraten von mehr als $80 \%$ wurden nach PEG-Transfektion des sGFP-S65T unter Kontrolle des starken HBT-Promotors in Tabak-Protoplasten erreicht (CHIU et al. 1996).

Da die Positivkontrollen eine Expression des sGFP-S65T unter Kontrolle des HBT-Promotors zeigten, ist auszuschließen, daß die fehlende Expression der ATPase-GFPFusionsproteine in Tabak-Protoplasten im Zusammenhang mit einem zu schwachen Promotor und einer nicht optimalen GFP-Variante steht.

\subsubsection{Unterbindung der Translation}

Bereits auf der Ebene der Translation könnte die Proteinsynthese der Fusionsproteine unterbunden worden sein. Die Effektivität der Translation in heterologen Expressionssystemen hängt unter anderem stark von der Codon-Präferenz (codon bias) ab (CHIAPELLO et al. 1998, BATARD et al. 2000). Es gibt Hinweise, daß geringfügige Abweichungen in der Codon Präferenz bei heterologer Expression von Genen zu Leserasterverschiebungen, Fehlablesungen und verfrühter Termination der Translation führen können (KANE 1995, KURLAND \& GALLANT 1996).

Für kerncodierte Gene aus Dunaliella (LAROCHE et al. 1990) und anderen einzelligen Grünalgen (SIFLOW et al. 1985, GOLDSCHMIDT-CLERMONT \& RAHIRE 1986, IMBAULT et al. 1988, LONG et al. 1989, WOLF et al. 1993) ist eine Präferenz für Tripletts zu beobachten, die in der dritten Position ein C oder G besitzen. Diese Präferenz zeigen auch die beiden ATPase-Gene von DBPMA1 (WOLF 1993) und DBCA1. In Hefen und dikotylen Pflanzen wie Tabak werden bevorzugt Codons verwendet, die an dritter Stelle mit T enden. Auch besitzen die Nukleinsäure-Sequenzen aus Tabak in der Regel einen geringeren GC-Gehalt als die aus Grünalgen. 
BATARD et al. (2000) haben nach Expression von P450 Enzymen, die einen hohen GC-Gehalt aufweisen, zwar die Transkription des Gens, nicht aber das Protein in Tabak und Hefe nachweisen können. Erst nach Anpassung der Codon-Präferenz an dikotyle Pflanzen im 5'-Bereich der Gene, konnte ein deutlicher Ansteig der Proteinsynthese in Tabak und Hefe beobachtet werden.

In der vorliegenden Arbeit wurden die ATPase-GFP-Fusionsgene unter Beibehaltung des natürlichen Basenkontext der möglichen Startcodons der ATPasen in Tabak-Protoplasten transfiziert. Dunaliella zeigt weder bei DBCA1 noch bei DBPMA1 in den Basen in unmittelbarer Nähe der möglichen ATG-Tripletts eine Übereinstimmung mit der für Pflanzen postulierten Consensus-Sequenz (LÜTCKE 1987). Das läßt auch vermuten, daß Grünalgen möglicherweise eine andere Consensus-Sequenz besitzen als höhere Pflanzen.

Unterschiede in der Codon-Präferenz von Tabak und Dunaliella und ein nicht optimaler Basenkontext der Translationsinitiationsstartstelle könnten daher eine Erklärung für die fehlende Expression der ATPase-GFP-Fusionsproteine in Tabak-Protoplasten sein.

\subsubsection{Aggregation der ATPase-GFP-Fusionsproteine}

Die Bildung nicht-fluoreszierender Einschlußkörper durch Aggregation der Fusionsproteine in Tabak-Protoplasten kann als weiterer Grund für eine fehlende Fluoreszenz der Fusionsproteine in Frage kommen. Einschlußkörper sind intrazelluläre, unlösliche Protein-Aggregationen aus biologisch inaktiven und wahrscheinlich nicht korrekt gefalteten Proteinen. Sie werden bei der Expression von rekombinanten Proteinen in heterologen Systemen häufig beobachtet und werden auch bei GFP-Chimären als Grund für eine geringe Fluoreszenzintensität bis zur vollständigen Unterbindung der Fluoreszenz angeführt (HEIM 1994, CRAMERI et al. 1996). SIEMERING et al. (1996) haben für GFP auch eine temperaturabhängige Faltung des Apoproteins analysiert, die dazu führt, daß der größte Teil des GFP bei einer Inkubationstemperatur von $37^{\circ} \mathrm{C}$ als nicht fluoreszierendes Protein in unlöslichen Zellfraktionen zu finden ist. Die Unterbindung der Fluoreszenz durch Fehlfaltungen der Apoproteine bei hohen Inkubationstemperaturen (SIMERING et al. 1996) kann weitestgehend ausgeschlossen werden, da die Inkubationstemperaturen der Tabak-Protoplasten nicht über $25^{\circ} \mathrm{C}$ lag.

Über 10.000 Moleküle GFP-S65T oder EGFP sind erforderlich, um GFP in Laser Scanning Mikroskop (CLSM) zu detektieren (PATTERSON et al. 1997). Das Chromophor ist kovalent mit dem GFP verbunden. Die Tripeptidsequenz des Chromophors wird durch Zyklisierung und 0xidation durch eine post-translationale Modifikation innerhalb der Polypeptidkette geformt (CUBITT et al. 1995, HEIM et al. 1994, ORM0 et al. 1996, PRASHER 1995). Eine nicht ausreichende Molekülmenge richtig gefalteter grün fluoreszierender (Fusions-) Proteine kann daher als Ursache für eine nicht sichtbare 
Expression der ATPase-GFP-Fusionsproteine im Mikroskop in Frage kommen. Die Bildung des reversiblen, autokatalytischen Chromophors und damit dessen Lichtemission wird unterbunden, wenn die Zyklisierung nicht vor der Aggregation erfolgt. Besonders transient exprimiertes Membran-assoziertes GFP begünstigt die Multimerisation der Fusionsproteine (CUBITT et al. 1995; DE ANGELIS et al. 1998). Es ist daher möglich, daß die Fusionsgene zwar translatiert wurden, die Expression aber fluoreszenzoptisch nicht nachgewiesen werden konnte, da eine Coagulation von Membranproteinen oder Fehlfaltungen der ATPase-GFP-Fusionsproteine zu einer Aggregation führten.

\subsubsection{Proteinabbau}

Fehlende Fluoreszenz nach Transfektion der jeweils ersten beiden GFP-markierten Transmembransegmente in Tabak-Protoplasten kann jedoch auch durch einen Abbau der Fusionsproteine bedingt sein.

Die erste klonierte plasmamembranständige $\mathrm{Ca}^{2+}$-ATPase At-ACA8 (BONZA et al. 2000) wurde GFP-markiert und in Arabidopsis stabil exprimiert. Obwohl die transgenen Pflanzen auf Ampicillin selektierbar waren, konnte die Expression der GFPmarkierten ATPase weder fluoreszenzmikroskopisch noch immunocytologisch nachgewiesen werden (C. OLIVARI, persönliche Mitteilung). PLEMPER et al. (1998) zeigten in Hefe, daß der plasmamembranständige ABC-Transporter Pdr5, der nach Mutation in die ER-Membran inseriert wird, vermutlich mit Hilfe eines Translokons aus der Membran extrahiert wird und anschließend im cytoplasmatischen Ubiquitin-Proteasomen-System abgebaut wird. Ebenso der $\mathrm{Cl}^{-}$-Translokator CFTR der Epithelien; der Verlust des Phenylalanins in Position 508 der Polypeptidkette unterbindet die korrekte Faltung des Proteins im ER und führt dazu, daß kein CFTR in der Plasmamembran erscheint. Statt dessen wird es über den ER-assoziierten Proteasomenweg abgebaut (BROWN et al. 1996, QU et al. 1997).

Neben dem regulierten Abbau von Zellproteinen findet in Proteasomen unter anderem der Abbau fehlgefalteter Polypeptide statt. Proteasomen sind die zentralen Enzyme des nicht-lysosomalen Proteinabbaus in Zellen höherer Organismen. Der Abbauprozeß über das Ubiquitin-Proteasomen-System ist in Tieren, Pflanzen und Hefen konserviert (VOGES et al. 1999). Es ist daher nicht auszuschließen, daß in den verwendeten Fusionsproteinen Fehlfaltungen durch fehlende C-terminale Sequenzbereiche der ATPasen oder durch die Fusion mit GFP eingetreten sind. Ein Abbau der membranständigen Fusionsproteine über den ATP-abhängigen UbiquitinKonjugat-Weg ist daher nicht ausgeschlossen. 


\subsection{Expression der ATPase-GFP-Fusionsproteine in tierischen Expressionssystemen}

Wie bereits erwähnt, besitzen einzellige Grünalgen im Gegensatz zu dikotylen Pflanzen einen hohen GC-Gehalt und eine auf G und $C$ endende Codon-Präferenz in der dritten Position. Diese Codon-Präferenz wird auch bei vielen Säugetiergenen beobachtet (SUEOKA \& KAWANISHI 2000).

Die $\mathrm{Ca}^{2+}$ - ATPase DBCA1 aus Dunaliella bioculata zeigt starke Homologien zu tierischen P-Typ ATPasen des (Sarko-)Endoplasmatischen Retikulums (54\% Identität, $70 \%$ Ähnlichkeit, dagegen zu pflanzlichen Typ IIA ATPasen $44 \%$ Identität und $57 \%$ Ähnlichkeit).

Die Möglichkeit, ATPasen aus Dunaliella in tierischen Expressionssystemen zu untersuchen, sollte daher in weiterführenden Versuchen abgeschätzt werden.

Erste Expressionsversuche in HeLa-Zellen verliefen positiv: In der subzellulären Lokalisation waren deutliche Unterschiede zwischen nativem GFP und den Fusionsproteinen erkennbar.

Aufgrund sehr geringer Expressionsraten sowohl des nativen GFP als auch der Fusionsproteine in HeLa-Zellen wurden detailliertere Untersuchungen an COS-7-Zellen durchgeführt, in denen höhere Transfektionsraten erzielt werden konnten.

\subsubsection{Natives GFP in heterologen Expressionssystemen}

Die Transfektion von nativem pEGFP-N1 in HeLa- und in COS-7-Zellen sowie sGFP-S65T in Tabak-Protoplasten führte in allen drei Expressionssystemen zu einer gleichmäßigen Expression des GFP mit Lokalisation im Cytoplasma, verstärkt im perinukleären Bereich und im Nukleoplasma.

Das gleiche Fluoreszenzmuster konnte auch bei anderen Expressionsversuchen mit nativem GFP in HeLa-Zellen (CHATTERJEE \& STOCHAJ 1996), COS-7-Zellen (SIMONOVA et al. 1999) sowie auch in pflanzlichen Zellsystemen wie Tabak (CHIU et al. 1996), Zwiebelepidermiszellen (SCOTT et al. 1999) und Wurzelzellen von Arabidopsis (HASELOFF et al. 1997) beobachtet werden. Die Proteinlokalisation des nativen GFP $(26,9 \mathrm{kDa})$ im Zellkern transfizierter Zellen und Protoplasten ist auf passive bidirektionale Diffusion durch den Kernporenkomplex zurückzuführen. Die Ausschlußgröße des Kernporenkomplexes liegt bei 40 - 60 kDa (GREBENOK et al. 1997, STOCHAJ \& SILVER 1992, VON ARNIM et al. 1998). Proteine, die größer als die Ausschlußgröße des Kernporenkomplexes sind, werden mit Hilfe eines energieabhängigen Transportprozeßes über die Kernmembran in den Zellkern aufgenommen. Dieser Import benötigt spezielle Kernlokalisationssignale (GÖRLICH 1997), die im GFP-Gen nicht vorhanden sind (VON ARNIM et al. 1998). 
Das Fluoreszenzmuster nach Expression der ATPase-GFP-Fusionsproteine unterschied sich deutlich von dem des nativen GFP. Das Protein-Targeting der Fusionsproteine muß daher durch die N-terminalen Sequenzbereiche, einschließlich der ersten beiden Transmembransegmente beider ATPasen, bedingt sein.

\subsubsection{ER-Lokalisation der $\mathrm{H}^{+}$- und $\mathrm{Ca}^{2+}$-ATPase-GFP- Fusionsproteine in COS-7-Zellen}

Während bei fluoreszenzmikroskopischen Untersuchungen der transfizierten HeLaZellen die genaue Lokalisation der Fusionsproteine nicht bestimmt werden konnte, zeigten Aufnahmen von transfizierten COS-7-Zellen mit konfokaler Laser Scanning Mikroskopie nähere Details der subzellulären Fluoreszenzverteilung. So war nach

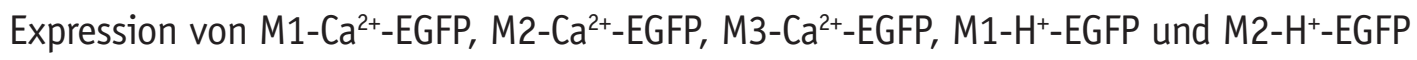
die Fluoreszenz der ATPase-GFP-Fusionsproteine verstärkt im perinukleären Bereich und in netzartigen Strukturen innerhalb der Zellen sichtbar. Vergleichbare Fluoreszenzmuster mit gesicherter ER-Lokalisation zeigten sich in COS-1-Zellen nach Immunofluoreszenzmarkierung mit dem monoklonalen Antikörpern Y/1F4, der gegen die phosphorylierende Domäne der SERCA1a gerichtet war (CARAFOLI et al. 1996) sowie einem Konstrukt, bestehend aus dem ER Targeting-Signal von $\alpha_{1}$-Antitrypsin, GFP und dem ER-retrievel-Signal KDEL, das in COS-7-Zellen exprimiert wurde (VAN GOETHEM et al. 1998).

Die Expression der $\mathrm{Ca}^{2+}$-ATPase-EGFP-Fusionsproteine und der $\mathrm{H}^{+}$-ATPase-EGFPFusionsproteine zeigte somit in COS-7-Zellen ein ER-typisches Fluoreszenzmuster. Jedoch kann auch eine zusätzliche Lokalisation der Fusionsproteine in kernnahen Zellorganellen, besonders dem Golgi-Apparat, durch die starke Fluoreszenz im kernnahen ER-Bereich nicht ausgeschlossen werden.

\subsubsection{Signalsequenzen/Signalsequenzbereiche für ER-Insertion}

Das Targeting von ATPasen in das Membransystem des ER findet über den cotranslationalen Transportweg statt (KLEINIG \& SITTE 1999). N-terminale Sequenzbereiche der hier verwendeten ATPasen, einschließlich der ersten beiden Transmembransegmente, waren ausreichend, die Translokation ins ER zu vermitteln.

Die für die Insertion ins ER notwendigen Signalsequenzen/Signalsequenzbereiche müssen auf der mRNA der $\mathrm{Ca}^{2+}$ - und $\mathrm{H}^{+}$-ATPase in den $\mathrm{N}$-terminalen Sequenzbereichen lokalisiert sein, da C-terminale Sequenzabschnitte in den ATPase-GFP-Fusionsproteinen fehlten.

Die sukzessive Verkürzung der N-Termini der beider hier untersuchten ATPase Sequenzen hatte auf die Translokation der Fusionsproteine ins tierische ER keinen 
Einfluß. Weder konnten fehlende noch cytoplasmatische Fluoreszenz bei einem der ATPase-GFP-Fusionsproteinen mit verkürztem N-Terminus beobachtet werden. Dies läßt darauf schließen, daß die ersten 17 Aminosäuren des N-Terminus von DBPMA1 und die ersten 24 Aminosäuren von DBCA1 keine essentiellen Bestandteile möglicher Signalsequenzen oder Sequenzbereiche für eine ER-Insertion sind. Andere Aminosäure-Sequenzbereiche, die eine Translokation ins ER einleiten, müssen daher in den N-terminalen Sequenzbereichen, einschließlich der ersten beiden Transmembrandomänen von DBPMA1 und DBCA1, vorhanden sein.

Dieses Ergebnis steht bei DBPMA1 in Übereinstimmung mit der Beobachtung, daß die ersten beiden Transmembransegemente der $\mathrm{H}^{+}$-ATPase aus Neurospora Membraninsertion ins ER vermitteln können (LIN \& ADDISON 1995).

Anzunehmen ist, daß der ER-Eintritt durch die ersten beiden Transmembransegmente vermittelt werden kann. Diese hydrophoben Bereiche ermöglichen Proteinen unter anderem translokaseunabhängig, in die ER-Membran zu inserieren (HARTMANN et al. 1994, WANG et al. 1997).

Den einzigen Hinweis, daß Unterschiede bei der ER-Translokation der verschiedenen naszierenden $\mathrm{Ca}^{2+}$-GFP-Fusionsproteine vorhanden sein könnten und $\mathrm{M3}^{-} \mathrm{Ca}^{2+}$-EGFP begünstigt ins ER inseriert, lieferte das verstärkte Auftreten von fluoreszierenden punktförmigen Proteinansammlungen in COS-7-Zellen. Während diese Partikel bei $\mathrm{M} 1-\mathrm{Ca}^{2+}-\mathrm{EGFP}$ in $20 \%$ der transienten Zellen und dort verstärkt auftraten, waren sie bei M3-Ca ${ }^{2+}$-EGFP nur bei $5 \%$ aller transfizierten Zellen und dort in geringerer Anzahl feststellbar. Es war daher anzunehmen, daß das Targeting der Ribosomen mit dem naszierenden Polypeptid zum ER und die Translokation ins ER suboptimal verläuft bzw. nicht stattfindet je länger der N-Terminus der $\mathrm{Ca}^{2+}$-ATPase ist. Ein Teil der Fusionsproteine hätte somit im Cytoplasma und nicht am ER synthetisiert werden können, wo sie, aufgrund der Tendenz integraler Membranproteine zur Polymerisation, aggregieren. Gegen diese Hypothese, daß ein Teil der Fusionsproteine im Cytoplasma synthetisiert wurde, spricht jedoch, daß die fluoreszierenden Proteinansammlungen nicht in allen transfizierten Zellen, sondern nur in $5-20 \%$ beobachtet wurden und in den restlichen Zellen nur sehr vereinzelt auftraten. Nach Expression der $\mathrm{H}^{+}$-GFP-Fusionsproteine waren sie nicht vorhanden.

SIMONOVA et al. (1999) beobachteten nach Expression des GFP-markierten N-Terminus (N-terminale cytoplasmatische und hydrophobe membrandurchspannende Domäne) des integralen Membranproteins Neutral-Endopeptidase aus Kaninchen wider deren Erwartungen nur eine sehr geringe Proteinmenge an der Zelloberfläche. Statt dessen war das Fusionsprotein im Golgi-Apparat und in punktförmigen fluoreszierenden Strukturen erkennbar. SIMONOVA et al. (1999) führen diese fluoreszierenden Strukturen auf die Tendenz GFP-markierter-Membranproteine zur Polymerisation und Bildung von Nanoclustern zurück. 
Große Mengen an transient exprimierten Membran-assoziertem GFP können eine vorteilhafte Umgebung zur Multimerisation der Fusionsproteine darstellen (CUBITT et al. 1995, DE ANGELIS et al. 1998).

In der vorliegenden Arbeit nahm die Anzahl fluoreszierender punktförmiger Proteinansammlungen mit Verkürzung des $\mathrm{N}$-Terminus der $\mathrm{Ca}^{2+}$-ATPase ab. Es ist daher für die $\mathrm{Ca}^{2+}$-ATPase anzunehmen, daß ein langer $\mathrm{N}$-Terminus eine Multimerisation begünstigt.

\subsubsection{Lokalisation oder Retention im ER tierischer Zellen}

Die Aminosäuresequenz von DBPMA1 weist 17 Positionen auf, die charakteristisch für Protonen-translozierende P-Typ ATPasen sind (WOLF 1993). Die ersten an der Plasmamembran immunocytologisch nachgewiesenen P-Typ $\mathrm{H}^{+}$-ATPasen waren die Isoformen AHA2 und AHA3 aus Arabidopsis (DE WITT et al. 1996). Mittlerweile wurden mehrere Isoformen unter anderem durch Verwendung des Reportergens GUS an der Plasmamembran lokalisiert (MORIAU et al. 1999). Die einzigen bisher bekannten Ausnahmen sind HAA13 und HAA1 aus der marinen Goldalge Heterosigma akashiwo. Durch Antikörper wurde ihre Lokalisation in intrazellulären Membranen der Alge bestimmt (WADA et al. 1994). Ein Sequenzvergleich von DBPMA1 zu dem ATPasenFragment HAA1 aus Heterosigma akashiwo zeigte nur eine $36 \%$-ige Identität und eine $48 \%$-ige Ähnlichkeit.

Große Identität zeigt DBPMA1 dagegen zur $\mathrm{H}^{+}$-ATPase aus Dunaliella acidophila. Das Protein aus Dunaliella acidophila wurde aus der Plasmamembran aufgereinigt und die Aminosäuresequenz ansequenziert. Mit den gewonnenen Sequenzdaten wurden Primer erstellt und aus der genomischen DNA von Dunaliella acidophila wurde die plasmamembranständige $\mathrm{H}^{+}$-ATPase amplifiziert (WEISS \& PICK 1996).

Die Lokalisation der $\mathrm{H}^{+}$-ATPase DBPMA1 aus Dunaliella bioculata an der Plasmamembran kann aufgrund der Sequenzidentität von $78 \%$ und einer Ähnlichkeit von $87 \%$ zur Primärstrukturen der plasmamembranständigen $\mathrm{H}^{+}$-ATPase aus Dunaliella acidophila und der phylogenetischen Verwandtschaft beider Algen, als gesichert angesehen werden.

Die Primärstruktur von DBCA1 zeigt größte Ähnlichkeiten zu P-Typ Ca+-ATPasen des (S)ERs tierischer Organismen (RASCHKE \& WOLF 1996). Eine Calmodulin-Bindungsstelle wurden nicht gefunden. Die kalkulierte Molekülmasse der ATPase von 114 kDa ist nur geringfügig geringer als die Molekülmasse bisher klonierter Typ IIA $\mathrm{Ca}^{2+}$-ATPasen (115 - $116 \mathrm{kDa}$ ) aus Pflanzenzellen (GEISLER et al. 2000).

Die Lokalisation der $\mathrm{Ca}^{2+}$-ATPase-GFP-Fusionsproteine im ER von HeLa- und COS-7Zellen könnte die durch Sequenzhomologien vermutete ER-Lokalisation von DBCA1 bestätigen. 
Die Interpretation dieser Ergebnisse wird jedoch durch die ausschließliche Lokalisation der $\mathrm{H}^{+}$-ATPase-GFP-Fusionsproteine im ER tierischer Zellen in Frage gestellt. So reichten zwar die ersten beiden Transmembransegmente der $\mathrm{H}^{+}$-ATPase für eine ER-Insertion aus, nicht aber für das Targeting der Fusionsproteine zur Plasmamembran.

\subsubsection{Topogene Signale für ER-Retention der $\mathrm{Ca}^{2+}$-ATPase-GFP- Fusionsproteine}

Die Strukturen, die für das subzelluläre Targeting von ATPasen und deren Zurückhaltung im ER verantwortlich sind, sind noch weitestgehend unbekannt (GEISLER et al. 2000). Daß die Insertion ins tierische ER durch N-terminale Sequenzbereiche der ATPasen vermittelt wird, konnte in der vorliegenden Arbeit gezeigt werden.

Die Lokalisation der Fusionsproteine $\mathrm{M} 1-\mathrm{H}^{+}$-EGFP und M2- $\mathrm{H}^{+}$-EGFP im ER anstelle der Plasmamembran von COS-7-Zellen wirft aber die Frage auf, ob die Lokalisation der $\mathrm{Ca}^{2+}$-ATPase-GFP-Fusionsproteine die Lokalisation von DBCA1 im ER bestätigen kann.

Für eine ER-Lokalisation der $\mathrm{Ca}^{2+}$-ATPase-GFP-Fusionsproteine spricht das Aminosäuremotiv KILL im ersten Transmembransegment der $\mathrm{Ca}^{2+}$-ATPase DBCA1.

Das R/KILL Motiv ist auch im ersten Transmembransegment der SER Ca ${ }^{2+}$-ATPasen von Drosophila lokalisiert und wird als topogenes Signal für eine ER-Retention diskutiert (MAGYAR \& VARADI 1990, EVANS \& WILLIAMS 1998). Es kommt auch bei T-Zellen Antigen Rezeptoren aus dem ER vor und ist bei einer Vielzahl tierischer $\mathrm{Ca}^{2+}$-ATPasen des (S)ERs konserviert. In tierischen Typ IIB Ca ${ }^{2+}$-ATPasen tritt es dagegen nicht auf. Ein Multiples Alignment von GEISLER et al. (2000) zeigte, daß das R/KILL-Motiv auch bei den meisten pflanzlichen Typ IIA $\mathrm{Ca}^{2+}$-ATPasen im ersten Transmembransegment konserviert ist. So ist es unter anderem in den Aminosäuresequenzen der pflanzlichen $\mathrm{Ca}^{2+}$-ATPasen aus Acetabularia acetabulum, Orzya sativa, einigen Isoformen aus Arabidopsis und Lycopersicon esculentum zu finden.

Die Expression chimärer SERCA1a/PMCA3-ATPasen zeigte, daß die ersten zwei Drittel der ATPase zur Determinierung der ER-Lokalisation ausreichend sind (BLACK et al. 1998).

Immunofluoreszenzuntersuchungen mit rekombinanten Chimären aus einer tierischen SER (rSERCA1) und einer PM Ca ${ }^{2+}$-ATPase (hPMCA4CI) grenzten diese Bereiche weiter ein und konnten zeigen, daß die Zielsteuerungssignale der SER-ständigen $\mathrm{Ca}^{2+}$-ATPase in das ER von COS-7-Zellen, durch Aminosäuresequenzen am N-Terminus (einschließlich des ersten Transmembransegmentes) festgelegt sind (FOLETTI et al. 1995).

Neben dem R/KILL Motiv im ersten Transmembransegment werden für integrale Membranproteine auch noch C-terminale Sequenzbereiche für eine ER-Retention diskutiert (JACKSON et al. 1990, SHIN et al. 1991, EVANS \& WILLIAMS 1998, GEISLER 
et al. 2000). In tierischen Zellen enthalten viele ER-residente Membranproteine C-terminale Retentionssignale mit dem Consensus (K/X)(K/X)KXX-Stop (JACKSON et al. 1993). Die Lysin-reichen Motive KKXX oder KXKXX treten zwar bei Tomate und Arabidopsis auf, kommen aber bei der $\mathrm{Ca}^{2+}$-ATPase aus Dunaliella nur in abgewandelter Form als KLK-Motiv vor. Bei der tierischen SERCa1p aus Huhn sind sie gar nicht vorhanden (KARIN \& SETTLE 1992).

Neben den bis jetzt bekannten $\mathrm{C}$ - und N-terminalen topogenen Signalen für eine ERRetention müssen aber noch andere Faktoren oder Sequenzen eine Rolle spielen. So ist die $\mathrm{Ca}^{2+}$-ATPase Isoform ACA2p aus Arabidopsis im ER lokalisiert, hat aber weder ein bekanntes ER-Retetions-Motiv am C-Terminus noch eine konservierte erste Transmembrandomäne (HONG et al. 1999).

Eine Chimäre, die aus dem N-Terminus mit den ersten beiden Transmembransegmenten der hPMCA4CI und dem Rest der rSERCA1 bestand, zeigte eine Lokalisation sowohl in der Plasmamembran als auch im ER. Dies könnte bedeuten, daß die SER $\mathrm{Ca}^{2+}$-ATPase zusätzlich zu den am N-Terminus lokalisierten Signalen weitere topogene Signale besitzt, die für eine Retention im ER verantwortlich sind. Da sich aber auch bei der SER $\mathrm{Ca}^{2+}$-ATPase am Ende des C-Terminus keine typischen lysinreichen ER-Retensions-Signale befanden, könnte angenommen werden, daß noch andere Regionen des Proteins in den ER-Retensionsprozess involviert sind. GUERINI et al. (1998) dagegen schließen mit Chimären ATPase-Konstrukten aus PMCA1 und SERCA1 die Transmembrandomänen-vermittelte Lokalisation im ER aus und konnten belegen, daß in den ersten 28 Aminosäuren der SERCA1 des Menschen ein ER-Retentionssignal lokalisiert ist.

FOLETTI et al. (1995), GUERINI et al. (1998) und auch BLACK et al. (1998) belegten, daß N-terminale Sequenzbereiche für eine Translokation von $\mathrm{Ca}^{2+}$-ATPasen ins ER und auch für deren dortige Retention ausreichten. Das in DBCA1 im ersten Transmembransegment vorkommende und als Retentionssignal postulierte R/KILL Motiv stellt ein universelles, organismenübergreifendes Aminosäure-Motiv für die Zurückhaltung von Membranproteinen im ER dar. Obgleich GUERINI et al. (1998) zeigten, daß das R/KILL-Motiv nicht notwendigerweise Einfluß auf die ER-Retention hat, sondern N-terminale Aminosäuren die Zurückhaltung vermitteln, ist anzunehmen, daß die N-terminalen Aminosäuresequenzen von DBCA1, einschließlich der ersten beiden Transmembransegmente, das Targeting der ATPase-Fusionsproteine ins ER und ihre dortige Lokalisation bedingen. 


\subsubsection{Retention der $\mathrm{H}^{+}$-ATPase-GFP-Fusionsproteine im ER}

Die Lokalisation der $\mathrm{H}^{+}$-ATPase-GFP-Fusionsproteine im ER tierischer Zellen zeigte, daß es weitere Faktoren für eine Zurückhaltung der ATPase-GFP-Fusionsproteine im ER geben muß, die eine Retention beeinflussen und das Targeting zur Plasmamembran unterbinden können.

Die $\mathrm{H}^{+}$-ATPase-GFP-Fusionsgene wurden unter Kontrolle des starken CMV-Promotors in multicopy Plasmiden zur Expression gebracht. Die daraus resultierende Überexpression der Fusionsproteine kann dazu führen, daß ein Großteil der Proteine im ER verbleibt und nicht zur Plasmamembran gelangt. Chimäre Konstrukte von PMCA3 und SERCA1a zeigten aber bei Überexpression in COS-7-Zellen sowohl eine ER- als auch eine Plasmamembran-Lokalisation (BLACK et al. 1998). Die Expression der $\mathrm{H}^{+}$-ATPase in COS-7-Zellen zeigte dagegen keine Plasmamembran-Lokalisation. Die Fluoreszenz der in COS-7-Zellen exprimierten Fusionsproteine grenzte sich nicht gegen das Außenmedium ab. Es kann daher davon ausgegangen werden, daß kein Targeting der $\mathrm{H}^{+}$-ATPase-GFP-Chimären zur Plasmamembran stattgefunden hat und die Ursachen nicht in einer Überexpression der Fusionsproteine lagen.

\subsubsection{Qualitätskontrolle im ER}

Die selektive Zurückhaltung und Degradation falsch gefalteter oder mutierter Proteine im ER könnte eine weitere Erklärung für die ER-Lokalisation der ATPase-GFPFusionsproteine sein.

Das Endoplasmatische Retikulum ist der Eingang der Membranproteine in den Sektretorischen Transportweg. Im ER beginnt die Prozessierung der entstehenden Proteine. Außerdem findet hier eine Qualitätskontrolle der fertigen Proteine statt (PLEMPER \& WOLF 1999). Fehlgefaltete und nicht richtig assemblierte Proteine können durch Chaperone erkannt werden (KOPITO 1997) und verbleiben im ER, bevor sie zum größten Teil durch Ubiquitinylierung in Proteasomen abgebaut werden. Bei Plasmamembran $\mathrm{Ca}^{2+}$-ATPasen konnte dies nach Verkürzung des C-Terminus (ZVARITCH et al. 1995) und Punktmutationen an Aminosäuren, die vermutlich die Pore für Calcium bilden (GUERINI et al. 1996), festgestellt werden. Gegen die generelle Retention fehlgefalteter Proteine sprechen jedoch die Versuche von HEIM et al. (1992) und ZVARITCH et al. 1995 (FOLETTI et al. 1995), die N-terminal verkürzte (die ersten beiden Transmembransegmente fehlten) und inaktive Formen einer PM-Ca ${ }^{2+}$-ATPase nach Expression in COS-7-Zellen und Sf9-Zellen an der Plasmamembran vorfanden.

Es kann daher nicht ausgeschlossen werden, daß die Retention der ATPase-GFPChimären im ER auf Fehlfaltung der Fusionsproteine beruht. Zwar konnten FOLETTI et al. (1995), GUERINI et al. (1998) und BLACK et al. (1998) an ATPase-Chimären zeigen, daß die ersten beiden Transmembransegmente der plasmamembranständigen 
$\mathrm{Ca}^{2+}$-ATPase ein Targeting zur Plasmamembran vermitteln, jedoch setzten sich in deren Versuchen die rekombinanten ATPase-Chimären aus Membranstruktur-ähnlichen ATPasen zusammen.

Eventuelle Fehlfaltungen der in der Arbeit verwendeten Fusionsproteine können durch den Einfluß des GFP oder aber durch fehlende Aminosäuresequenzen der ATPasen bedingt sein. Gegen eine GFP-bedingte Fehlfaltung der Fusionsproteine spricht jedoch, daß die mit GFP markierte SERCA1a durch die Fusion mit GFP die Fähigkeiten zum Calciumtransport nicht verloren hatte (VAN GOETHEM et al. 1998) und auch die GFP-markierte $\mathrm{Ca}^{2+}$-ATPase SCA1 aus Soja nach heterologer Expression in BY-2 Zellen an der Plasmamembran lokalisiert war (CHUNG et al. 2000).

\subsubsection{Zusätzliche Signale}

In der Arbeit sollte geklärt werden, ob N-terminale GFP-markierte Sequenzbereiche der ATPasen ausreichen, die subzelluläre Lokalisation der ATPase in heterologen Expressionssystemen zu bestimmen. Die Lokalisation der $\mathrm{H}^{+}$-ATPase-GFP-Fusionsproteine im ER von COS-7-Zellen wirft daher auch die Frage auf, ob in den fehlenden Aminosäuresequenzen der ATPasen weitere Informationen codiert sind, die den Transport zur Plasmamembran bewirken oder für eine Retention im ER sorgen.

Zum Targeting der PMCA3/SERCA1a Chimäre an die Plasmamembran in COS-7-Zellen reichten die ersten beiden Transmembrandomänen von PMCA3 aus (BLACK et al. 1998). Auch FOLETTI et al. (1995) konnten mit PMCA/SERCA-Chimären in COS-7Zellen zeigen, daß die ersten beiden Transmembransegmente von PMCA aus dem Menschen, den Transport der Chimären an die Plasmamembran bedingen.

ZVARITCH et al. (1995) konnten dagegen durch Mutageneseversuche an plasmamembranständigen $\mathrm{Ca}^{2+}$-ATPasen zeigen, daß sich am C-Terminus in unmittelbarer Nähe der CaM-Bindungsstelle ein ER-Retentions-Signal befindet, das im vollständigen Protein nicht zum tragen kommt, jedoch bei verkürztem C-Terminus zur Retention und zum Abbau des Proteins im ER führt. Die Verkürzung des C-Terminus der plasmamembranständigen $\mathrm{Ca}^{2+}$-ATPase führt dazu, daß die ATPase durch Calmodulin nicht mehr regulierbar ist. Es ist daher zu vermuten, daß es sich bei der Zurückhaltung von verkürzten ATPasen im ER um einen Schutzmechanismus handelt, der die Zelle vor unkontrollierbaren und nicht vorhersehbaren Eigenschaften der in ihrer Struktur veränderten ATPasen schützt. Dieses Retentionssignal führt nicht zur Zurückhaltung andere Proteine, wenn es ihnen an den C-Terminus angehängt wurde. Es ist auch in anderen P-Typ ATPasen nicht vorhanden, sondern scheint spezifisch für $\mathrm{Ca}^{2+}$-ATPasen der Plasmamembran zu sein.

Inwieweit solche ER-Retentionssignale auch bei $\mathrm{H}^{+}$-ATPasen vorhanden sind, ist nicht bekannt. Jedoch konnte bei Verkürzung des $\mathrm{N}$-Terminus der $\mathrm{H}^{+}$-ATPasen aus Hefe, eine Retention im Endomembransystem von Hefen beobachtet werden (VILLALBA et al. 1992). 
Die heterologe Expression individueller pflanzlicher $\mathrm{H}^{+}$-ATPasen in Hefe zeigte, daß die Isoformen AHA1, AHA2 und AHA3 aus Arabidopsis thaliana in den internen Hefemembranen akkumulierten (VILLALBA et al. 1992, PALMGREN \& CHRISTENSEN 1993, PALMGREN \& CHRISTENSEN 1994), während die Expression der Isoformen PMA2 und PMA4 aus Tabak zu einer plasmamembranständigen Lokalisation führte (LU0 et al. 1999, DE KERCHOVE D’EXAERDE et al. 1995). Daß die ER-Retention nicht durch Fehlfaltung bedingt war, zeigt die Tatsache, daß alle heterolog in Hefe exprimierten Isoformen biochemisch aktiv waren (LU0 et al. 1999).

Diese Ergebnisse machen deutlich, daß es neben der Zurückhaltung fehlgefalteter, inaktiver und unregulierbarer ATPasen noch andere Mechanismen geben muß, die eine Retention im ER bewirken. Neben der Fehlfaltung von Proteinen werden auch andere Einflüsse der intrazellulären Prozessierung, wie die Phosphorylierung und Glykosylierung für Fehler des intrazellulären Targetings und einer Retention im ER vermutet (BROWN \& BRETON 2000).

Alle bisher bekannten Signalsequenzen für die ER-Insertion sind ähnlich strukturiert und an Proteinen untereinander austauschbar (VON HEIJNE 1985). Das zum Erkennungsmechanismus zugehörige SPR (signal recognition particle) kommt in allen Organismen vor (HARTMANN et al. 1994). Der Prozeß der Insertion in das ER scheint daher ein konservierter Mechanismus aller Organismen zu sein. So konnte auch in der Arbeit gezeigt werden, daß die Translokation pflanzlicher ATPasen in das ER tierischer Zellen erfolgt.

Über die Weiterleitung der Proteine über das ER zu ihren Bestimmungsorten in der Zelle gibt es bei Hefe und tierischen Systemen zahlreiche Erkenntnisse. Der Vesikeltransport- und der Sortiermechanismus in Pflanzenzellen ist dagegen noch weitestgehend unbekannt (ROBINSON et al. 1998). Die Retention pflanzlicher und biochemisch aktiver $\mathrm{H}^{+}$-ATPasen im ER von Hefen (VILLALBA et al. 1992, PALMGREN \& CHRISTENSEN 1993, PALMGREN \& CHRISTENSEN 1994) sind Hinweise, daß sich Sortierungs-Signale und -Mechanismen in verschiedenen Organismen unterscheiden können.

Es kann daher nicht abschließend geklärt werden, ob die Retention der $\mathrm{H}^{+}$-ATPaseGFP-Fusionsproteine im ER tierischer Zellen auf die Zurückhaltung fehlgefalteter Proteine zurückzuführen ist oder ob strukturelle Einflüsse des reifen Proteins den Transport zur Plasmamembran beeinflussen. Auch Retentionssignale oder Unterschiede in den Sortierungsmerkmalen zwischen pflanzlichen und tierischen integralen Membranproteinen, die den Eintritt in den Sekretorischen Transportweg verhindern, können als Grund für eine ER-Retention der Fusionsproteine nicht ausgeschlossen werden. 


\subsection{Translationsstartcodons der Fusionsproteine}

Im richtigen Leserahmen der Nukleinsäuresequenz von DBCA1 und DBPMA1 befinden sich am jeweiligen N-Terminus mehrere ATG-Tripletts, die theoretisch als Translationsstart fungieren könnten.

Durch sukzessive Verkürzung der N-Termini bis zum jeweils nächsten ATG in $5^{\prime} \rightarrow 3^{\prime}$-Richtung sollte nach dem Ausschlußprinzip Informationen über die Lokalisation möglicher Signalsequenzen/Signalsequenzbereiche und tatsächlich genutzter Startcodons erhalten werden.

Es zeigte sich, daß alle Fusionsproteine exprimiert und ins ER inseriert wurden. Während die Länge des N-Terminus keinen Einfluß auf die Insertion ins ER hatte, führte jedoch die gezielte Verkürzung der Fusionsproteine sowohl bei der $\mathrm{H}^{+}$- als auch bei der $\mathrm{Ca}^{2+}$-ATPase zu einem deutlichen Anstieg der Proteinsynthese.

Die Translation von Proteinen wird primär durch die Initiation kontrolliert (GRAY \& WICKENS 1998).

Bei Eukaryoten bindet ein Initiationsfaktor, das CAP-bindende Protein eIF4E, an die 5'-CAP-Struktur und fördert die Bildung eines Komplexes zwischen mRNA und der 40S-Untereinheit der Ribosomen. Die 40S-Untereinheit wandert dann an der mRNA entlang. Nach dem "Scanning Modell" findet die Translationsinitation der meisten Gene am ersten AUG in $5^{\prime} \rightarrow 3^{\prime}$-Richtung statt. Dort wird die 60S-Untereinheit des Ribosomens angefügt, und es resultiert ein 80S-Initiationskomplex, der für die Elongation bereit ist. Die Initiation wird dabei durch die Consensus-Sequenz um das Startcodon (KOZAK 1987a, LÜTCKE 1987) positiv begünstigt.

Es kommt aber auch vor, daß die Translation nicht am ersten AUG beginnt, sondern die Translationinitiation erst am zweiten oder dritten in 3'-Richtung gelegenen AUGTriplett stattfindet. Der von KOZAK (1989) als "Leaky scanning Modell” bezeichnete Mechanismus, der die Ribosomen veranlaßt, potentielle Startcodons zu ignorieren, ist nicht genau bekannt. Begünstigt wird er durch eine nicht optimale ConsensusSequenz um das erste Startcodon, nahe aufeinanderfolgende AUG-Tripletts, ein Stopcodon nach dem AUG im selben Leseraster und ein darauffolgendes AUG sowie einen nicht ausreichenden Basenabstand zwischen CAP-Struktur und AUG (KOZAK 1995).

Diskutiert wird auch der Prozeß einer Reinitiation der Ribosomen. Nach Translation eines kurzen offenen Leserahmens (sORF) im 5'-UTR kann am Startcodon im eigentlichen offenen Leserahmen (ORF) die Translation erneut beginnen (RYABOVA \& HOHN 2000). Die sORF der meist längeren $5^{\prime}$-UTRs haben dabei regulatorische Funktionen auf die Translation. Eine Reinitiation von Ribosomen wurde für viele virale mRNAs, aber auch bei pflanzlichen (FUTTERER \& HOHN 1996) und tierischen Genen (KOZAK 1991), die für eine Vielzahl von Transkriptionsfaktoren, Wachstumsfaktoren und Tumor-Suppressoren kodieren, beobachtet. Auch für die pflanzliche plasma- 
membranständige $\mathrm{H}^{+}$-ATPase PMA3 aus Tabak wurde ein langer $5^{\prime}$-UTR mit kurzem offenen Leserahmen und regulierender Wirkung beschrieben (LUKASZEWICZ et al. 1998). Der genaue Mechanismus, der die Ribosomen zur Reinitiation bewegt, ist bis jetzt nicht bekannt. Von Hefe weiß man, daß der Transfer der Ribosomen durch Phosphorylierung der Aminosäure Ser ${ }^{51}$ des Faktors eIF2a kontrolliert wird, der die Initiation der tRNA aktiviert (YUDKOVSKY et al. 2000). Je länger jedoch der SORF, desto ineffizienter wird die Translation reguliert. Die Reinitiation steigt mit wachsender Distanz zwischen dem sORF und dem eigentlichen ORF (KOZAK 1989, HINNEBUSH 1997) und beträgt bei einer Länge von 79 Nukleotiden nahezu $100 \%$ (KOZAK 1987b).

\subsubsection{Steigerung der Proteinsynthese mit Verkürzung der $\mathrm{N}$-Termini der $\mathrm{H}^{+}$- und $\mathrm{Ca}^{2+}$-ATPase}

In der Annahme, daß die Translation der ATPase-GFP-Fusionsgene dem normalen "Scanning Modell" folgt, wurde zur Translations-0ptimierung der pflanzlichen ATPase-GFP-Fusionsproteine in tierischen Expressionssystemen, das jeweils erste ATG jedes Fusionsgens der tierischen Kozak Consensus-Sequenz angepaßt. Es wurden damit auch identische Voraussetzungen für die Translation der verschiedenen Fusionsgene geschaffen.

Während im konfokalen Laser Scanning Mikroskop keine Unterschiede in der Intensität und Lokalisation der verschieden Konstrukte zu beobachten waren, zeigte sich bei der quantitativen Bestimmung der Expressionsrate, daß die Proteinsynthese der ATPase-GFP-Fusionsproteine M2-H+-EGFP und M3-Ca ${ }^{2+}$-EGFP in COS-7-Zellen am höchsten war. Dies deutet darauf hin, daß die ATG-Tripletts an Position 117 - 119 der Nukleinsäuresequenz von DBCA1 und Position 72 - 74 von DBPMA1 die effektiveren Translationsstartstellen für die Proteinsynthese der beiden ATPasen in tierischen Zellen darstellen.

Für DBCA1 stimmt dieses Ergebnis mit der durch Sequenzvergleiche mit anderen Typ IIA $\mathrm{Ca}^{2+}$-ATPasen gewonnenen Annahme überein, daß nicht das erste ATG im offenen Leseraster das eigentliche Translationsstartcodon darstellt, sondern das dritte ATG an Position 117 - 119 (3.1.1). Bei der $\mathrm{H}^{+}$-ATPase DBPMA1 wurde hingegen das erste ATG an Position 23 - 25 aufgrund der Übereinstimmung mit der tierischen ConsensusSequenz als Startcodon favorisiert. Die unterschiedlich starke Proteinsynthese von M1- $\mathrm{H}^{+}$-EGFP und M2- $\mathrm{H}^{+}-$EGFP weist jedoch auf das zweite Startcodon an Position $72-74$ als tatsächliches Startcodon hin.

Der dem tierischen Kozak Consensus angepaßte Basenkontext um das jeweils erste ATG-Triplett der Fusionsgene, hätte theoretisch bei allen Fusionsproteinen eine ideale Translationsinitiationsstartstelle darstellen müssen. Davon ausgehend, daß daher 
bei allen Fusionsgenen das jeweils erste optimierte Startcodon als Translationsstart benutzt würde, hätte die Proteinsynthese der drei Fusionsproteine der $\mathrm{Ca}^{2+}$-ATPase sowie der beiden Fusionsproteine der $\mathrm{H}^{+}$-ATPase annähernd gleich stark sein müssen. Da aber deutliche Unterschiede in der Expressionsrate der einzelnen Fusionsgene vorhanden waren, kann nicht ausgeschlossen werden, daß die Translationsinitiation aller Fusionsgene doch nicht am jeweils ersten AUG-Codon der mRNA beginnt, sondern in tierischen Systemen am zweiten AUG an Position 72 - 74 von DBPMA1 und am dritten AUG an Position 117 - 119 bei DBCA1 einsetzt.

Eine mögliche Erklärung für die Initiation der Ribosomen an in 3'-Richtung gelegenen nachfolgenden AUG-Tripletts liefert das bereits erwähnte "Leaky scanning Modell" (KOZAK 1989). Diesem Mechanismus entsprechend, wäre die Steigerung der Proteinsynthese von M1- $\mathrm{H}^{+}$-EGFP zu M2-H+-EGFP bzw. M1-Ca ${ }^{2+}$-EGFP zu M3-Ca ${ }^{2+}$-EGFP auf die optimierte Translationsinitiationsstelle an Position 117 - 119 bei M3-Ca ${ }^{2+}$-EGFP und Position 72 - 74 bei M2-H+-EGFP zurückzuführen. Diese Translationsstartstellen werden eventuell auch in den anderen Fusionsgenen benutzt, wo aber das ATG an Position 72 - 74 bei DBPMA1 und Position 117 - 119 bei DBCA1 keinen optimierten Basenkontext für die Translationsinitiation besitzt. Daher könnte die Expressionsrate

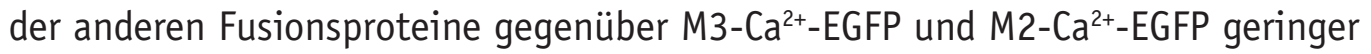
sein.

Die Steigerung der Proteinsynthese mit Verkürzung des N-Terminus beider ATPasen zeigt, daß ein an den tierischen Kozak Consensus angepaßter Basenkontext um das Startcodon, die Translationsinitiation nicht alleine beeinflußt, sondern auch andere Translationsinitiations-Mechanismen bei der Erkennung der Startcodons eine Rolle spielen müssen.

\subsection{2 Übertragbarkeit der Ergebnisse auf Dunaliella bioculata}

Inwieweit diese in tierischen Zellen beobachteten Ergebnisse auf Dunaliella bioculata übertragbar sind, ist nicht eindeutig zu klären. Zu wenig Gene sind aus Algen charakterisiert, um für deren Translationsstart eine Consensus-Sequenz ableiten zu können bzw. eine Übereinstimmung mit den für tierische und pflanzliche Systeme postulierten Consensus-Sequenzen eindeutig festzustellen.

Bei der $\mathrm{Ca}^{2+}$-ATPase aus Dunaliella bioculata zeigt keines der drei ATG-Tripletts eine Übereinstimmung mit der für pflanzliche Gene bestimmten Consensus-Sequenz (3.1.1, Tab. 5), aber alle drei ATG-Tripletts stehen in einem fast identischen Basenkontext. Bei der $\mathrm{H}^{+}$-ATPase ist eine Übereinstimmung mit dem tierischen, nicht aber mit der pflanzlichen Consensus-Sequenz bei einem ATG-Triplett vorhanden.

Bei tierischen mRNAs, deren Nukleotide in unmittelbarer Nähe des ersten ATG nicht mit der von KOZAK postulierten Consensus-Sequenz in den beiden wichtigen Basen 
an Position -3 und +4 übereinstimmt, wurde beobachtet, daß die Initiation der Translation am nächsten ATG in 3'-Richtung beginnen kann (KOZAK 1995, 1996) oder zwei Proteine von einer mRNA synthetisiert werden können (KOZAK 1996). Ein Beispiel hierfür lieferten OSSIPOW et al. (1993). Von denselben mRNAs des LeucinZipper Proteins C/EBP und dem Transkriptionsaktivierungsprotein LAP, mit jeweils mehreren ATG-Tripletts im offenen Leseraster, wurden zwei Proteine mit unterschiedlich langem N-Terminus synthetisiert, wenn keines der Startcodons sich im optimalen von KOZAK (1987a) beschriebenen Basenkontext befand.

Die pflanzlichen P-Typ $\mathrm{H}^{+}$- und $\mathrm{Ca}^{2+}$-ATPasen werden durch Multigenfamilien kodiert, von deren Isoformen manche auch in Spleißvarianten auftreten (CARAFOLI \& GUERINI 1993, MORSOMME \& BOUTRY 2000, PORTILL0 2000, GEISLER et al. 2000, OUFATTOLE et al. 2000).

Es konnte gezeigt werden, daß zahlreiche Isoformen in höheren Pflanzen entwicklungs- und gewebespezifisch exprimiert werden (DE WITT \& SUSSMAN 1995, GEISLER et al. 2000, EVANS \& WILLIAMS 1998). So sind z. B. aus Tomate die beiden Isoformen LCA1A und LCA1B mit $100 \%$-iger Sequenzidentität aber unterschiedlich langen 5'-UTRs identifiziert worden (SZE et al. 2000). Die Bedeutung zweier mRNAs, hervorgerufen durch unterschiedliche Translationsinitiation, ist bis jetzt nicht klar. Die Beteiligung individueller Isoformen an funktionell und biochemisch unterschiedlichen physiologischen Funktionen in der Pflanze werden daher vermutet (GEISLER et al. 2000). Vor diesem Hintergrund ist nicht auszuschließen, daß von der mRNA der $\mathrm{Ca}^{2+}$-ATPase und $\mathrm{H}^{+}$-ATPase Isoformen mit unterschiedlich langen $\mathrm{N}$-Termini synthetisiert werden.

Auffällig ist bei der $\mathrm{Ca}^{2+}$-ATPase aus Dunaliella bioculata, daß die Codons vor den drei potentiellen Startcodons, im Gegensatz zur H+-ATPase, zu den Codons gehören, die ansonsten im Gen der $\mathrm{Ca}^{2+}$-ATPase seltener genutzt werden. BATARD et al. (2000) zeigten, daß neben der Consensus-Sequenz auch Codons vor dem Startcodon, die im codon usage des Organismus eher selten genutzt werden, die Effizienz der Translation in Hefen und Pflanzen beeinflussen können. Das Auftreten mehrerer Startcodons mit einem nahezu identischen Basenkontext könnte daher auch auf Translationsebene regulatorische Funktionen auf die Expressionsrate des Proteins ausüben.

\subsubsection{Steigerung der Proteinsynthese in COS-7-Zellen durch Mutation in der Kozak Consensus-Sequenz}

Das Ignorieren von potentiellen Startcodons und die Initiation an folgenden AUGTripletts in 3'-Richtung wird oft mit suboptimalen Consensus-Sequenzen für die Translationsinitiation in Verbindung gebracht.

Daß die für tierische Zellen ermittelte Kozak Consensus-Sequenz keinen idealen 
Basenkontext für die Translationsinitiation der Fusionsgene in COS-7-Zellen darstellen muß, zeigte die M1-Ca²+EGFP-Kozak-Mutante.

Der optimale Basenkontext für die Initation der Translation in tierischen Systemen wurde von KOZAK $(1986,1987,1991,1996)$ mit GCCACCATGG ermittelt. Dabei zeigten sich in Mutageneseversuchen (KOZAK 1996, CAO \& GEBALLE 1995, PORTIS et al. 1994), daß die zwei Nukleotide $G$ an Position +4 und $A$ an Position -3 relativ zum $A$ des ATG den stärksten Einfluß auf die Translationsinitation haben.

In der durch Punktmutation entstandenen M1-Ca ${ }^{2+}$-EGFP-Kozak-Mutante wurde die Consensus-Sequenz durch die Nukleotidabfolge GCCCCATGG kodiert, und enthielt somit einen Basenaustausch an der für die Translationsinitiation-Effizienz in tierischen Systemen als wichtig erachteten Position -3 von der Purin-Base Adenin zur Pyrimidin-Base Cytosin. Das in COS-7-Zellen exprimierte Fusionsprotein zeigte im Vergleich zu M1-Ca ${ }^{2+}$-EGFP, deren Consensus-Sequenz genau mit der von KOZAK (1986, 1987, 1991, 1996) ermittelten Consensus-Sequenz GCACCATGG übereinstimmte, eine bis zu $60 \%$ gestiegene Expressionsrate. Eine um 150 - $350 \%$ gesteigerte Proteinproduktion einer an der Plasmamembran sitzenden $\mathrm{Ca}^{2+}$-ATPase aus Erythrocyten (hPMCA4) in COS-1-Zellen konnte auch nach Veränderung der Consensus-Sequenz nach A/G-N-N-ATG-G festgestellt werden (ADAMO 1992). Diese Veränderung entspricht jedoch dem in der Mehrzahl tierischer mRNAs vorkommenden festen Kontext der Startcodons RNNATGG (R kodiert für Purine) (KOZAK 1996). Von KOZAK (1996) wurden die Consensus-Sequenzen RNNATGY oder YNNATGG (Y kodiert für Pyrimidin) als ausreichender, aber nicht optimaler Kontext für die Translationsinitiation gewertet. Es zeigte sich aber anhand der sich nur durch die Consensus-Sequenz unterscheidenden Fusionsproteine M1-Ca ${ }^{2+}$-EGFP und M1-Ca ${ }^{2+}$-EGFP-Kozak-Mutante, daß die Punktmutation von $\mathrm{A}$ nach $\mathrm{C}$ an Position -3 in der Consensus-Sequenz zu einer deutlichen Steigerung der Proteinsynthese führte.

Die Nukleotidabfolge GCCCCATGG scheint daher einen besseren Kontext für die Translationseffizienz des M1- $\mathrm{H}^{+}$-ATPase-GFP-Fusionsproteins in COS-7-Zellen darzustellen als der für tierische Zellen von KOZAK $(1986,1987 a, 1991,1996)$ postulierte.

\subsubsection{Reinitiation am Startcodon des EGFP}

Die Mutante M1-H+-TAG-EGFP unterschied sich von M1-H+-EGFP durch ein Stopcodon zwischen den für die ATPase und der EGFP kodierenden Sequenzen und einer Verschiebung des Leserahmens der EGFP kodierenden Nukleinsäuresequenz um eine Base. Während das Fusionsprotein M1- $\mathrm{H}^{+}-$EGFP eine Lokalisation im ER von COS-7und HeLa-Zellen besaß, war nach Expression von M1-H+-TAG-EGFP in HeLa-Zellen trotz des Stopcodons das typische Fluoreszenzmuster des nativen EGFP sichtbar. Zu erwarten war, daß das Stopcodon den Translationsvorgang nach Ablesen der 
ATPase-Sequenzen terminiert und keine Fluoreszenz in den HeLa-Zellen auftritt. Entgegen diesen Erwartungen wurde das native EGFP synthetisiert. Mögliche Gründe für die Translation des nativen EGFP werden im folgenden diskutiert.

Die Translation des nativen EGFP dieser Mutante M1-H+-TAG-EGFP könnte zum einen nach dem beschriebenen "Leaky Scanning-Modell" verlaufen.

Im Fall des vorliegenden Konstruktes würde dies bedeuten, daß das erste ATG an Position 23 - 25 im offenen Leserahmen trotz angepaßter Consensus-Sequenz und das zweite ATG an Position 72 - 74 keine optimale Translationsinitiationstelle in tierischen Systemen sind. Daher läßt sich vermuten, daß ein Teil der Ribosomen das 508 bzw. 480 Nukleotide in 3'-Richtung liegende ATG des EGFP, mit seinem dem tierischen Consensus angepaßten Basenkontext, als Translationsstart benutzt.

Da die Expression der Fusionsproteine $\mathrm{M1}-\mathrm{H}^{+}$-EGFP und $\mathrm{M} 2-\mathrm{H}^{+}$-EGFP aber keine sichtbare Fluoreszenz des nativen EGFP im Zellkern und Cytoplasma zeigte, kann davon ausgegangen werden, daß die Expression des nativen EGFP nicht diesem Modell folgte. Die Expression des nativen EGFP muß daher auf einen Translationsmechanismus zurückzuführen sein, der durch das Stopcodon oder die Verschiebung des Leserahmens der EGFP-Sequenz des Konstruktes M1- $\mathrm{H}^{+}-$TAG-EGFP bedingt ist.

Eine mögliche Erklärung liefert der Prozeß der Reinitiation der Ribosomen. Wie bereits erwähnt, kann nach Translation eines kurzen offenen Leserahmens (sORF) des 5'-UTR am Startcodon des eigentlichen offenen Leserahmen (ORF), die Translation erneut beginnen (RYABOVA \& HAHN 2000). An Position 458 - 460 der Nukleinsäuresequenz von DBPMA1 und 30 Nukleotide vor dem Stopcodon befindet sich ein weiteres ATG-Triplett. Das ATG-Triplett besitzt eine Basenumgebung, die mit der tierischen Consensus-Sequenz starke Homologien aufweist und sich nur in der Base $G$ an Position -3 relativ zum A des ATG an Position 458 unterscheidet. Diese Nukleotidsequenz könnte möglicherweise als sORF erkannt werden. Die Reinitiation der Translation könnte 49 Nukleotide in 3'-Richtung am Startcodon der EGFP-Sequenz erfolgen und zur Translation des nativen EGFP führen. 


\subsection{Weiterführende Experimente}

In der vorliegenden Arbeit konnte die durch Sequenzanalysen angenommene Lokalisation von DBCA1 und DBPMA1 mit den in der Arbeit verwendeten Versuchsansätzen nicht eindeutig bestätigt werden.

Die ersten beiden mit GFP-markierten Transmembransegmente beider ATPasen zeigten in tierischen Expressionssystemen eine ER-Lokalisation, wohingegen die Fusionsproteine in Tabak nicht detektiert werden konnten. Folgt man der Annahme, daß die beiden $\mathrm{N}$-terminalen Membransegmente für ein erfolgreiches Protein-Targeting nicht ausreichen, wäre es interessant, das gesamte Protein von DBCA1 und DBPMA1 mit GFP zu markieren und die Expression sowie die Lokalisation in tierischen und pflanzlichen Zellen zu bestimmen. Durch immunocytologische Untersuchungen mit Antiköpern gegen das Reportergen GFP könnte auch bei geringer Expressionsrate die Lokalisation der Fusionsproteine nachgewiesen werden.

Nach den vorliegenden Ergebnissen ist nicht auszuschließen, daß die Lokalisation der beiden ATPasen im ER tierischer Zellen auf Fehlfaltungen der Proteine zurückzuführen ist. Um eine solche Retention im ER auf Grund von Fehlfaltungen weitgehend auszuschließen, könnten zum Auffinden möglicher Signalsequenzbereiche ATPase-Chimären verschiedener Sequenzlängen von DBCA1 mit einer plasmamembranständigen $\mathrm{Ca}^{2+}$-ATPase, GFP-markiert, in heterologen Expressionssystemen untersucht werden.

Die sukzessive Verkürzung der N-Termini der ATPasen erbrachte keine eindeutigen Hinweise auf den eigentlichen Translationsstart. Die Mutation einzelner Startcodons unter Beibehaltung des gesamten N-Terminus könnte daher weitere Hinweise auf tatsächlich genutzte Startcodons und einen möglichen Einfluß auf die Translationsregulation liefern. 


\section{$5 \quad$ Zusammenfassung}

P-Typ ATPasen werden in Pflanzenzellen durch Multigenfamilien kodiert. Die Isoformen zeigen gewebe- und entwicklungsspezifische Expressionsmuster. Um Isoformenspezifische Informationen zu erhalten, ist es daher wichtig, die Lokalisation der verschiedenen ATPasen nachzuweisen.

In der vorliegenden Arbeit wurde daher untersucht, ob N-terminale Sequenzbereiche ausreichen, das subzelluläre Targeting von P-Typ ATPasen zu vermitteln.

Ausgangsmaterial waren die putative $\mathrm{H}^{+}$-ATPase DBPMA1 und die putative $\mathrm{Ca}^{2+}$-ATPase DBCA1 aus Dunaliella bioculata. Bei beiden ATPasen befinden sich im längsten offenen Leserahmen mehrere ATG-Tripletts, die als potentielle Translationsstartpunkte in Frage kommen könnten.

$\mathrm{N}$-terminale ATPase-Bereiche, einschließlich der ersten beiden Transmembransegmente, wurden unter Berücksichtigung möglicher Translationsinitiationsstellen und dort befindlicher Signalsequenzbereiche kloniert, mit GFP markiert und zunächst heterolog in Tabak-Protoplasten exprimiert. Während die Positivkontrollen zu einer Expression des nativen GFP in Tabak-Protoplasten führten, wurde nach Transfektion der ATPase-GFP-Fusionsgene keine Expression der Fusionsproteine beobachtet. Dagegen konnte nach Transfektion tierischer Zellen (HeLa- und COS-7-Zellen) eine Expression der Fusionsproteine im Weitfeld- und konfokalen Laser Scanning Mikroskop festgestellt werden. Sowohl die $\mathrm{Ca}^{2+}$-ATPase-GFP-Fusionsproteine als auch die $\mathrm{H}^{+}$-ATPase-GFP-Fusionsproteine waren in tierischen Expressionssystemen im Endoplasmatischen Retikulum lokalisiert, während die Plasmamembran nicht markiert war.

Demnach ist der N-terminale Sequenzbereich, einschließlich der ersten beiden Transmembransegmente beider P-Typ-ATPasen ausreichend, die Translokation ins ER tierischer Zellen einzuleiten. Eine Verkürzung der ATPasen bis zu den am weitesten in 3'-Richtung gelegenen ATG-Tripletts, hatte auf die Translokation ins ER keinen Einfluß.

Während die Translokation der Fusionsproteine ins ER von der Länge des N-Terminus unabhängig war, führte die gezielte Verkürzung der Fusionsproteine bis zum jeweils nächsten ATG-Triplett in 3'-Richtung zu einer deutlich ansteigenden Proteinsynthese sowohl der $\mathrm{Ca}^{2+}$ - als auch der $\mathrm{H}^{+}$-ATPase-GFP-Fusionsproteine. Es wird daher angenommen, daß nicht die ersten ATG-Tripletts im jeweils längsten offenen Leserahmen beider ATPasen als Translationsstartstelle genutzt werden, sondern die Translation an folgenden in 3'-Richtung liegenden ATG-Tripletts einsetzt. Dies läßt den Einfluß mehrerer potentieller Startcodons auf eine Translationsregulation der ATPasen vermuten.

Während bei allen Fusionsgenen das jeweils erste Startcodon bezüglich der Kozak Consensus-Sequenz (KOZAK 1987a) zur Translations-Optimierung in tierischen Expressionssystemen angepaßt wurde, zeigte sich in COS-7-Zellen bei einem von der 
tierischen Kozak Consensus-Sequenz abweichenden Basenkontext der Basenabfolge GCCCCATGG ein Anstieg der Proteinsynthese um $60 \%$.

Eine ER-Lokalisation der Ca ${ }^{2+}-$ ATPase DBCA1 wird aufgrund von Sequenzhomologien zu molekularbiologisch und immunocytologisch charakterisierten $\mathrm{Ca}^{2+}$-ATPasen des (S)ERs vermutet. Isoliert betrachtet, würde die Detektion der $\mathrm{Ca}^{2+}$-ATPase-GFPFusionsproteine im ER diese Vermutung bestätigen. Diese Interpretation wird jedoch durch die ausschließliche Detektion der $\mathrm{H}^{+}$-ATPase-GFP-Fusionsproteine im ER tierischer Zellen in Frage gestellt. Denn die Lokalisation von DBPMA1 muß aufgrund von $78 \%$ Identität und $87 \%$ Ähnlichkeit zu der definitiv plasmamembranständigen $\mathrm{H}^{+}$-ATPase aus der nahe verwandten Alge Dunaliella acidophila als Protein der Plasmamembran angenommen werden. Insgesamt bleibt daher offen, ob die ersten beiden Transmembransegmente der $\mathrm{H}^{+}$-ATPase für ein Protein-Targeting zur Plasmamembran ausreichten oder ob beide ATPasen möglicherweise wegen Fehlfaltung der Proteine im ER zurückgehalten worden sind. 


\section{$6 \quad$ Literaturverzeichnis}

AARONSON, L.R.; HAGER, K.M.; DAVENPORT, J.W.; MANDALA, S.M.; CHANG, A.; SPEICHER, D.W. \& SLAYMAN, C.W. (1988). Biosynthesis of the plasma membrane $\mathrm{H}^{+}$-ATPase of Neurospora crassa. J. Biol. Chem. 263: 14552-14558

ADAMO, H.P.; VERMA, A.K.; SANDERS, M.A.; SALISBURY, J.L.; WIEBEN, E.D. \& PENNISTON, J.T. (1992). Overexpression of the erythrocyte plasma membrane $\mathrm{Ca}^{2+}$ pump in COS-1 cells. Biochem. J. 285: 791-797

ASKERLUND, P. (1996). Modulation of an intracellular calmodulin-stimulated $\mathrm{Ca}^{2+}$ pumping ATPase in califlower by trypsin. Plant Physiol. 110: 913-922

ASKERLUND, P. (1997). Calmodulin-stimulated $\mathrm{Ca}^{2+}$-ATPases in the vacuolar and plasma membranes in cauliflower. Plant Physiol. 114: 999-1007

ASKERLUND, P. \& SOMMARIN, M. (1996). Calcium efflux transporters in higher plants. In Smallwood, M.; Knox, J.P. \& Bowles, D.J. eds; Membranes: Specialized functions in plants. BIOS Scientific Publishers, Oxford, pp 281-299

AUER, M.; SCARBOROUGH, G.A. \& KUHLBRANDT, W. (1998). Three-dimensional map of the plasma membrane $\mathrm{H}^{+}$-ATPase in the open conformation. Nature 392: 840-843

AXELSEN, K.B. \& PALMGREN, M.G. (1997). Evolution of substrate specificities in the P-Type ATPase superfamily. J. Mol. Evol. 46: 84-101

BARBKOV, A.V.; CHELYSHEVE, V.V.; KLYCHNIKOV, O.I.; ZORINYANZ, S.E.; TROFIMOVA, M.S. \& DE BOER, A.H. (2000). Involvement of 14-3-3 proteins in the osmotic regulation of $\mathrm{H}^{+}$-ATPase in plant plasma membranes. Planta 211: 446-448

BATARD, Y.; HEHN, A.; NEDELKINA, S.; SCHALK, M.; PALLETT, K.; SCHALLER, H. \& WERCK-REICHHART, D. (2000). Increasing expression of P450 and P450reductase proteins from monocots in heterologous systems. Arch. Biochem. Biophys. 379: 161-169

BAULCOMBE, D.; CHAPMAN, S. \& SANTA CRUZ, S. (1995). Jellyfish green fluorescent protein as a reporter for virus infections. Plant Journal 7: 1045-1053

BAUR, M.; MEYER, A.J.; LÜTZELSCHWAB, M. \& MICHALALKE, W. (1996). Distribution of plasma membrane $\mathrm{H}^{+}$-ATPase and polar current patterns in leaves and stems of Elodea canadensis. Bot. Acta 109: 382-387 
BEILBY, M.J. (1989). Electrophysiology of giant Algal cells. Meth. Enzymol. 174: $403-443$

BEGGAH, A.T.; BÉGUIN, P.; BAMBERG, K.; SACHS, G. \& GEERING, K. (1999). $\beta$-subunit assembly is essential for the correct packing and the stable membrane insertion of the $\mathrm{H}$-, K-ATPase $\alpha$-subunit. J. Biol. Chem.

274: $8217-8223$

BERRIDGE, M.J. (1995). Calcium signalling and cell proliferation. Bioessays 17: $491-500$

BIRNBOIM, H. \& DOLY, J. (1979). A rapid alkaline extraction procedure for screening recombinant plasmid DNA. Nucl Acids Res. 7: 1512-1523

BLACK, J.P.J.; CHAD, J.E.; LEE, A.G. \& EAST, J.M. (1998). Identification of endoplasmic reticulum targeting signals using SERCA/PMCA chimeras. Biochem. Soc. Trans. 26: 299

BLOBEL, G. \& DOBBERSTEIN, B. (1975). Transfer to proteins across membranes.

II. Reconstitution of functional rough microsomes from heterologous components. J. Cell Biol. 67: 852-862

BOEVINK, P.; SANTA CRUZ, S.; HAWAS, C.; HARRIS, N. \& OPARKA, K.J. (1996). Virus-mediated delivery of the green fluorescent protein to the endoplasmatic reticulum of plant cells. Plant Journal 10: 935-941

BONZA, C.; CARNELLI, A.; DE MICHELIS, M.I. \& RASI-CALDOGNO, F. (1998). Purification of the Plasma Membrane $\mathrm{Ca}^{2+}$-ATPase from Radish Seedlings by Calmodulin-Agarose Affinity Chromatography. Plant Physiol. 116: 845-851

BONZA, M.C.; MORANDINI, P.; LUONI, L.; GEISLER, M.; PALMGREN, M.G. \& DE MICHELIS, M.I. (2000). At-ACA8 encodes a plasma membrane-localized calcium-ATPase of Arabidopsis with a calmodulin-binding domain at the $\mathrm{N}$ terminus. Plant Physiol. 123: 1495-1506

BRANDT, P.C. \& VANAMAN, T.C. (1998). Calmodulin and ion flux regulation. In L. Van Eldik, D.M. Watterson, eds, Calmodulin and Signal Transduction. Academic Press, San Diego, pp. 397-471

BROCK, R.; HAMELERS, I.H.L. \& JOVIN, T.M. (1999). Comparison of fixation protocols for adherent cultured cells applied to a GFP fusion protein of the epidermal growth factor receptor. Cytometry 35: 353-362 
BROCK, R.; VÀMOSI, G.; VEREB, G. \& JOVIN, T.M. (1999). Rapid characterization of green fluorescent protein fusion proteins on the molecular and cellular level by fluorescence correlation microscopy. Proc. Natl. Acad. Sci. USA 96: 10123-10128

BROWN, D. \& BRETON, S. (2000). Sortin proteins to their target membranes. Kidney Int. 57: 816-824

BROWN, C.R.; HONG-BROWN, L.Q.; BIWERSI, J.; VERKMAN, A.S. \& WELCH, W.J. (1996). Chemical chaperones correct the mutant phenotype of the delta F508 cystic fibrosis transmembrane conductance regulator protein.

Cell Stress Chaperones 1: 117-125

BUSH, D.S. \& WANG, T. (1995). Diversity of calcium-efflux transporters in wheat aleurone cells. Planta 197: 397-400

CARAFOLI, E. (1991). Calcium pump of the plasma membrane. Physiol. Rev. 71: $129-153$

CARAFOLI, E. \& GUERINI, D. (1993). Molecular and cellular biology of plasma membrane calcium ATPase. Trend in Cardiovasc. Med. 3: 177-184

CARAFOLI, E. (1997). Plasma membrane calcium pump: structure, function and relationships. Basic Res. Cardiol. 1: 59-61

CARAFOLI, E.; GARCIA-MARTIN, E. \& GUERINI, D. (1996). The plasma membrane calcium pump: recent development and future perspectives. Experientia 52: $1091-1100$

CA0, J. \& GEBALLE, A.P. (1995). Translational inhibition by a human cytomegalovirus upstream open reading frame despite inefficient utilization of its AUG codon. J Virol. 69: 1030-1036

CHALFIE, M.; TU, Y.; EUSKIRCHEN, G.; WARD, W.W. \& PRASHER, D. (1994). Green fluorescent protein as a marker for gene expression. Science 263: 802-805

CHANG, A. \& SLAYMAN, C.W. (1991). Maturation of the yeast plasma membrane $[\mathrm{H}+]$ ATPase involves phosphorylation during intracellular transport. J. Cell Biol. 115: $289-295$

CHANG, A.; ROSE, M.D. \& SLAYMAN; C.W. (1993). Folding and intracellular transport of the yeast plasma-membrane $\mathrm{H}^{+}$-ATPase: effects of mutations in KAR2 and SEC65. Proc. Natl. Acad. Sci. USA 90: 5808-5812 
CHAPMAN, S.; KAVANAGH, T. \& BAULCOMBE, D. (1992). Potato virus $X$ as a vector for gene expression in plants. Plant Journal 2: 549-557

CHATTERJEE, S. \& STOCHAJ, U. (1996). Monitoring nuclear transport in HeLa Cells using the green fluorescent protein. BioTechniques Euro Edition 21: 62-63

CHIAPELLO, H.; LISACEK, F.; CABOCHE, M. \& HENAUT, A. (1998). Codon usage and gene function are related in sequences of Arabidopsis thaliana. Gene 209: 1-38

CHIU, W.; NIWA, Y.; ZENG, W.; HIRANO, T.; HIROKAZU, K. \& SHEEN, J. (1996). Engineered GFP as a vital reporter in plants. Curr. Biol. 6: 325-330

CHOU, M.M. \& KENDALL, D.A. (1990). Polymeric sequences reveal a functional interrelationship between hydrophobicity and length of signal peptides. J. Biol. Chem. 265: 2873-2880

CHUNG, W.S.; LEE, S.H.; KIM, J.C.; HEO, W.D.; KIM, M.C.; PARK, C.Y.; PARK, H.C.; LIM, C.0.; KIM, W.B.; HARPER, J.F. \& CH0, M.J. (2000). Identification of a calmodulin-regulated soybean $\mathrm{Ca}^{2+}$-ATPase (SCA1) that is located in the plasma membrane. Plant Cell 12: 1393-1408

CLAPHAM D.E. (1995). Intracellular calcium. Replenishing the stores. Nature 375: 634-635

CLONTECH (1996). Product Protocol: Living Colors ${ }^{\text {TM }}$ GFP Application Notes (PT2040-1)

CODY, C.W.; PRASHER, D.C.; WESTLER, W.M.; PENDERGAST, F.G. \& WARD, W.W. (1993). Chemical structure of the hexapeptide chromophore of Aequorea greenfluorescent protein. Biochemistry 32: 1212-1218

COHEN, S.N.; CHANG, A.C.Y. \& HSU, L. (1972). Nonchromosomal antibiotic resistance in bacteria: transformation of Escherichia coli by R-factor DNA. Proc. Natl. Acad. Sci. USA 69: 2110-2116

CORMACK, B.P.; VALDIVIA, R.H. \& FALKOW, S. (1996). FACS-optimized mutants of the green fluorescent protein (GFP). Gene 173: 33-38

CORTAS, N.; ELSTEIN, D.; MARKOWITZ, D. \& EDELMAN, I.S. (1991). Anomalous mobilities of $\mathrm{Na}$, K-ATPase alpha subunit isoforms in SDS-PAGE: identification by N-terminal sequencing. Biochim. Biophys. Acta 1070: 223-228 
CRAMERI, A.; WHITEHORN, E.A.; TATE, E. \& STEMMER, W.P. (1996). Improved green fluorescent protein by molecular evolution using DNA shuffling. Nat. Biotechnol. 14: 315-319

CUBITT, A.B.; HEIM, R.; ADAMS, S.R.; BOYD, A.E.; GROSS, L.A. \& TSIEN, R.Y. (1995). Understanding, improving and using green flourescent proteins. Trends Biochem. 20: $448-455$

DE ANGELIS, D.A.; MIESENBOCK, G.; ZEMELMAN, B.V. \& ROTHMAN, J.E. (1998). PRIM: proximity imaging of green fluorescent protein-tagged polypeptides. Proc. Natl. Acad. Sci. USA 95: 12312-12316

DE KERCHOVE D'EXAERDE, A.; SUPPLY, P.; DUFOUR, J.P.; BOGAERTS, P.; THINES, D.; GOFFEAU, A. \& BOUTRY, M. (1995). Functional complementation of a null mutation of the yeast Saccharomyces cerevisiae plasma membrane $\mathrm{H}^{+}$-ATPase by a plant $\mathrm{H}^{+}$-ATPase gene. J. Biol. Chem. 270: 23828-23837

DE WITT, N.D. \& SUSSMAN, M.R. (1995). Immunocytological localization of an epitope-tagged plasma membrane proton pump ( $\mathrm{H}^{+}$-ATPase) in phloem companion cells. Plant Cell 7: 2053-2067

DE WITT, N.D.; HONG, B.; SUSMANN, M.R. \& HARPER, J.F. (1996). Targeting of two Arabidopsis $\mathrm{H}^{+}$-ATPase Isoforms to the plasma membrane. Plant Physiol. 112: $833-844$

DELAGRAVE, S.; HAWTIN, R.E.; SILVA, C.M.; YANG, M.M. \& YOUVAN, D.C. (1995). Redshifted excitation mutants of the green fluorescent protein. Biotechnology 13: $151-154$

EHRIG, T.; O'KANE, D.J. \& PEDERGAST, F.G. (1995). Green-Fluorescent protein mutants with altered fluorescence excitation spectra. FEBS Letters 367: 163-166

ELLENBERG, J.; SIGGIA, E.D.; MOREIRA, J.E.; SMITH, C.L.; PRESLEY, F.; WORMAN, H.J. \& LIPPINCOTT-SCWARTZ, J. (1997). Nuclear membrane dynamics and reassembly in living cells: targeting of an inner nuclear membrane protein in interphase and mitosis. J. Cell Biol. 138: 1193-1206

EVANS, D.E. \& WILLIAMS, L.E. (1998). P-type calcium ATPases in higher plants biochemical, molecular and functional properties. Biochim. Biophys. Acta

1376: $1-25$ 
FELDHEIM, D. \& SCHEKMAN, R. (1994). Sec72p contributes to the selective recognition of signal peptides by the secretory polypeptide translocation complex. J. Cell Biol. 126: 935-943

FERROL, N. \& BENNETT A.B. (1996). A single gene may encode differentially localized $\mathrm{Ca}^{2+}$-ATPases in tomato. Plant Cell 8: 1159-1169

FOLETTI, D.; GUERINI, D. \& CARAFOLI, E. (1995). Subcellular targeting of the endoplasmatic reticulum and plasma membrane $\mathrm{Ca}^{2+}$ pumps: a study using recombinant chimeras. FASEB J. 8: 670-680

FRIAS, I.; CALDEIRA, M.T.; PEREZ-CASTINEIRA, J.R.; NAVARRO-AVIN0, J.P.; CULIANEZ-MACIA, F.A.; KUPPINGER, 0.; STRANSKY, H.; PAGES, M.; HAGER, A. \& SERRAN0, R. (1996). A major isoform of the maize plasma membrane $\mathrm{H}^{+}$-ATPase: characterization and induction by auxin in coleoptiles. Plant Cell 8: 1533-1544

FUTTERER, J. \& HOHN, T. (1996). Translation in plants - rules and exceptions. Plant Mol. Biol. 32: 159-189

FUTTERER, J. \& HOHN, T. (1992). Role of an upstream open reading frame in the translation of polycistronic mRNAs in plant cells. Nucleic Acids Res.

20: $3851-3857$

GALBRAITH, D.W.; LAMBERT, G.M.; GREBENOK, R.J. \& SHEEN, J. (1995). Flow cytometry analysis of transgene expression in higher plants: green-fluorescent protein. Meth. Cell Biol. 50: 3-14

GALLIE, D.R.; LUCAS, W.J. \& WALBOT, V. (1989). Visualizing mRNA expression in plant protoplasts: factors influencing efficient mRNA uptake and translation. Plant Cell 1: 301-311

GAUT, J.R. \& HENDERSHOT, L.M. (1993). The modification and assembly of proteins in the endoplasmic reticulum. Curr. Opin. Cell Biol. 4: 589-595

GEISLER, M.; AXELSEN, K.B.; HARPER, J.F. \& PALMGREN, M.G. (2000). Molecular aspects of higher plant P-type $\mathrm{Ca}^{2+}$ ATPases. Biochim. Biophys. Acta 1465: 52-78

GEY, G.; COFFMANN, W.D. \& KUBICEK, M.T. (1952). Tissue culture studies of the proliferative capacity of cervical carcinoma and normal epithelium. Cancer Res. 12: $264-265$ 
GILL, D.L.; WALDRON, R.T.; RYS-SIKORA, K.E.; UFRET-VINCENTY, C.A.; GRABER, M.N.; FAVRE, C.J. \& ALFONSO, A. (1996). Calcium pools, calcium entry, and cell growth. Biosci. Rep. 16: 139-157

GHISLAIN, M.; DE SADELEER, M. \& GOFFEAU, A. (1992). Altered plasma membrane $\mathrm{H}^{+}$-ATPase from the Dio-9-resistant pma1-2 mutant of Schizosaccharomyces pombe. Eur. J. Biochem. 209: 275-279

GÖRLICH, D. \& MATTAJ, I.W. (1996). Nucleocytoplasmic transport. Science 271: 1513-1518

GOLDSCHMIDT-CLERMONT, M. \& RAHIRE, M. (1986). Sequence, evolution and differential expression of the two genes encoding variant small subunits of ribulose bisphosphate carboxylase/oxygenase in Chlamydomonas reinhardtii. J. Mol. Biol. 191: 421-432

GOLOVINA, V.A. \& BLAUSTEIN, M.P. (1997). Spatially and functionally distinct $\mathrm{Ca}^{2+}$ stores in sarcoplasmic and endoplasmic reticulum. Science 275: 1643-1648

GÖRLICH, D. (1997). Nuclear protein import. Curr. Opinion Cell Biol. 9: 412-419

GRAY, N.K. \& WICKENS, M. (1998). Control of translation initiation in animals. Annu. Rev. Cell Dev. Biol. 14: 399-458

GREBENOK, R.J.; PIERSON, E.; LAMBERT, G.M.; GONG, F.-H.; ALFONSO, C.L.; HALDEMAN-CAHILL, R.; CARRINGTON, J.C. \& GALBRAITH, D.W. (1997). Green-fluorescent protein fusions for efficient characterization of nuclear targeting. Plant J. 11: 573-586

GREEN, N.M. (1989). ATP-driven cation pumps: alignment of sequences. Biochem. Soc. Trans. 17: 970-972

GREEN, N.M. \& MAC LENNAN, D.H. (1989). ATP driven ion pumps: an evolutionary mosaic. Biochem. Soc. Trans. 17: 819-822

GU, X. \& VERMA, D.P.S. (1997). Dynamics of phragmoplastin in living cells during cell plate formation and uncoupling of cell elongation from the plane of cell division. Plant Cell 9: 157-169

GUERINI, D. \& CARAFOLI, E. (1996). The targeting of the plasma membrane calcium pump in the cell. Biosci. Rep. 16: 129-137 
GUERINI, D.; FOLETTI, D.; VELLANI, F. \& CARAFOLI, E. (1996). Mutation of conserved residues in transmembrane domains 4,6 and 8 causes loss of $\mathrm{Ca}^{2+}$ transport by the plasma membrane $\mathrm{Ca}^{2+}$ pump. Biochemistry 35: 3290-3296

GUERINI, D.; CARCIA-MARTIN, E.; ZECCA, A.; GUIDI, F. \& CARAFOLI, E. (1998). The calcium pump of the plasma membrane: membrane targeting, calcium binding sites, tissue-specific isoform expression. Acta Physiol. Scand. 163, Suppl.

643: $265-273$

HAAS, J.; PARK, E.-C. \& SEED, B. (1996). Codon usage limitation in the expression of HIV-1 envelope glycoprotein. Curr. Biol. 6: 315-324

HANAHAN, D.J. (1985). Techniques for transformation of E. coli. In: DNA cloning. (D.M. Glover, eds) pp. 109-135, IRL Press, 0xford

HARPER, J.F.; MANNEY, L. \& SUSSMAN, M.R. (1994). The plasma membrane $\mathrm{H}(+)$-ATPase gene family in Arabidopsis: genomic sequence of AHA10 which is expressed primarily in developing seeds. Mol. Gen. Genet. 244: 572-587

HARPER, J.F; HONG, B.; HWANG, I.; GUO, H.Q.; STODDARD, R.; HUANG, J.F.; PALMGREN, M.G. \& SZE, H. (1998). A novel calmodulin-regulated $\mathrm{Ca}^{2+}$-ATPase (ACA2) from Arabidopsis with an $\mathrm{N}$-terminal autoinhibitory domain. J. Biol. Chem. 273: 1099-1106

HARTMANN, E.; SOMMER, T.; PREHN, S.; GÖRLICH, D.; JENTSCH, S. \& RAPOPORT, T.A. (1994). Evolutionary conservation of components of the protein translocation complex. Nature 367: 654-657

HASELOFF, J. \& AMOS, B. (1995). GFP in plants. Trends Genet. 11: 328-329

HASELOFF, J. \& SIEMERING, K.R. (1998). The Uses of GFP in Plants. In: Green Fluorescent Protein: Strategies, Applications and Protocols. (Chalfie, M. \& Kain, S., eds), Wiley, pp. 191-220

HASELOFF, J.; SIEMERING, K.R.; PRASHER, D.C. \& HODGE, S. (1997). Removal of a cryptic intron and subcellular localization of green fluorescent protein are required to mark transgenic Arabidopsis plants brightly.

Proc. Natl. Acad. Sci. USA 94: 2122-2127

HEIM, R.; IWATA, T.; ZVARITCH, E.; ADAMO, H.P.; RUTISHAUSER, B.; STREHLER, E.E.; GUERINI, D. \& CARAFOLI, E. (1992). Expression, purification, and properties of the plasma membrane $\mathrm{Ca}^{2+}$ pump and of its $\mathrm{N}$-terminally truncated $105 \mathrm{kDa}$ fragment. J. Biol. Chem. 267: 24476-24484 
HEIM, R.; PRASHER, D.C. \& TSIEN, R.Y. (1994). Wavelength mutations and posttranslational autoxidation of green fluorescent protein.

Proc. Natl. Acad. Sci. USA 91: 12501-12504

HEIM, R.; CUBITT, A.B. \& TSIEN, R.Y. (1995). Improved green fluorescence. Nature 373: 663-664

HEIM, R. \& TSIEN, R.Y. (1996). Engineering green fluorescent protein for improved brightness, longer wavelengths and fluorescence resonance energy transfer. Curr. Biol. 6: 178-182

HEINLEIN, M.; EPEL, B.; PADGETT, H.S. \& BEACHY, R.N. (1995). Interaction of tobaccovirus movement proteins with the plant cytoskeleton.

Science 270: 1983-1985

HELMER, G.; CASADABAN, M.; BEVAN, M.; KAYES, L. \& CHILTON, M.-D. (1984). A new chimeric gene as a marker for plant transformation: the expression of Escherichia coli b-galactosidase in sunflower and tobacco cells.

BioTechnology 2: 520-527

HIRSCHI, K.D.; ZHEN, R.G.; CUNNINGHAM, K.W.; REA, P.A. \& FINK, G.R. (1996). CAX1, an $\mathrm{H}^{+} / \mathrm{Ca}^{2+}$ antiporter from Arabidopsis.

Proc. Natl. Acad. Sci. USA 93: 8782-8786

HONG, B.A.; ICHIDA, S.; WANG, Y.; GENS, J.S.; PICKARD, B.G. \& HARPER, J.F. (1999). Identification of a calmodulin-regulated calcium ATPase in the ER. Plant Physiol. 119: 1165-1176

HOSKINS, J.M.; MEYNELL, G.G. \& SANDERS, F.K. (1956). A comparison of methods for estimating the viable count of a suspension of tumour cells.

Exp. Cell Res. 11: 297-305

HU, W. \& CHENG, C.-L. (1995). Expression of Aequorea green fluorescent protein in plant cells. FEBS Letters 369: 331-334

HUANG, C.-H.; BECKELMAN, T.; FRANKLIN, A.E. \& HOFFMANN, N.E. (1993). Characterization of a gene encoding a $\mathrm{Ca}^{2+}$-ATPase-like protein in the plastid envelope. Proc. Natl. Acad. Sci. USA 90: 10066-10070

IMBAULT, P.; WITTEMER, C.; JAHANNINGMEIER, U.; JACOBS, J.D. \& HOWELL, S.H. (1988). Structure of the Chlamydomonas reinhardtii cab II-1 gene encoding a chlorophyll $a / b$-binding protein. Gene 73: 397-407 
INOUYE, S. \& TSUJI, D.F.I. (1994). Evidence for redox forms of the Aequorea green fluorescent protein in plant cells. FEBS Letters 351: 211-214

JACKSON, M.R.; NILSSON, T. \& PETERSON, P.A. (1990). Identification of a consensus motif for retention of transmembrane proteins in the endoplasmic reticulum. EMBO J. 9: 3153-3162

JACKSON, M.R.; NILSSON, T. \& PETERSON, P.A. (1993). Retrieval of transmembrane proteins to the endoplasmic reticulum. J. Cell Biol. 121: 317-333

JAHN, T.; BALUSKA, F.; MICHALKE, W.; HARPER, J.F. \& VOLKMANN, D. (1998). Plasma membrane $\mathrm{H}^{+}$-ATPase in the root apex: Evidence for strong expression in xylem parenchyma and asymmetric localization within cortical and epidermal cells. Physiol. Plant. 104: 311-316

JEFFERSON, R.A. (1987). Assaying chimeric genes in plants: The GUS gene fusion system. Plant Mol. Biol. Rep. 5: 387-405

JEFFERSON, R.A.; KAVANAGH, T.A. \& BEVAN, M.W. (1987). GUS fusion:

$\beta$-glucuronidase as a sensitive and versatile gene fusion marker in higher plants. EMBO J. 6: 3901-3907

JOHNSON, C.H.; KNIGHT, M.R.; KONDO, T.; MASSON, P.; SEDBROOK, J.; HALEY, A. \& TREWAVAS, A. (1995). Circadian oscillations of cytosolic and chloroplastic free calcium in plants. Science 269: 1863-1865

KAETHER, C. \& GERDES, H.H. (1995). Visualization of protein transport along the secretory pathway using green fluorescence protein. FEBS Letters 369: 267-271

KANE, J.F. (1995). Effects of rare codon clusters on high-level expression of heterologous proteins in Escherichia coli. Curr. Opin. Biotechnol. 6: 494-500

KANE, J.F. \& HARTLEY, D.L. (1988). Formation of recombinant protein inclusion bodies in Escherichia coli. Trends Biotechnol. 6: 95-101

KARIN, N.J. \& SETTLE, V.J. (1992). The sarcoplasmic reticulum Ca ${ }^{2+}$-ATPase, SERCA1a, contains endoplasmic reticulum targeting information. Biochem. Biophys. Res. Commun. 186: 219-227

KASEI, M. \& MUTO, S. (1990). $\mathrm{Ca}^{2+}$ pump and $\mathrm{Ca}^{2+} / \mathrm{H}^{+}$antiporter in plasma membrane vesicles isolated by aqueous Two-phase partitioning from corn leaves. J. Membrane Biol. 114: 133-142 
KLEINIG, H \& SITTE, P. (1999). Zellbiologie. Gustav Fischer Verlag, Stuttgart, Jena, Lübeck, Ulm

KÖHLER, R.H.; CA0, J.; ZIPFEL, W.R.; WEBB, W.W. \& HANSON, M.R. (1997a). Exchange of protein molecules through connections between higher plant plastids. Science 276: 2039-2042

KÖHLER, R.H.; ZIPFEL, W.R.; WEBB, W.W. \& HANSON, M.R. (1997b). The green fluorescent protein as a marker to visualize plant mitochondria in vivo. Plant J. 11: 613-621

KOPITO, K.R. (1997). ER quality control: The cytoplasmic connection. Cell 88: $427-430$

KOZAK, M. (1987a). An analysis of 5'-noncoding sequences from 699 vertebrate messenger RNAs. Nucl Acids Res. 15: 8135-8148

KOZAK, M. (1987b). Effects of intercistronic length on the efficience of reinitiation by eucaryotic ribosomes. Mol. Cell Biol. 10: 3438-3445

KOZAK, M. (1989). The scanning model for translation: An update.

J. Cell Biol. 108: 229-241

KOZAK, M. (1990). Downstream secondary structure facilitates recognition of initiator codons by eukarcotic ribosomses.

Proc. Natl. Acad. Sci. USA 87: 8301-8305

KOZAK, M. (1991). An analysis of vertebrate mRNA sequences: intimations of translational control. J. Cell Biol. 115: 887-903

KOZAK, M. (1995). Adherence to the first-AUG rule when a second AUG follows closely upon the first. Proc. Natl. Acad. Sci. USA 92: 7134

KOZAK, M. (1996). Interpreting cDNA sequences: some insights from studies on translation. Mammalien Genom 7: 563-574

KREIMER, G.; MELKONIAN, M. \& LATZKO, K. (1985). An electrogenic uniport mediates light-dependent $\mathrm{Ca}^{2+}$ influx into intact spinach chloroplasts. FEBS Letters 180: 253-258

KURLAND, C. \& GALLANT, J. (1996). Errors of heterologous protein expression. Curr. Opin. Biotechnol. 7: 489-493 
KUTAY, U.; AHNERT-HILGER, G.; HARTMANN, E.; WIEDENMANN, B. \& RAPOPORT, T.A. (1995). Transport route for synaptobrevin via a novel pathway of insertion into the endoplasmic reticulum membrane. EMBO J. 14: 217-223

LAROCHE, J.; BENNETT, J. \& FALKOWSKI, P.G. (1990). Characterization of a cDNA encoding for the 28.5-kDa LHCII apoprotein from the unicellular marine chlorophyte, Dunaliella tertiolecta. Gene 95: 165-171

LEFFEL, S.M.; MABON, S.A. \& STEWART, C.N., Jr. (1997). Applications of green fluorescent protein in plants. Biotechniques 23: 912-918

LIANG, F.; CUNNINGHAM, K.W.; HARPER, J.F. \& SZE, H. (1997). ECA1 complements yeast mutants defective in $\mathrm{Ca}^{2+}$ pumps and encodes an endoplasmic reticulum-type $\mathrm{Ca}^{2+}$-ATPase in Arabidopsis thaliana.

Proc. Natl. Acad. Sci. USA 94: 8579-8584

LIM, C.R.; KIMATA, Y.; OKO, M.; NOMAGUCHI, K. \& KOHNO, K. (1995).

Thermosensitivity of green fluorescent protein fluorescence utilized to reveal noval nuclear-like compartments in a mutant nucleoporin NSP1.

J. Biochem. 118: 13-17

LIN, J. \& ADDISON, R. (1995). A novel integration signal that is composed of two transmembrane segments is required to integrate the Neurospora plasma membrane $\mathrm{H}^{+}$-ATPase into microsomes. J. Biol. Chem. 270: 6935-6941

LUKASZEWICZ, M.; JEROUVILLE, B. \& BOUTRY, M. (1998). Signs of translational regulation within the transcript leader of a plant plasma membrane $\mathrm{H}(+)$-ATPase gene. Plant J. 14: 413-423

LONG, Z.W.; WANG, S.Y. \& NELSON, N. (1989). Cloning and nucleotide sequence analysis of genes coding for the major chlorophyll-binding protein of the moss Physcomitrella patens and the halotolerant alga Dunaliella salina. Gene 76: 299-312

LUO, H.; MORSOMME, P. \& BOUTRY, M. (1999). The two major types of plant plasma membrane $\mathrm{H}^{+}$-ATPases show different enzymatic properties and confer differential pH sensitivity of yeast growth. Plant Physiol. 119: 627-634

LÜTCKE, H.A.; CHOW, K.C.; MICKEL, F.S.; MOSS, K.A.; KERN, H.F. \& SCHEELER, G.A. (1987). Selection of AUG initiation codons differs in plants and animals. EMBO J. 6: 43-48 
MARTOGLIO, B. \& DOBBERSTEIN, B. (1998). Signal sequences: more than just greasy peptides. Trends in Cell Biology 8: 410-415

MAGYAR, A. \& VARANDI, A. (1990). Molecular cloning and chromosomal localization of a sarco/endoplasmic reticulum-type Ca2(+)-ATPase of Drosophila melanogaster. Biochem. Biophys. Res. Commun. 173: 872-877

MALMSTRÖM, S.; ASKERLUND, P. \& PALMGREN, M.G. (1997). A calmodulin-stimulated $\mathrm{Ca}^{2+}$-ATPase from plant vacuolar membranes with a putative regulatory domain at its N-terminus. FEBS Letters 400: 324-328

MARTIN, P.E.M.; STEGGLES, J.; WILSON, C.; AHMAD, S. \& EVANS, W.H. (2000). Targeting motifs and functional parameters governing the assembly of connexins into gap junctions. Biochem. J. 349: 281-287

MILLAR, A.J.; SHORT, S.R.; HIRATSUKA, K.; CHUA, N.-H. \& KAY, S.A. (1992). Firefly luciferase as a reporter of regulated gene expression in higher plants.

Plant Mol. Biol. Rep. 10: 324-337

MONIAKIS, J.; COUKELL, M.B. \& FORER, A. (1995). Molecular cloning of an intracellular P-type ATPase from Dictyostelium that is up-regulated in calciumadapted cells. J. Biol. Chem. 270: 28276-28281

MORIAU, L.; MICHELET, B.; BOGAERTS, P.; LAMBERT, L.; MICHEL, A.; OUFATTOLE, M. \& BOUTRY, M. (1999). Expression analysis of two gene subfamilies encoding the plasma membrane $\mathrm{H}^{+}$-ATPase in Nicotiana plumbaginifolia reveals the major transport functions of this enzyme. Plant J. 19: 31-41

MORSOMME, P. \& BOUTRY, M. (2000). The plant plasma membrane $\mathrm{H}^{+}$-ATPase: structure, funktion and regulation. Biochim. Biophys. Acta 1465: 1-16

MOSTOV, K.E.; DEFOOR, P.; FLEISCHER, S. \& BLOBEL, G. (1981). Co-translational membrane integration of calcium pump protein without signal sequence cleavage. Nature 292: 87-88

NAGY, J.I. \& MALIGA, P. (1976). Callus Induction and Plant Regeneration from Mesophyll Protoplasts of Nicotiana sylvestris. Z. Pflanzenphysiol. 78: 453-455

NG, D.T.; BROWN, J.D. \& WALTER, P. (1996). Signal sequences specify the targeting route to the endoplasmic reticulum membrane. J. Cell Biol. 134: 269-278 
NIEDZ, R.P.; SUSSMAN, M.R. \& SATTERLEE, J.S. (1995). Green fluorescent protein: an in vivo reporter of plant gene expression. Plant Cell Rep. 14: 403-406

OHTA, T.; NOGUCHI, S.; NAKANISHI, M.; MUTOH, Y.; HIRATA, H.; KAGAWA, Y. \& KAWAMURA, M. (1991). The amino acid sequence of the fluorescein-labeled peptides of electric ray and brine shrimp ( $\mathrm{Na}, \mathrm{K})$-ATPase.

Biochem. Biophys. Res. Commun. 130: 221-228

OPARKA, K.J.; BOEVINK, P. \& SANTA-CRUZ, S. (1996). Studying the movement of plant viruses using green fluorescent protein. Trends Plant Sci. 1: 412-418

ORMO, M.; CUBITT, A.B.; KALLIO, K.; GROSS, L.A.; TSIEN, R.Y. \& REMINGTON, J. (1996). Crystal structure of the Aequorea victoria green fluorescent protein. Science 273: 1392-1395

OSSIPOW, V.; DESCOMES, P. \& SCHIBLER, U. (1993). CCAAT / enhancer-binding protein $\mathrm{mRNA}$ is translated into multiple proteins with different transcription activation potentials. Proc. Natl. Acad. Sci. USA 90: 8219-8223

OUFATTOLE, M.; ARANG0, M. \& BOUTRY, M. (2000). Identification and expression of three new Nicotiana plumbaginifolia genes which encode isoforms of the plasma-membrane $\mathrm{H}^{+}$-ATPase, and one of which is induced by mechanical stress. Planta 210: 751-752

OW, D.W.; WOOD, K.V.; DELUCA, M.; DE WET, J.R.; HELINSKI, D.R. \& HOWELL, S.H. (1986). Transient and stabile expression of the firefly luciferase gene in plant cells and transgenic plants. Science 234: 856-859

PALMGREN, M.G. \& AXELSEN, K.B. (1998). Evolution of P-type ATPases. Biochim. Biophys. Acta 1365: 37-45

PALMGREN, M.G. \& CHRISTENSEN, G. (1993). Complementation in situ of the yeast plasma membrane $\mathrm{H}^{+}$-ATPase gene pma1 by an $\mathrm{H}^{+}$-ATPase gene from a heterologous species. FEBS Letters 317: 216-222

PALMGREN, M.G. \& CHRISTENSEN, G. (1994). Functional comparisons between plant plasma membrane $\mathrm{H}^{+}$-ATPase isoforms expressed in yeast.

J. Biol. Chem. 269: 3027-3033

PANG, S.; DEBOER, D.L.; WAN, Y.; YE, G.; LAYTON, J.G.; NEHER, M.K.; ARMSTRONG, C.L.; FRY, J.E.; HINCHEE, M.A.W. \& FROMM, M.E. (1996). An improved green fluorescent protein gene as a vital marker in plant. Plant Physiol. 112: 893-900 
PATTERSON, G.H.; KNOBEL, S.M.; SHARIF, W.D.; KAIN, S.R. \& PISTON, D.W. (1997). Use of the green fluorescent protein and its mutants in quantitative fluorescence microscopy. Biophys. J. 73: 2782-2790

PEDERSEN, P.L. \& CARAFOLI, E. (1987). Ion motive ATPases. I. Ubiquity, properties and significance to cell function. Trends Biochem. Sci. 12: 146-150

PLEMPER, R.K.; EGNER, R.; KUCHLER, K. \& WOLF, D.H. (1998). Endoplasmic reticulum degradation of a mutated ATP-binding cassette transporter Pdr5 proceeds in a concerted action of Sec61 and the proteasome.

J. Biol. Chem. 273: 32848-32856

PLEMPER, R.K. \& WOLF, D.H. (1999). Endoplasmatic reticulum degradation. Reverse protein transport and its end to the proteasome. Mol. Biol. Rep. 26: 125-130

PORTILLO, F. (2000). Regulation of plasma membrane $\mathrm{H}^{+}$-ATPase in fungi and plants. Biochim. Biophys. Acta 1469: 31-42

PORTIS, J.L.; SPANGRUDE, G. \& MCATEE, F.J. (1994). Identification of a sequence in the unique $5^{\prime}$ open reading frame of the gene encoding glycosylated Gag which influences the incubation period of neurodegenerative disease induced by a murine retrovirus. J Virol. 68: 3879-3887

PRASHER, D.C. (1995). Using GFP to see the light. Trends Genet. 11: 320-323

PRASHER, D.C.; ECKENRODE, V.K.; WARD, W.W.; PRENDERGRAST, F.G \& CORMINER, M.J. (1992). Primary structure of the Aequorea victoria green fluorescent protein. Gene 111: 229-233

PREISLER, H.D. (1978). Alteration of binding of the supervital dye Hoechst 33342 to human leukemic cells by adriamycin. Cancer Treatment Reports 62: 1393-1396

QU, B.H.; STRICKLAND, E. \& THOMAS, P.J. (1997). Cystic fibrosis: A disease of altered protein folding. J. Bioenerg. Biomembr. 29: 483-490

RA0, R.; DRUMMOND-BARBOSA, D. \& SLAYMAN, CW. (1993). Transcriptional regulation by glucose of the yeast PMA1 gene encoding the plasma membrane $\mathrm{H}^{+}$-ATPase. Yeast 9: 1075-1084

RAPOPORT, T.A.; JUNGNICKEL, B. \& KUTAY, U. (1996). Protein transport across the eukaryotic endoplasmic reticulum and bacterial inner membranes.

Annu. Rev. Biochem. 65: 271-303 
RASCHKE, B.C. (1996). Molekulare Charakterisierung von $\mathrm{Ca}^{2+}$-ATPasen aus einzelligen Grünalgen. Dissertation, Math.-Nat. Fachbereich der Universität Göttingen.

RASCHKE, B.C. \& WOLF, A.H. (1996). Molecular cloning of a P-type Ca ${ }^{2+}-A T P a s e$ from the halotolerant alga Dunaliella bioculata. Planta 200: 78-84

RASI-CALDOGNO, F.; CARNELLI, A. \& DE MICHAELIS, M.I. (1992). Identification of the plasma memrane $\mathrm{Ca}^{2+}$-ATPase and its autoinhibitory domain.

Plant Physiol. 108: 105-113

REICHEL, C.; MATHUR, J.; ECKES, P.; LANGENKEMPER, K.; KONCZ, C.; SCHELL, J.; REISS, B. \& MAAS, C. (1996). Enhanced green fluorescence by expression of an Aequorea victoria green fluorescent protein mutant in mono- and dicotyledonous plant cells. Proc. Natl. Acad. Sci. USA 93: 5888-5893

ROBINSON, D.G.; HINZ, G. \& HOLSTEIN, S.E. (1998). The molecular characterization of transport vesicles. Plant Mol. Biol. 38: 49-76

RUYSSCHAERT, J.-M.; EL QUAHABI, A.; WILLEAUME, V.; HUEZ, G.; FUKS, R.; VANDENBRADEN, M. \& DI STEFANO, P. (1994). A novel cationic amphiphile for transfection of mammalian cells. Biophys. Res. Commun. 203: 1622-1628

RYABOVA, L.A. \& HOHN, T. (2000). Ribosome shunting in the cauliflower mosaic virus 35S RNA leader is a special case of reinitiation of translation functioning in plant and animal systems. Genes Dev. 14: 817-829

SAIKI, R.K.; GELFAND, D.H.; STOFFEL, S.; SCHARF, S.J.; HIGUCHI, R.; HORN, G.T.; MULLIS, K.B. \& EHRLICH, HA. (1988). Primer-directed enzymatic amplification of DNA with a thermostable DNA polymerase. Science 239: 487-491

SAMBRO0K, J.; FRITSCH, E.F. \& MANIATIS, T. (1989). Molecular Cloning: A Laboratory Handbook. Cold Spring Habor N.Y.: Cold spring Habor Laboratory Press.

SANDERS, D.; BROWNLEE, C. \& HARPER J.F. (1999). Communicating with calcium. Plant Cell 11: 691-706

SANGER, F.; NICKLEIN, S. \& COULSON, A.R. (1977). DNA-sequencing with chain-terminating inhibitors. Proc. Natl. Acad. Sci. USA 74: 5463-5467 
SANSEBASTIANO DI, G.-P.; PARIS, N.; MARC-MARTIN, S. \& NEUHAUS, J.-M. (1998). Specific accumulation of GFP in a non-acidic vacuolar compartment via a C-terminal propeptide-mediated sorting pathway. Plant Journal 15: 449-457

SANTELLA, L. \& CARAFOLI, E. (1997). Calcium signaling in the cell nucleus. FASEB J. 11: 1091-1109

SCOTT, A.; WYATT, S.; TSOU, P.L.; ROBERTSON, D. \& STRÖMGREN, A. (1999). Model system for plant cell biology: GFP imaging in living onion epidermal cells. BioTechnicques 26: 1125-1132

SEED, B. \& SHEEN, J.-Y. (1988). A simple phase-extraction assay for chloramphenicol acetyltransferase activity. Gene 67: 271-277

SERRANO, R. (1988). Structure and function of plasma membrane ATPase in plasma membranes of plants and fungi. Biochim. Biophys. Acta 947: 1-28

SERRANO, R. (1989). Structure and function of plasma membrane ATPase. Annu. Rev. Plant Physiol. Plant Mol. Biol. 40: 61-94

SERRANO, R. \& PORTILLO, F. (1990). Catalytic and regulatory sites of yeast plasma membrane $\mathrm{H}(+)$-ATPase studied by directed mutagenesis. Biochim. Biophys. Acta 1018: 195-199

SHARP, P.A.; SUDGEN, B. \& SAMBR00K, J. (1973). Detection of two restriction endonuclease activities in Haemophilus parainfluenzae using analytical agarose-ethidium bromide electrophoresis. Biochemistry 12: 3055-3060

SHEEN, J. (1993). Protein phosphatase activity is required for light-inducible gene expression in maize. EMBO J. 12: 3497-3505

SHEEN, J.; HWANG, S.; NIWA, Y.; KOBAYASHI, H. \& GALBAITH, D.W. (1995). Green fluorescent protein as a new vital marker in plant cells.

Plant Journal 8: 777-784

SHIN, J.; DUNBRACK, R.L.; LEE, S. \& STROMINGER, J.L. (1991). Signals for retention of transmembrane proteins in the endoplasmic reticulum studied with CD4 truncation mutants. Proc. Natl. Acad. Sci. USA 88: 1918-1922

SHINE, J. \& DALGARNO, L. (1974). The 3'-terminal sequence of Escherichia coli $16 \mathrm{~S}$ ribosomal RNA: complementarity to nonsense triplets and ribosome binding sites. Proc. Natl. Acad. Sci. USA 71: 1342-1346 
SHULL, G.E. (2000). Gene knockout studies of $\mathrm{Ca}^{2+}$-transporting ATPases. Eur. J. Biochem. 267: 5284-5290

SIEMERING, K.R.; GOLBIK, R.; SEVER, R. \& HASELOFF, J. (1996). Mutations that suppress the thermosensitivity of green fluorescent protein.

Curr. Biol. 6: 1653-1663

SIFLOW, C.D.; CHRISHOLM, R.L.; CONNER, T.W. \& RANEEM, L.P.W. (1985). The two alpha-tubulin genes of Chlamydomonas reinhardtii code for slightly different proteins. Mol. Cell Biol. 5: 2389-2398

SIMONOVA, M.; WEISSLEDER, R.; SERGEYEV, N.; VILISSOVA, N. \& BOGDANOV, A. (1999). Targeting of green fluorescent protein expression to the cell surface. Biochem. Biophys. Res. Comm. 171: 890-897

SMAHEL, M.; HAMANN, A. \& GRADMANN, D. (1990). The prime plasmalemma ATPase of the halophilic alga Dunaliella bioculata: purification and characterization. Planta 181: 496-504

STEIPE, B. \& SKERRA, A. (1997). Das grün fluoreszierende Protein. Biospektrum 1: 22-30

STOCHAJ, U. \& SILVER, P. (1992). Nucleocytoplasmic traffic of proteins. Eur. J. Cell Biol. 59: 1-11

SUEOKA, N. \& KAWANISHI, Y. (2000). DNA G+C content of the third codon position and codon usage biases of human genes. Gene 261: 53-62

SZE, H. (1985). H-Translocating ATPases: Advances using membrane vesicles. Ann. Rev. Plant Physiol. 36: 175-208

SZE, H.; LIANG, F. \& HARPER, I. (2000). Diversity and Regulation of plant $\mathrm{Ca}^{2+}$ pumps: Insights from expression in yeast. Annu. Rev. Plant Physiol. Plant Mol. Biol. 51: 433-462

TERRI, T.H.; LEHVÄSHAIHO, H.; FRANCK, M.; HEINO, U.P.; PALVA, E.T.; VAN MONTAGU, M. \& HERRERA-ESTRELLA, L. (1989). Gene fusions to lacZ reveal new expression patterns of chimeric genes in transgenic plants. EMBO J. 8: 343-350

THOMSON, L.J.; XING, T.; HALL, J.L. \& WILLIAMS, L.E. (1993). Investigation of the calcium-transporting ATPases at the endoplasmatic reticulum and plasma membrane of the red beet (Beta vulgaris). Plant Physiol. 102: 553-564 
TOOMRE, D.; KELLER, P.; WHITE, J.; OLIV0, J.-C. \& SIMONS, K. (1999). Dual-color visualization of trans-Golgi network to plasma membrane traffic along microtubules in living cells. J. Cell Sci. 112: 21-33

TOWNSLEY, F.M. \& PELHAM, H.R. (1994). The KKXX signal mediates retrieval of membrane proteins from the Golgi to the ER in yeast. Eur. J. Cell Biol.

64: $211-216$

VAN GOETHEM, I.D.A.; ADAMS, P.; CHAD, J.E.; MATHER, A.M.; GRIFFITHS, B.; LEE, A.G. \& EAST, J.M. (1998). Localization of endoplasmic reticulum in living cells using green fluorescent protein chimeras. Biochem. Soc. Trans. 26: 298

VENEMA, K. \& PALMGREN, M.G. (1995). Metabolic modulation of transport coupling ratio in yeast plasma membrane $\mathrm{H}^{+}$-ATPase. J. Biol. Chem. 270: 19659-19667

VILLALBA, J.M.; PALMGREN, M.G.; BERBERIAN, G.E.; FERGUSON, C. \& SERRANO R. (1992). Functional expression of plant plasma membrane $\mathrm{H}^{+}$-ATPase in yeast endoplasmic reticulum. J. Biol. Chem. 267: 12341-12349

VOGES, D.; ZWICKL, P. \& BAUMEISTER, W. (1999). The 26S Proteasome: A molecular machine designed for controlled proteolysis. Annu. Rev. Biochem.

68: $1015-1068$

VON ARNIM, A.G.; DENG, X.-W. \& STACEY, M.G. (1998). Cloning vectors for expression of green fluorescent protein fusion proteins in transgenic plants. Gene 221: 35-43

VON HEIJNE, G. (1985). Signal sequences. The limits of variation. J. Mol. Biol. 184: 99-105

VON HEIJNE, G. (1986 ). Towards a comparative anatomy of N-terminal topogenic protein sequences. J. Mol. Biol. 189: 239-242

WACH, A.; SCHLESSER, A. \& GOFFEAU, A. (1992). An alignment of 17 deduced protein sequences from plant, fungi, and ciliate $\mathrm{H}^{+}$-ATPase genes.

J. Bioenerg. Biomem. 24: 309-317

WADA, K.; WADA, Y.; DOI, H.; ISHIBASHI, F.; GOJOBORI, T. \& IKEMURA, T. (1991). Codon usage tabulated from the GenBank genetic sequence data. Nuc. Acid. Res. 19: 1981-1986 
WADA, M.; SHONO, M.; URAYAMA, 0.; SATOH, S.; HARA, Y.; IKAWA, Y. \& FUJII, T. (1994). Molecular cloning of P-typ ATPases on intracellular membranes of the marine alga Heterosigma akashiwo. Plant Mol. Biol. 26: 699-708

WANG, C.; CHEN, M.; HAN, E. \& ZHANG, J.-T. (1997). Role of ribosomes in reinitiation of membrane insertion of internal transmembrane segments in a polytopic membrane protein. Biochemistry 36: 11437-11443

WANG, I.; RATTERMAN, D.M. \& SZE, H. (1997). Distinction between endoplasmic reticulum-type and plasma membrane-type $\mathrm{Ca}^{2+}$ pumps.

Plant Physiol. 113: 535-548

WANG, S. \& HAZELRIGG, T. (1994). Implications for bcd mRNA localization from spatial distribution of exu protein in Drosophila oogenesis. Nature 369: 400-403

WARBURG, 0. \& CHRISTIAN, W. (1942). Isolierung und Kristallisation des Gärungsfermentes Enolase. Biochemische Zeitschrift 310: 384-421

WEBB, C.D.; DECATUR, A.; TELEMAN, A. \& LOSICK, R. (1995). Use of green fluorescent protein for visualization of cell-specific gene expression and subcellular protein localization during sporulation in Bacillus subtilis. J. Bacteriol. 177: 5906-5911

WEISS, M. \& PICK, U. (1996). Primary structure and effect of $\mathrm{pH}$ on the expression of the plasma membrane $\mathrm{H}^{+}$-ATPase from Dunaliella acidophila and Dunaliella salina. Plant Physiol. 112: 1693-702

WIMMERS, L.E.; EWING, N.N. \& BENNETT, A.B. (1992). Higher plant Ca²+-ATPase: primary structure and regulation of mRNA abundance by salt. Proc. Natl. Acad. Sci. USA 89: 9205-9209

WOLF, A.H. (1993). Primärstruktur von P-Typ ATPasen halophiler Algen. Dissertation, Math.-Nat. Fachbereich der Universität Göttingen.

WOLF, A.H.; SLAYMAN, C.W. \& GRADMANN, D. (1995). Primary structure of the plasma membrane $\mathrm{H}(+)$-ATPase from the holotolerant alga Dunaliella bioculata. Plant Mol. Biol. 28: 657-666

WOLF, A.H.; KIRSCH, M. \& WIESSNER, W. (1993). Nucleotide sequence of a cDNA encoding ribosomal protein L27 from Chlamydobotrys stellata.

Plant Physiol. 101: 1123 
YUDKOVSKY, N.; RANISH, J.A. \& HAHN, S. (2000). A transcription reinitiation intermediate that is stabilized by activator. Nature 408: 225-229

ZHANG, P.; TOYOSHIMA, C.; YOKENURA, K.; GREEN, N.M. \& STOKES, D.L. (1998). Structure of the calcium pump from sarcoplasmic reticulum at 8-A resolution. Nature 392: 835-839

ZHENG, N. \& GIERASCH L.M. (1996). Signal sequences: the same yet different. Cell 86: 849-852

ZVARITCH, E.; VELLANI, F.; GUERINI, D. \& CARAFOLI, E. (1995). A signal for endoplasmic reticulum retention located at the carboxyl terminus of the plasma membrane Ca ${ }^{2+-A T P a s e}$ isoform 4Cl. J. Biol. Chem. 270: 2679-2688

ZYLKA, M.J. \& SCHNAPP, B.J. (1996). Optimized Filter Set and Viewing Conditions for the S65T Mutant of GFP in Living Cells. BioTechniques Euro Edition 21: $220-226$ 
... Hanna Bork

... Barbara Ebert

... Sabine Geisendorf

... Dietrich Gradmann

... Giselbert Hinz

... Ulrike Homann

... Susanne Holstein und ihrer Arbeitsgruppe

... Wolfgang Jahn

... Elke Onken

... Steffi Riemann

... Rudi Schmitt

... Bärbel Schönberg

... Gerhard Thiel

... Alexandra Thiele

... Andreas Wolf

... meiner Familie und Johann Janssen 


\title{
Lebenslauf
}

\author{
Name Sandra Schönberg \\ Geburtsdatum 7. April 1971 in Witzenhausen \\ Staatsangehörigkeit deutsch
}

\section{Schulbildung}

1977 - 1981 Besuch der Ernst-Reuter Schule in Eichenberg

1981 - 1987 Besuch der Gesamtschule Witzenhausen

1987 - 1990 Besuch des Rhenanus-Gymnasiums

in Bad Sooden-Allendorf

\section{Studium}

1990 - 1991 Studium der Sozialwissenschaften

an der Georg-August-Universität zu Göttingen

1991 - 1997 Studium der Biologie

an der Georg-August-Universität zu Göttingen

1. November 1993 Vordiplom im Fach Biologie

1996 - 1997 Diplomarbeit am Albrecht-von-Haller-Institut für Pflanzenwissenschaften der

Georg-August-Universität zu Göttingen

11. März 1997 Diplom im Fach Biologie

1997 - 2001 Dissertation am Albrecht-von-Haller-Institut für Pflanzenwissenschaften der

Georg-August-Universität zu Göttingen 